\title{
Mission archéologique franco-albanaise du bassin de Korçë
}

Cécile Oberweiler, Petrika Lera, Rovena Kurti, Gilles Touchais, Ole Christian Aslaksen, Charlotte Blein, Gazmend Elezi, Maja Gori, Tobias Krapf, Yannis Maniatis et Stéphanie Wagner

\section{OpenEdition} Journals

Édition électronique

URL : http://journals.openedition.org/baefe/1660

DOI : $10.4000 /$ baefe. 1660

ISSN : 2732-687X

Éditeur

ResEFE

\section{Référence électronique}

Cécile Oberweiler, Petrika Lera, Rovena Kurti, Gilles Touchais, Ole Christian Aslaksen, Charlotte Blein, Gazmend Elezi, Maja Gori, Tobias Krapf, Yannis Maniatis et Stéphanie Wagner, « Mission archéologique franco-albanaise du bassin de Korçë » [notice archéologique], Bulletin archéologique des Écoles françaises à l'étranger [En ligne], Balkans, mis en ligne le 01 novembre 2020, consulté le 11 décembre 2020. URL : http://journals.openedition.org/baefe/1660 ; DOI : https://doi.org/10.4000/ baefe.1660

Ce document a été généré automatiquement le 11 décembre 2020.

\section{c)}

Le Bulletin archéologique des Écoles françaises à l'étranger est mise à disposition selon les termes de la Licence Creative Commons Attribution - Pas d'Utilisation Commerciale - Pas de Modification 4.0 International. 


\title{
Mission archéologique franco- albanaise du bassin de Korçë
}

\author{
Cécile Oberweiler, Petrika Lera, Rovena Kurti, Gilles Touchais, Ole Christian \\ Aslaksen, Charlotte Blein, Gazmend Elezi, Maja Gori, Tobias Krapf, Yannis \\ Maniatis et Stéphanie Wagner
}

\section{NOTE DE L'AUTEUR}

Autorité nationale présente : Rovena Kurti (Institut archéologique de Tirana) Numéro de mission : AL02

Composition de l'équipe : Susan E. Allen (Université de Cincinnati) : paléobotanique ; Laurence Astruc (UMR 7041 ArScAn) : tracéologie ; Magali Bénet (chercheur indépendant) : prospection, DAO ; Charlotte Blein (chercheur associée, UMR 5189 HiSoMa) : céramique hellénistique et romaine ; Athina Boleti (chercheur associée, UMR 7041 ArScAn) : industries lithiques polies ; Antoine Chabrol (UMR 8591 LGP), géomorphologie ; Carole Cheval (chercheur associée, UMR 7041 ArScAn) : industries textiles ; Rosalia Christidou (chercheur associée, UMR 5133 Archéorient) : industries osseuses ; Stéphane Desruelles (Université Paris 4 - UMR $8185 \mathrm{ENeC}$ ) : géographie ; Gazmend Elezi (Université de Californie Los Angeles) : céramique néolithique ; Lionel Fadin (Efa) : topographie ; Éric Fouache (Université Paris 4-Abou Dhabi - UMR 8185 $\mathrm{ENeC}$ ) : géographie ; Armelle Gardeisen (CNRS, UMR 5140 ASM) : archéozoologie; Maja Gori (CNR, Rome) : céramique de l'âge du Bronze ; Ergys Hasa (Institut archéologique de Tirana) : administrateur ; Georgia Kourtessi-Philippakis (Université d'Athènes UMR 7041 ArScAn) : industries lithiques taillées ; Rovena Kurti (Institut archéologique de Tirana) : codirectrice du projet ; Tobias Krapf (ESAG) : céramiques des âges du Bronze et du Fer) ; Petrika Lera (Université de Korçë, Institut archéologique de Tirana) : conseiller scientifique du projet ; Anne-Marie Lézine (CNRS, UMR 182 LOCEAN) : palynologie ; Julien Mahoudeau (Altearch-Médiation) : site web ; Michel Magny (CNRS, UMR 6565 LCE) : paléoclimatologie ; Cécile Oberweiler (chercheur associée, UMR 7041 ArScAn) : codirectrice du projet ; Luan Përzhita (Institut 
archéologique de Tirana) : céramique médiévale ; Gaël Piquès (CNRS, UMR 5140 ASM) : ichtyologie ; Sandra Prévost-Dermarkar (chercheur associée, UMR 7041 ArScAn) : architecture en terre ; Rudenc Ruka (Institut archéologique de Tirana ) : industries lithiques taillées ; Eduard Shehi (Institut archéologique de Tirana) : céramique hellénistique ; Nathalie Thomas (UMR 7041 ArScAn) : industries lithiques polies ; Gilles Touchais (Université Paris 1 - UMR 7041 ArScAn) : conseiller scientifique du projet, responsable des publications.

Partenariats institutionnels : Institut archéologique de Tirana, UMR 7041 " Archéologies et Sciences de l'Antiquité (ArScAn) », Ministère de l'Europe et des Affaires étrangères, Université Bordeaux I - UMR 1202 « Biodiversité, gènes et communautés (INRA) », Université de Berne

Établissements porteurs de l'opération : EFA, Ministère de l'Europe et des Affaires étrangères, UMR 7041 « Archéologies et Sciences de l'Antiquité (ArScAn) », Institut archéologique de Tirana

\section{Données scientifiques produites :}

Site de la Mission archéologique franco-albanaise du bassin de Korçë

BCH 119-2 (1995)

Chapitre XVII. Sovjan et le lac Maliq en Albanie : Un site protohistorique dans son environnement

Bassin de Korçë, Kallamas

Les campagnes de 2017 et 2018 ont été consacrées en priorité à la poursuite de l'étude des données des fouilles de Sovjan (1993-2006) et de Kallamas (2008-2011), ainsi que du programme PALM (Prospection Archéologique du Lac Maliq, 2007-2013), en vue de leur publication. Et c'est dans la continuité de ce dernier qu'a été lancée en 2018 une nouvelle opération de terrain : la prospection des nombreux sites de hauteur du Bronze Récent/Fer Ancien qui bordent le bassin de Korçë.

\section{L'étude des données des fouilles de Sovjan}

2 Dans le cadre de la préparation du premier volume de la publication - dont le manuscrit est en grande partie achevé - on a procédé à un réexamen systématique des données stratigraphiques et chronologiques, complétant en outre ces dernières par une nouvelle série de datations absolues, et l'on a amorcé la reprise de l'étude dendrologique, qui était au point mort depuis plusieurs années. D'autre part, on a poursuivi l'étude de la céramique des niveaux du Bronze Récent et du Fer Ancien, qui fera l'objet d'un volume ultérieur.

\section{Stratigraphie et chronologie}

\section{La séquence chrono-culturelle}

3 La rédaction - en cours - du chapitre III du premier volume, consacré à la présentation détaillée des divers niveaux d'occupation, a entraîné de nombreuses vérifications (dans les carnets de fouille, la documentation graphique et photographique, etc.) et permis de préciser certains points encore litigieux de la stratigraphie. On a ainsi pu établir, en connexion avec les nouvelles datations absolues obtenues pour plusieurs couches, la 
séquence chrono-culturelle définitive du site. Celle-ci se subdivise en sept phases principales, datées ici selon la chronologie en vigueur dans le monde égéen :

- Sovjan I et II = niveaux du Néolithique (NA et NM) correspondant aux couches 11, 12 et 13.

- Sovjan II = niveaux du BA III correspondant aux couches 7, 8 et 9 .

- Sovjan IV = niveau du début du Bronze Moyen représenté par la couche 6 .

- Sovjan V = niveaux du Bronze Récent qui regroupent les couches 5c3, 5c2 et le bas de $5 \mathrm{c} 1$.

- Sovjan VI = niveau de transition Bronze Récent / Fer Ancien matérialisé par le haut de la couche $5 \mathrm{c} 1$.

- Sovjan VII = niveaux du Fer Ancien qui correspondent aux couches $5 a$ et $5 b$.

4 La synchronisation de ces phases avec celles de la chronologie en usage dans le monde égéen est résumée dans le tableau ci-dessous.

Tableau 1 - Séquence chrono-culturelle révisée du site de Sovjan.

\begin{tabular}{|c|c|c|c|}
\hline $\begin{array}{l}\text { SOVJAN } \\
\text { PHASES CHRONO-CULTURELLES }\end{array}$ & $\begin{array}{l}\text { PÉRIODES } \\
\text { (chronologie } \\
\text { albanaise) }\end{array}$ & $\begin{array}{l}\text { DATATIONS ABSOLUES } \\
\text { (BC calibrées) }\end{array}$ & $\begin{array}{l}\text { PÉRIODES } \\
\text { (chronologie } \\
\text { égéenne) }\end{array}$ \\
\hline VII & début du FA & $\pm 1000 / 900-800 / 700$ & Géométrique \\
\hline VI & Transition BR/FA & $\pm 1100-1000 / 900$ & $\begin{array}{l}\text { Protogéométrique } \\
\text { Submycénien }\end{array}$ \\
\hline \multirow{2}{*}{$\mathbf{V}$} & \multirow{2}{*}{ BR (seconde moitié) } & $\pm 1300-1100$ & $\begin{array}{l}\text { HR IIIB-C } \\
\text { HR IIIA }\end{array}$ \\
\hline & & $\pm 1600-1300$ & $\begin{array}{l}\text { HR II } \\
\text { HR I }\end{array}$ \\
\hline \multicolumn{3}{|l|}{ hiatus } & \multirow{2}{*}{ BM } \\
\hline IV & transition $\mathrm{BM} / \mathrm{BR}$ & $\pm 2200-1900$ & \\
\hline III & BM & $\pm 2500-2000$ & BA III \\
\hline \multicolumn{3}{|l|}{ hiatus } & $\begin{array}{l}\text { BA I-II } \\
\text { NR }\end{array}$ \\
\hline II & $\begin{array}{l}\text { Néolithique } \\
\text { Moyen }\end{array}$ & $\pm 6000-5600$ & NM \\
\hline I & $\begin{array}{l}\text { Néolithique Ancien/ } \\
\text { Mésolithique? }\end{array}$ & $\pm 7300-7000$ & $\begin{array}{l}\text { NA/ } \\
\text { Mésolithique? }\end{array}$ \\
\hline
\end{tabular}

\section{Les nouvelles datations absolues}

5 L'étude de la céramique des couches 6 et $5 \mathrm{c}$ a amené à remettre en question leur datation, en particulier celle de la couche 6 qui avait été initialement datée du BR selon 
la chronologie albanaise, soit entre 1600 et $1400 \mathrm{BC}^{1}$. Or l'étude du matériel céramique de cette couche a montré qu'il présentait des différences notables avec celui de la couche supérieure (5c) dont la datation au BR a été largement confirmée par le radiocarbone $e^{2}$, mais aussi avec celui de la couche sous-jacente (7), qui est attribuée avec certitude au BA $\mathrm{III}^{3}$. En outre, l'étude finale de la stratigraphie du site a permis de réévaluer l'appartenance chrono-stratigraphique de plusieurs US, en particulier celles des premières campagnes de fouilles, entre 1993 et 1996 (cf. supra). C'est ainsi que certaines US initialement rattachées à la couche 6 ont pu être réattribuées avec certitude à la couche $5 \mathrm{c} 3$, notamment celles qui avaient fourni les premières datations de la couche 6 par le radiocarbone $e^{4}$. Afin de clarifier ce point, on a fait dater deux échantillons de charbon supplémentaires provenant de deuxUS attribuées avec certitude, l'une à la couche 6 et l'autre au sommet de la couche 7. Les analyses, réalisées par le laboratoire du Centre Demokritos d'Athènes, ont fourni les résultats suivants.

Tableau 2 - Nouvelles datations absolues des couches 6 et 7 de Sovjan.

\begin{tabular}{|c|c|c|c|c|c|c|}
\hline $\mathrm{N}^{\circ}$ labo. & $\begin{array}{l}\mathrm{N}^{\circ} \text { échantillon/ } \\
\text { sondage/ } \\
\text { couche }\end{array}$ & Matériau & $\begin{array}{ll}\text { Âge } & { }^{14} \mathrm{C} \\
\text { (BP) } & \end{array}$ & $\begin{array}{l}\delta 13 C \\
(\% o)\end{array}$ & $\begin{array}{l}\text { Date calibrée } \\
\text { (BC) }\end{array}$ & Probabilités \\
\hline $\begin{array}{l}\text { DEM } \\
2352\end{array}$ & $\begin{array}{l}\text { Éch. Sov.205 } \\
\text { Sondage A9b } \\
\text { Couche } 6\end{array}$ & Charbon & $3762 \pm 30$ & -25.30 & $\begin{array}{l}2274-2136 \text { BC } \\
\mathbf{2 2 8 7}-\mathbf{2 0 4 6} B C\end{array}$ & $\begin{array}{l}(68.2 \%) \\
(95.4 \%)\end{array}$ \\
\hline $\begin{array}{l}\text { DEM } \\
2353\end{array}$ & $\begin{array}{l}\text { Éch. Sov. } 210 \\
\text { Sondage A9b } \\
\text { Couche } 7\end{array}$ & Charbon & $3821 \pm 30$ & -25.92 & $\begin{array}{l}2294-2206 \text { BC } \\
\mathbf{2 4 0 1}-\mathbf{2 1 4 8} \text { BC }\end{array}$ & $\begin{array}{l}(68.2 \%) \\
(95.4 \%)\end{array}$ \\
\hline
\end{tabular}

6 La datation de la base de la couche 6, entre 2287 et $2046 \mathrm{BC}$ cal., est en accord avec les deux précédentes, qui se situaient respectivement entre 2287 et $1981 \mathrm{BC}$ cal. et entre 2200 et $1920 \mathrm{BC}$ cal. ${ }^{5}$. La cohérence de ces trois mesures permet d'établir avec une relative assurance la chronologie absolue de la couche 6 : entre 2200 et 2000/1900 av. J.C. Cela assignerait, en chronologie égéenne, les niveaux d'occupation de la couche 6 à l'interface entre la fin du BA III et le début du BM. En termes de chronologie albanaise traditionnelle - et eu égard aux différences entre le matériel céramique de cette couche et celui des couches supérieure et inférieure - on parlera d'un niveau de transition BM/ BR (Sovjan IV).

7 La datation du sommet de la couche 7, entre 2401 et $2148 \mathrm{BC}$ cal., est elle-aussi en accord avec les quatre anciennes datations de cette couche, qui se situaient toutes entre 2300 et $2000 \mathrm{BC}$ cal. Ainsi, on observe une continuité chronologique et stratigraphique entre la couche 7 et la couche 6 , la première n'étant que très légèrement antérieure à la seconde. En revanche, avec la réattribution de certaines US à des niveaux plus récents, on constate un nouveau hiatus dans l'occupation humaine, entre 1900 et $160 \mathrm{BC}$ cal. (tableau 1), soit deux à trois siècles d'abandon, compte tenu des marges d'erreur dans la datation d'échantillons à vie longue (charbons de bois). Soulignons toutefois que ce hiatus n'est pour l'instant attesté que dans la partie du site qui a été fouillée : compte tenu de la superficie du tell, il est tout à fait possible que 
l'habitat n'ait pas été complètement déserté mais qu'il se soit légèrement déplacé durant ce laps de temps.

Enfin, pour vérifier si la chronologie absolue des plus anciens niveaux d'occupation du site était vraiment aussi haute que le suggéraient les premières datations, on a fait analyser des échantillons de charbons prélevés dans deuxUS appartenant respectivement aux couches 11 et $13^{6}$. Les datations obtenues sont identiques à celles qui avaient été réalisées en 2002, soit entre 6000 et $5600 \mathrm{BC}$ cal. pour la couche 11 et entre 7300 et $7000 \mathrm{BC}$ cal. pour la couche $13^{7}$.

Tableau 3 - Nouvelles datations absolues des couches 11 et 13 de Sovjan.

\begin{tabular}{|c|c|c|c|c|c|c|}
\hline $\mathrm{N}^{\circ}$ labo. & $\begin{array}{l}\mathrm{N}^{\circ} \text { échantillon/ } \\
\text { sondage/ } \\
\text { couche }\end{array}$ & Matériau & $\begin{array}{ll}\text { Âge } & { }^{14} \mathrm{C} \\
\text { (BP) } & \end{array}$ & $\begin{array}{l}\delta 13 C \\
(\% o)\end{array}$ & $\begin{array}{l}\text { Date calibrée } \\
\text { (BC) }\end{array}$ & Probabilités \\
\hline $\begin{array}{l}\text { DEM } \\
2428\end{array}$ & $\begin{array}{l}1026-01 / 697 . \\
\text { A12, couche } 11 \\
Z=811.66 / 60 m\end{array}$ & Charbon & $7151 \pm 30$ & -26.02 & $\begin{array}{l}6050-6003 B C \\
6069-5986 B C\end{array}$ & $\begin{array}{l}(68.2 \%) \\
(95.4 \%)\end{array}$ \\
\hline $\begin{array}{l}\text { DEM } \\
2429\end{array}$ & $\begin{array}{l}1024-01 / 694.2 \\
\text { A12, couche } 11 \\
Z=811.67 \mathrm{~m}\end{array}$ & Charbon & $6793 \pm 30$ & -24.83 & $\begin{array}{l}5716-5664 \mathrm{BC} \\
\mathbf{5 7 2 7}-\mathbf{5 6 4 0} \mathrm{BC}\end{array}$ & $\begin{array}{l}(68.2 \%) \\
(95.4 \%)\end{array}$ \\
\hline $\begin{array}{l}\text { DEM } \\
2431\end{array}$ & $\begin{array}{l}1031-01 / 710.2 \\
\text { A12, couche } 13 \mathrm{~b}\end{array}$ & Charbon & $8233 \pm 30$ & -24.85 & $\begin{array}{l}7310-7137 \text { BC } \\
7356-7085 \text { BC }\end{array}$ & $\begin{array}{l}(68.2 \%) \\
(95.4 \%)\end{array}$ \\
\hline
\end{tabular}

Ces résultats confirment donc la date particulièrement haute du premier habitat de Sovjan, puisqu'en Grèce du Nord les premiers établissements sédentaires ne sont pas antérieurs à $6700 / 6500 \mathrm{BC}$ cal. En l'absence de tout vestige mobilier associé à la couche 13 - fouillée sur une superficie très réduite - la question de son appartenance au NA plutôt qu'au Mésolithique reste posée. Et bien qu'il soit difficile de savoir si les structures en bois associées à ce niveau (restes de plancher) ont un caractère pérenne ou saisonnier, on serait enclin à penser qu'un tel aménagement appartient plutôt à un habitat durable.

\section{La reprise de l'étude dendrologique}

Les problèmes rencontrés depuis plusieurs années dans la collaboration avec le Laboratoire d'Analyses et d'Expertises (LAE) de Bordeaux - à qui nous avions confié l'étude des bois archéologiques de Sovjan mais qui ne nous avait jamais fourni de résultats définitifs - nous avaient conduits à envisager la réouverture partielle la fouille pour y effectuer de nouveaux prélèvements. En 2018, le décès subit de la responsable du laboratoire, en faisant disparaître tout espoir d'obtenir jamais les données qui nous manquaient, nous a incités à réaliser ce projet. À cela sont venues s'ajouter les offres de collaboration faites par deux directeurs de laboratoires qui nous avaient contactés en 2017 : Albert Hafner, de l'Institut des sciences archéologiques de l'Université de Berne - qui est notamment en charge de l'étude dendrochronologique des habitats 
néolithiques de la région d'Amyntaion ${ }^{8}$ en Grèce - et Antoine Kremer, de l'INRA (UMR 1202 "Biodiversité, génomes communautés», Université de Bordeaux I), qui pilote un programme de recherche sur la génétique des chênes européens à partir de prélèvement d'ADN ancien sur des macrorestes de bois de chêne issus notamment des fouilles de sites palafittiques.

11 C'était là l'occasion de compléter les données très lacunaires dont nous disposions sur la dendrochronologie du site de Sovjan, notamment sur la chronologie absolue de la séquence des constructions, mais aussi d'intégrer les chênes du bassin de Korçë dans la base de données sur la génétique des populations de Quercus. Le second point est d'autant plus important que l'étude des sédiments du lac d'Ochrid, menée dans le cadre de l'étude paléoenvironnementale du site de Sovjan ${ }^{9}$, a montré que les montagnes du Sud de l'Albanie ont fonctionné comme un refuge forestier durant une bonne partie de la dernière période froide ${ }^{10}$. Toutes ces raisons nous ont décidés à réaliser cette année l'opération de terrain envisagée mais longtemps différée.

\section{La réouverture de la fouille}

12 Les travaux, supervisés par G. Touchais et P. Lera, ont mobilisé quatre ouvriers pendant neuf jours. Ils ont porté sur deux secteurs de la grande tranchée A7B-10 qui avait été remblayée à l'issue de la campagne de $2003^{11}$ et se trouvait depuis lors enfouie sous la boue et les roseaux du marécage : le sondage A10, à l'extrémité Nord de la tranchée, et le sondage A7 dans sa moitié Sud. Le choix de ces deux secteurs a été dicté par la présence, dans l'un comme dans l'autre, de restes de constructions en chêne bien conservées et censées appartenir, d'après les travaux préliminaires du LAE, à des phases différentes de la séquence relative ${ }^{12}$. La plupart de ces bois (pieux et poteaux, rondins, poutres) ayant déjà été échantillonnés, on aurait ainsi l'occasion, d'une part, de contrôler la séquence relative établie et, d'autre part, de la caler enfin en chronologie absolue.

13 Après un débroussaillage de la grande tranchée et de ses abords immédiats, envahis par une végétation sauvage d'autant plus luxuriante qu'elle n'avait pas été coupée depuis quinze ans, on a retrouvé en place trois des bornes topographiques en ciment $(\mathrm{X}, \mathrm{Z}, \mathrm{AD})$ qui avaient été coulées durant la fouille, ce qui a permis de contrôler les hypsométries et de réimplanter les limites des sondages.

14 C'est ainsi que l'on a d'abord piqueté puis déblayé, en A10, un carré de $2 \times 2 \mathrm{~m}$ correspondant au quart Nord-Est de l'ancien sondage et, dans la moitié Est des sondages A7-A7B, un rectangle de $2 \times 6 \mathrm{~m}$ parallèle au canal. L'épaisseur moyenne $\mathrm{du}$ remblai de terre humide (en surface) ou gorgée d'eau (en profondeur) qui recouvrait les niveaux d'arrêt de la fouille en 2003 était de $1 \mathrm{~m}$ à $1,20 \mathrm{~m}$. Compte tenu du niveau relativement haut de l'eau dans le canal en $2018( \pm 815,10)$, il a fallu utiliser des pompes en permanence pour évacuer l'eau des sondages.

On a eu la satisfaction de constater que, grâce aux protections mises en place avant le remblaiement ${ }^{13}$, les structures en bois avaient très bien résisté. Tous les éléments ont été retrouvés à leur place, beaucoup d'entre eux munis de l'étiquette en plastique portant leur numéro d'identification (fig. 1), ce qui a grandement facilité les prélèvements. 
Fig. 1 - Sovjan. Éléments d'architecture en bois retrouvés en place dans le sondage A7.

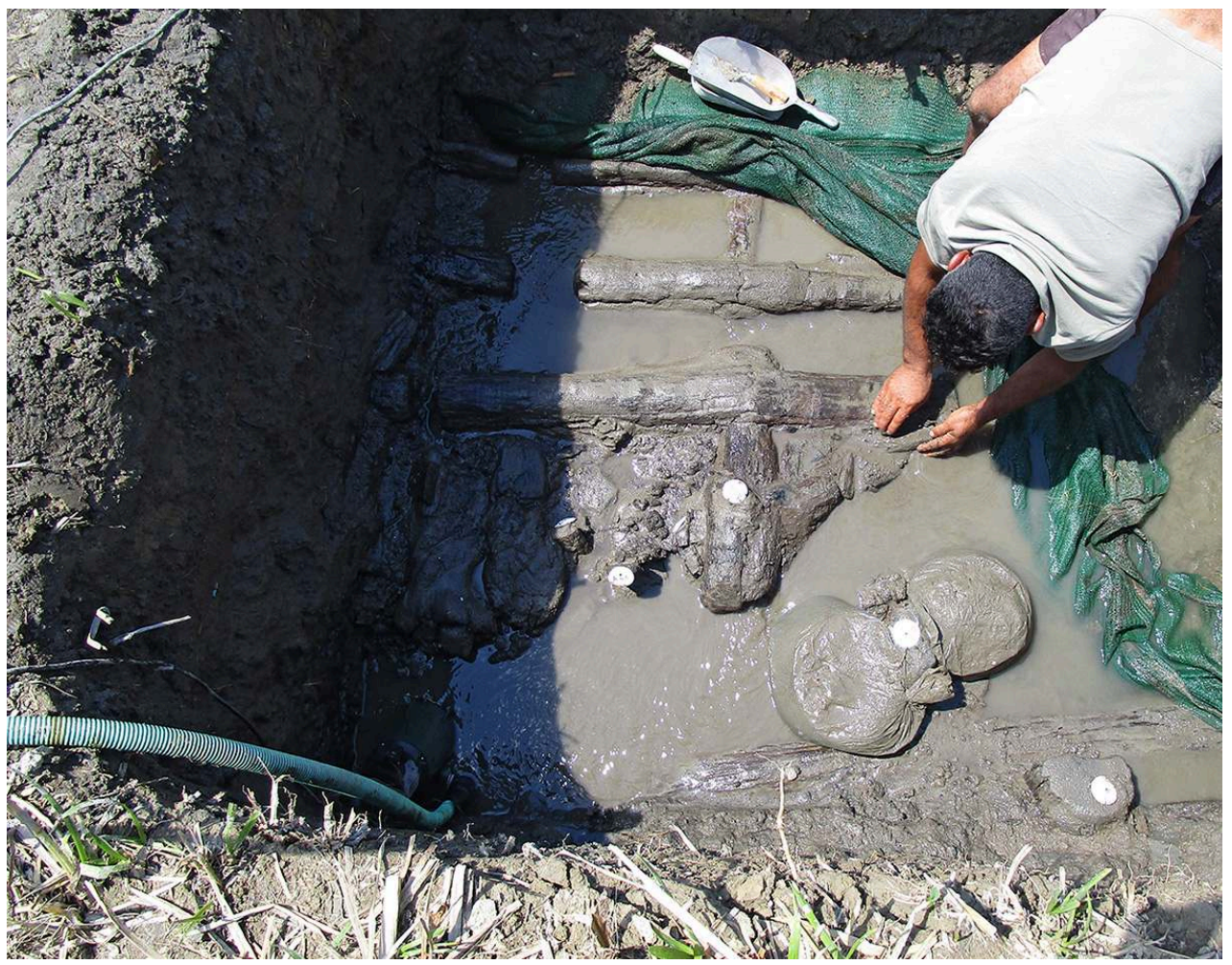

Mission archéologique Korçë.

\section{Les prélèvements pour analyses génétiques} génétiques, il faut prélever des fragments d'aubier ${ }^{14}$. Les contraintes étaient donc multiples si l'on voulait avoir une chance de retrouver de l'ADN ancien sur les bois de Sovjan : il fallait trouver des bois dont l'aubier était visible et, d'autre part, encore intact ou le moins détérioré possible. Seuls quatre échantillons répondant à ces exigences ont pu être prélevés à l'aide d'une scie métallique - en limitant au maximum les risques de contaminations humaines - puis stockés immédiatement dans une glacière à $5{ }^{\circ} \mathrm{C}$. Ils ont ensuite été expédiés au laboratoire d'ADN ancien de Toulouse (AMIS), où leur contenu sera testé grâce à des techniques biomoléculaires développées ces dernières années. S'il y en a suffisamment, il sera séquencé par des techniques de séquençage NGS (Next Generation Sequencing).

\section{Les prélèvements pour analyses dendro- et radiochronologiques}

La seconde série de prélèvements a été effectuée en même temps que la précédente. Il s'agissait cette fois de prélever une coupe transversale complète du bois à analyser, une rondelle de celui-ci étant découpée à la scie (fig. 2). Au total, on a prélevé 33 
échantillons issus des couches 8 et 9. Quinze échantillons de chêne ont été prélevés dans le sondage A10 (couche 8), sur des structures architecturales contemporaines de la maison du Canal (chemin de rondins, maison du Pêcheur). Onze échantillons de chêne ou de pin proviennent du sondage $\mathrm{A} 7 \mathrm{~b}$ (couche 8) et appartiennent à des poteaux ou pieux constituant un ensemble architectural supposé plus ancien que la maison du Canal. Les sept échantillons restants (chêne ou pin) proviennent du sondage A7 (couches 8 et 9) et appartiennent à différentes structures (éléments de plancher, pieuplanche, poteau) qui ne sont pas contemporaines. À l'issue des analyses dendrochronologiques, certains de ces échantillons seront datés par la méthode du radiocarbone, ce qui permettra un calage de la séquence dendrochronologique en dates absolues ${ }^{15}$.

Fig. 2 - Sovjan. Prélèvement d'une rondelle de bois de chêne pour analyses dendro- et radiochronologiques.

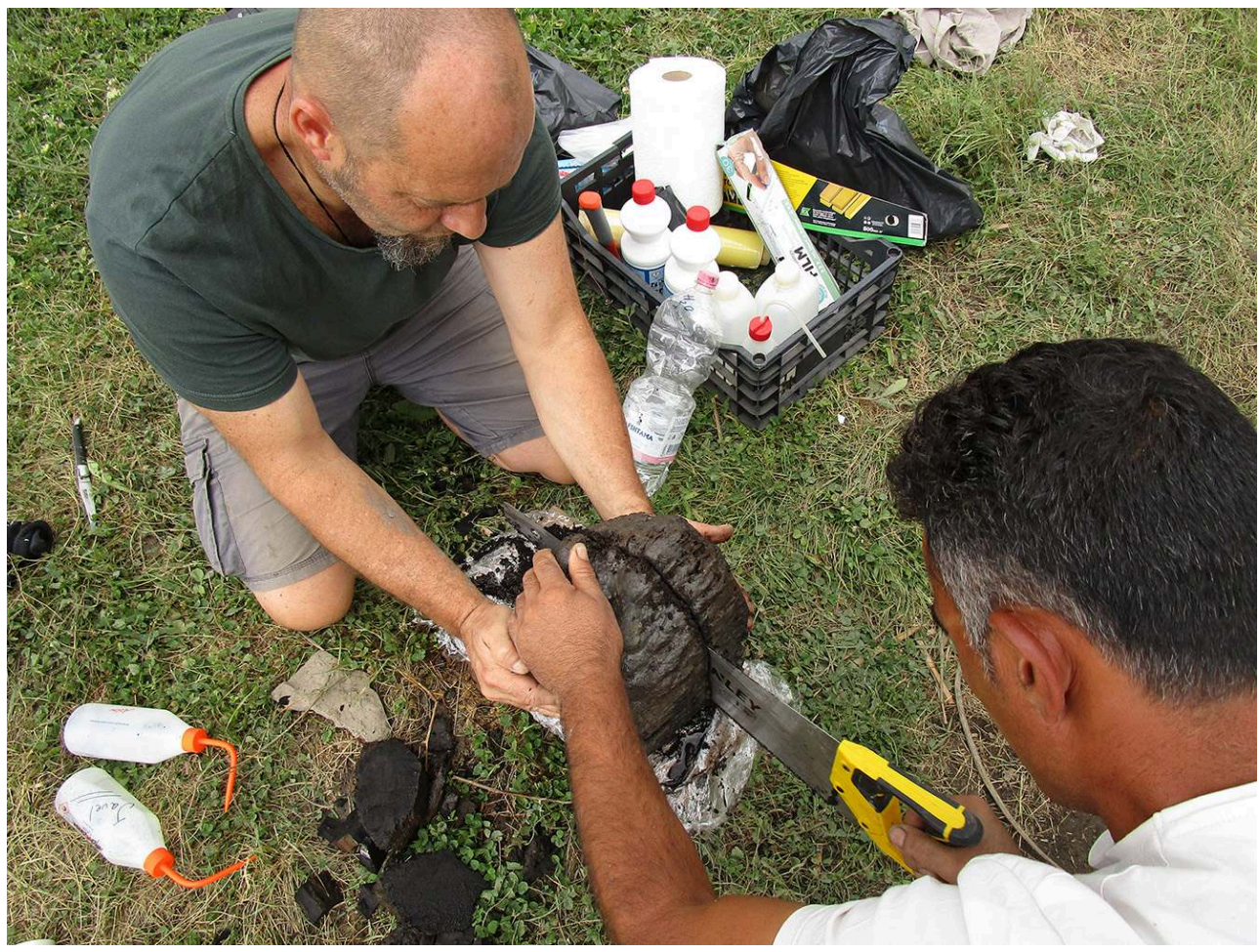

Mission archéologique Korçë.

\section{L'étude de la céramique du Bronze Récent et du Fer Ancien}

\section{Étude typo-chronologique}

T. Krapf a poursuivi l'étude de la céramique des couches 4 à 6 lors de plusieurs séjours à Korçë entre octobre 2016 et février 2018. Cela lui a permis, d'une part, de compléter la documentation graphique et photographique du matériel, qui compte actuellement près de 25000 photos et de 1700 dessins, ainsi que l'étude statistique des formes diagnostiques, qui porte désormais sur environ 3000 fragments; d'autre part, de poursuivre l'étude technologique des vases.

La campagne de 2017 s'est plus spécialement concentrée sur la séquence de la céramique dans les carrés A1 et A2 fouillés par P. Lera en 1990, ainsi que sur le matériel 
provenant du sommet de la couche $5 \mathrm{c} 1$, qui date de la transition entre BR/FA et où l'on a notamment identifié trois nouveaux fragments de céramique tournée sans traces de décor. L'année suivante, on a trié la céramique du FA de la campagne de 1991 et réalisé des photos d'ensembles par décapage. Une série de contextes perturbés des fouilles franco-albanaises a aussi été revue, ce qui a permis l'identification de plusieurs formes de vases intéressantes, ainsi que celle d'un nouveau fragment peint de céramique importée.

D'autre part, deux nouvelles caisses datées de 1988 contenant du matériel de surface de Sovjan et de Maliq ont été localisées dans la réserve et documentées. L'ensemble présente quelques décors et formes qui ne sont pas représentés dans le reste du matériel. Il a en outre été possible d'examiner et de photographier, dans la réserve de l'Institut archéologique à Tirana, le matériel du BR et du FA issu des fouilles de Gradishte e Symizes, Drenove et Maliq (secteur C) (fig. 3) en compagnie de P. Lera, auteur des fouilles ${ }^{16}$. Les deux premiers sites présentent un intérêt majeur car ils ont livré du matériel postérieur à l'abandon de Sovjan et de Maliq, permettant ainsi de suivre la séquence céramique après le $\mathrm{VIIII}^{\mathrm{e}} \mathrm{s}$. av. J.-C. On y trouve notamment des fragments de céramique à peinture mate ornés de motifs à lignes courbes, qui ne se rencontrent pas à Sovjan.

Fig. 3 - Céramique à peinture mate des sites de Drenova, Maliq et Sovjan.
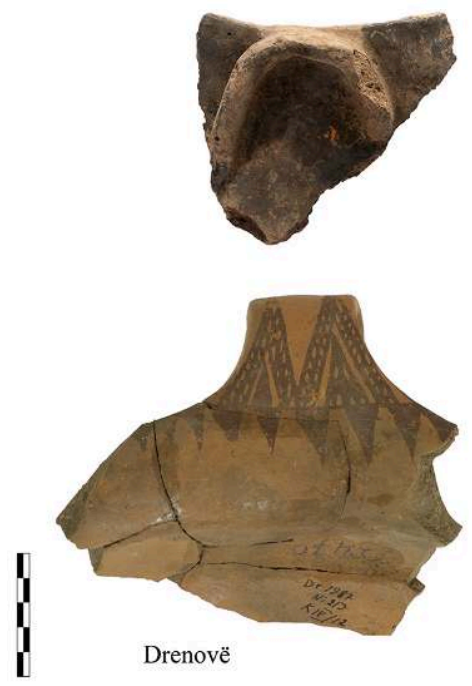

Mission archéologique Korçë.
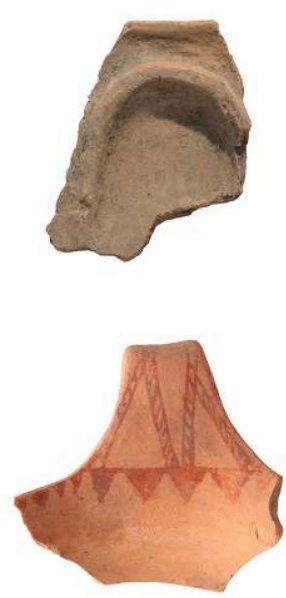

Maliq
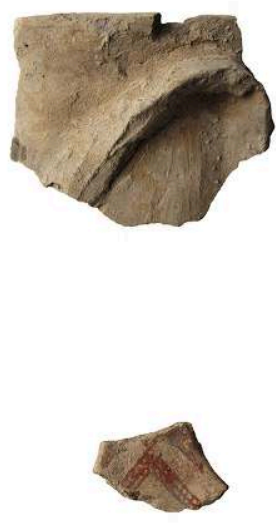

Sovjan

\section{Étude technologique : analyses de pâte et prélèvements d'argile}

L'étude de la caractérisation des pâtes de la céramique de l'Âge du Bronze et du Fer entreprise par O. Aslaksen, aidé de T. Krapf et M. Gori, s'est poursuivie en 2017 par une campagne d'échantillonnage d'argiles dans le bassin de Korçë. L'objectif était d'explorer au mieux le choix des matériaux mis en œuvre par les potiers préhistoriques de Sovjan. Un total de neuf échantillons a été prélevé et analysé directement sur place puis, après séchage, dans la réserve archéologique de Korçë à l'aide d'un spectromètre Thermo Niton XL3t Goldd+ pXRF à anode en argent. Les échantillons d'argile proviennent d'un canal perpendiculaire au Devoll, ainsi que des sites de Sovjan et de 
Maliq (secteur C) et d'un canal situé au Nord du site de Sovjan. On a aussi pu analyser deux argiles utilisées par une briqueterie moderne à Qatrom: l'une provient d'une fosse située à côté de l'usine (fig. 4), l'autre d'un gisement qui se trouve en bordure du Dunavec, près du village de Polena. Les briques produites par cette usine sont faites d'un mélange de ces deux argiles. Quatre autres échantillons et deux vases modernes (l'un séché au soleil et l'autre cuit à $950^{\circ} \mathrm{C}$ ) ont été acquis chez un potier à Drenova. Ces argiles - qu'il utilise en mélange - proviennent de Maliq, du Devoll et du plateau de Kolonje sans plus de précision. Enfin, deux échantillons supplémentaires proviennent du village de Sovjan : il s'agit d'une brique moderne en terre crue séchée prise dans un mur effondré, et de fragments de briques ramassés près d'une ancienne fosse d'extraction d'argile aujourd'hui remblayée.

Fig. 4 - Échantillonnage d'argile à Qatrom à l'aide d'un spectromètre portable XRF.

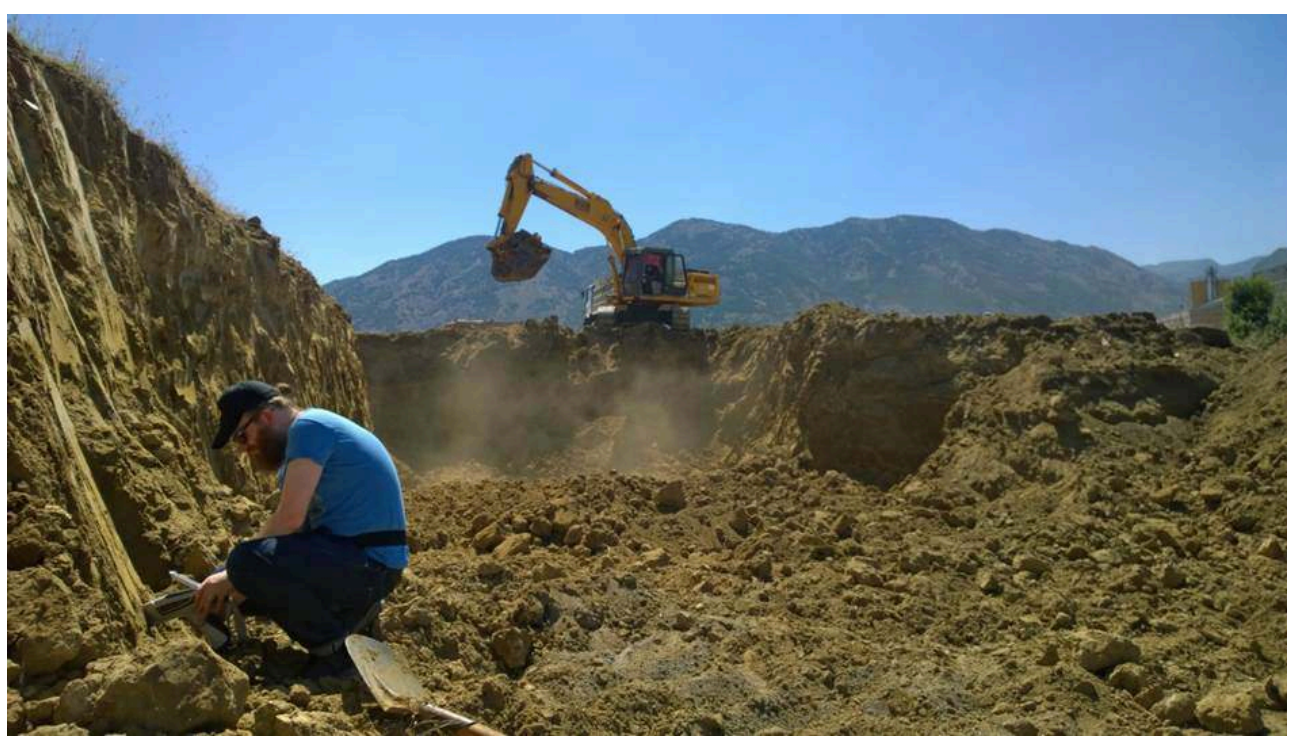

Mission archéologique Korçë.

L'étude préliminaire montre, d'une part, que les analyses donnent des résultats différents suivant qu'elles sont pratiquées avant ou après séchage des échantillons au soleil, alors que ceux-ci sont scannés avec des paramètres identiques (le taux de $\mathrm{Fe}, \mathrm{Si}$, $\mathrm{Al}$ et Ti est significativement plus élevé après séchage) et qu'il est donc important de prendre en compte l'état des échantillons; d'autre part, que les échantillons de Maliq contiennent plus de $\mathrm{Fe}$, tandis que ceux qui proviennent de la couche d'argile bleue au fond du canal de Sovjan sont plus riches en Si. Des analyses complémentaires sont prévues. Les résultats obtenus à l'issue de ce programme d'analyses XRF alimenteront une base de données de référence pour la plaine de Korçë et permettront de mieux comprendre la production locale de céramique à l'Âge de Bronze et au début de l'Âge de Fer, permettant du même coup d'en distinguer les importations. L'une des questions en suspens est de savoir si les habitants de Sovjan utilisaient seulement l'argile la plus proche ou bien s'ils choisissaient des argiles plus adaptées à leurs besoins et effectuaient des mélanges, comme le font aujourd'hui encore les potiers de la région.

En 2018 on a sélectionné 75 échantillons de céramique aux fins d'analyses pétrographiques ${ }^{17}: 71$ tessons de Sovjan (couches $5 \mathrm{a}$ à 9 ) et quatre fragments de céramique à peinture mate de Maliq (secteur $\mathrm{C}$ ) choisis à titre de comparaison. On 
prépare aussi un programme de radiographie des vases, qui permettra d'identifier les techniques de façonnage mises en œuvre pour leur fabrication.

Enfin, on a pu compléter l'étude fonctionnelle des récipients en mesurant (à l'aide de sable) la capacité d'un choix de petits vases complets issus des couches 4 à 6 . Il est apparu, par exemple, que les canthares ont une contenance qui varie de 0,1 à 0,4 litre.

\section{Restauration}

La restauration des vases du locus 984/987, qui avait été commencée en $2012^{18}$, a été achevée en 2017. Quatre grands vases de stockage en céramique monochrome claire ont ainsi pu être remontés plus ou moins complètement ; ils ont été rangés dans la réserve sur des supports métalliques fabriqués sur mesure, qui permettront de les exposer, le moment venu, dans le musée de Korçë (fig. 5).

Fig. 5 - Sovjan. Vases du BR restaurés.

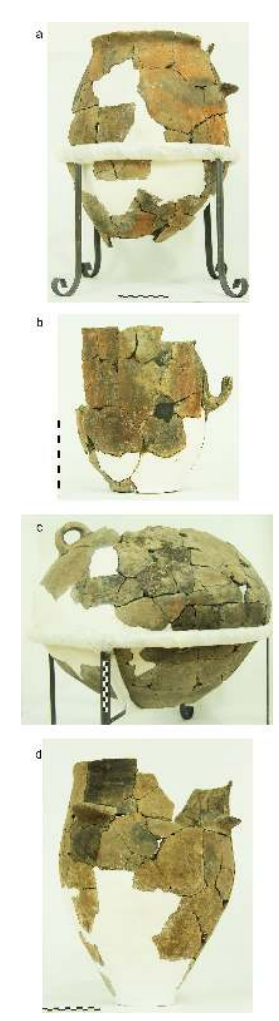

a) SV $33 / 611.1$; b) SV 03/620.3 ; c) 06/616.1 ; d) 03/624.7.

Mission archéologique Korçë.

\section{L'étude des données des fouilles de Kallamas}

En 2017 et 2018 G. Elezi a poursuivi l'étude de la céramique néolithique, avec l'aide de P. Lera ${ }^{19}$. On a d'autre part mis en chantier le volume de la publication finale ${ }^{20}$. 


\section{Les datations absolues}

Trois nouvelles datations ont été réalisées dans les niveaux les plus profonds du sondage principal C1 (phase III) à partir d'échantillons de charbon de bois; elles viennent compléter celles qui avaient été faites en 2015 sur des graines ${ }^{21}$. Une quatrième datation (de la phase Ic), faite sur un échantillon de collagène d'os animal, donne un résultat aberrant au regard de l'ensemble de la séquence chronologique de Kallamas et ne doit donc pas être prise en compte.

Tableau 4 - Nouvelles datations absolues des niveaux d'occupation de Kallamas.

\begin{tabular}{|c|c|c|c|c|c|c|}
\hline $\mathrm{N}^{\circ}$ labo. & $\begin{array}{l}\mathrm{N}^{\circ} \text { échantillon/ } \\
\text { sondage/couche }\end{array}$ & Matériau & $\begin{array}{ll}\text { Âge } & { }^{14} \mathrm{C} \\
\text { (BP) } & \end{array}$ & $\begin{array}{l}\delta 13 C \\
(\%)\end{array}$ & $\begin{array}{l}\text { Date calibrée } \\
(\mathrm{BC})\end{array}$ & Probabilités \\
\hline $\begin{array}{l}\text { DEM } \\
2550\end{array}$ & $\begin{array}{l}\text { Éch. KL82, } \\
\text { Sondage C1 } \\
\text { Phase III }\end{array}$ & Charbon & $6286 \pm 30$ & -25.77 & $\begin{array}{l}5306-5227 \mathrm{BC} \\
\mathbf{5 3 1 7}-\mathbf{5 2 1 7} \mathrm{BC}\end{array}$ & $\begin{array}{l}(68.2 \%) \\
(95.4 \%)\end{array}$ \\
\hline $\begin{array}{l}\text { DEM } \\
2551\end{array}$ & $\begin{array}{l}\text { Éch. KL 84, } \\
\text { Sondage C1 Phase } \\
\text { III }\end{array}$ & Charbon & $6497 \pm 30$ & -23.21 & $\begin{array}{l}5491-5384 \text { BC } \\
5519-5376 \text { BC }\end{array}$ & $\begin{array}{l}(68.2 \%) \\
(95.4 \%)\end{array}$ \\
\hline $\begin{array}{l}\text { DEM } \\
2556\end{array}$ & $\begin{array}{l}\text { Éch. KL 91, } \\
\text { Sondage C1 Phase } \\
\text { III }\end{array}$ & Charbon & $6492 \pm 40$ & -24.22 & $\begin{array}{l}5491-5384 \mathrm{BC} \\
5519-5376 \mathrm{BC}\end{array}$ & $\begin{array}{l}(68.2 \%) \\
(95.4 \%)\end{array}$ \\
\hline $\begin{array}{l}\text { DEM } \\
2344\end{array}$ & $\begin{array}{l}\text { Éch. KL180, } \\
\text { Sondage C1 } \\
\text { Phase Ic }\end{array}$ & Os & $4446 \pm 134$ & -22.64 & $\begin{array}{l}3336-2931 \text { BC } \\
\mathbf{3 6 2 0}-\mathbf{2 7 6 3} B C\end{array}$ & $\begin{array}{l}(68.3 \%) \\
(95.4 \%)\end{array}$ \\
\hline
\end{tabular}

Les échantillons de charbon de bois $\mathrm{n}^{\text {os }} 82$ et 84 proviennent de la même US que la graine datée en 2015. Ils donnent des dates entre 5500 et $5200 \mathrm{BC}$ cal., tandis que la graine est datée de 5207 à $5028 \mathrm{BC}$ cal., ce qui peut s'expliquer par la différence de nature entre les échantillons (à vie longue pour le charbon, courte pour la graine). Les dates restent néanmoins cohérentes et inviteraient donc à dater cette US autour de $5200 \mathrm{BC}$ cal. L'échantillon $\mathrm{n}^{\circ} 91$ appartient, quant à lui, à la dernière US avant le sol vierge, donc à la plus ancienne du sondage ; il donne une datation de 5519-5376 BC cal., donc légèrement antérieure à celle des échantillons précédents, mais il faut tenir compte du fait que l'on a daté ici un échantillon à vie longue.

Quoi qu'il en soit, le plus ancien niveau d'occupation du sondage C1 (phase III) apparaît comme exactement contemporain de l'unique niveau - jusqu'alors plus ancien - mis au jour dans le sondage $\mathrm{D} 1(5400-5200 \mathrm{BC} \text { cal. })^{22}$ Cela signifie que le sondage $\mathrm{C} 1$ présente bien l'intégralité de la séquence du site de Kallamas tel qu'il a été fouillé jusqu'à présent.

31 Le modèle chronologique élaboré en 2016 pour l'ensemble des niveaux d'occupation du sondage $\mathrm{C} 1$ a été mis à jour à partir de ces dernières datations, mais il ne diffère pas fondamentalement $d u$ précédent ${ }^{23}$. Tout au plus la première occupation du site 
pourrait-elle être un peu plus ancienne qu'on ne le pensait, entre 5400 et $5200 \mathrm{BC}$ cal., et dater ainsi du début du NR I en termes de chronologie égéenne.

Tableau 5 - Nouvelle séquence des datations absolues de Kallamas après modélisation.

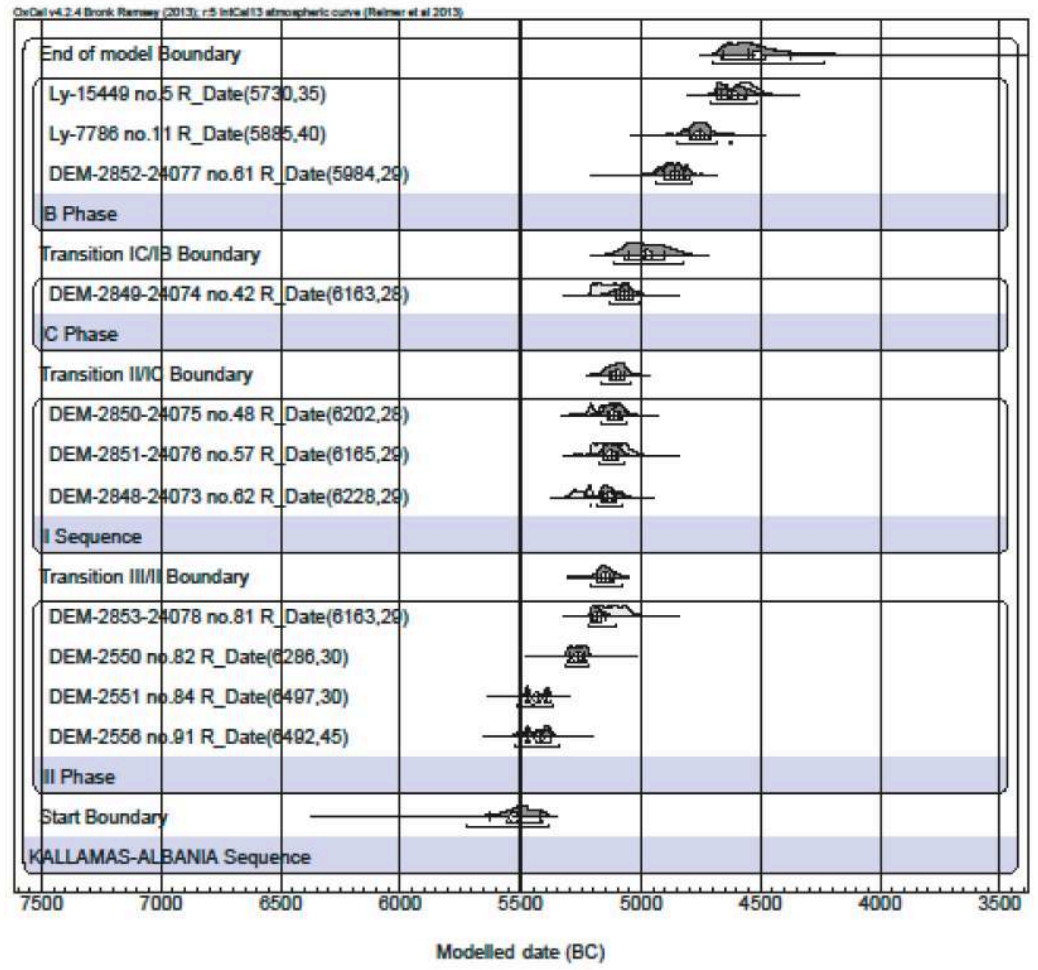

\section{L'étude de la céramique}

G. Elezi a poursuivi l'enregistrement, dans la base de données, de la céramique néolithique issue des fouilles menées entre 2008 et 2011, achevant notamment celui de la totalité du matériel issu des sondages $\mathrm{C} 1$ et $\mathrm{C} 6$. Il a effectué un certain nombre de recollages qui ont permis de reconstituer partiellement plusieurs vases (fig. 6-7), réalisé plus de 170 dessins, et complété l'échantillonnage de tessons en vue des analyses pétrographiques des pâtes et des analyses chimiques des résidus organiques, qui ont fourni les premiers résultats. 
Fig. 6 - Kallamas. Vase noir poli partiellement restauré (KL 11/333).

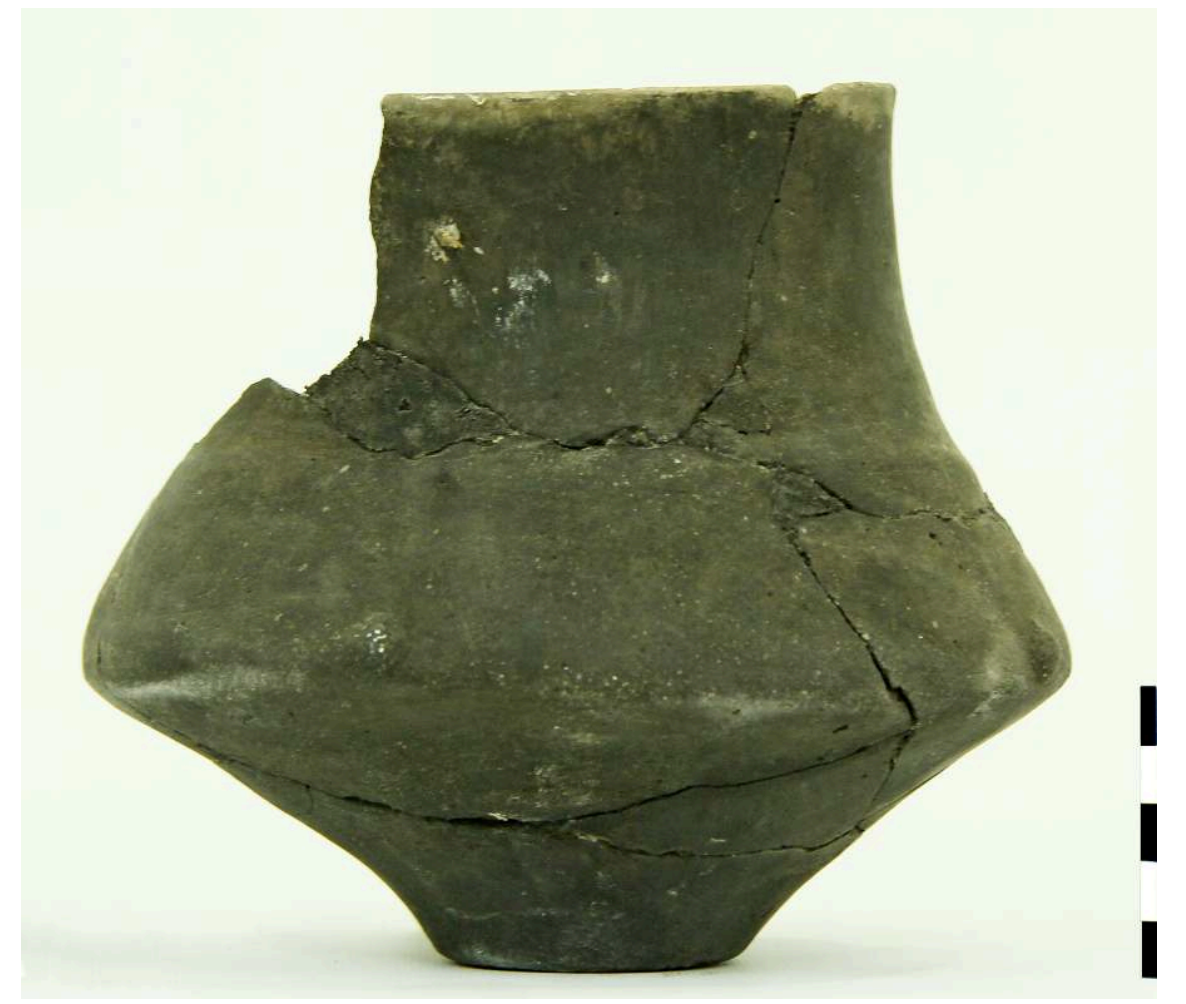

Mission archéologique Korçë.

Fig. 7 - Kallamas. Vase black-topped partiellement restauré (KL 11/153.27).

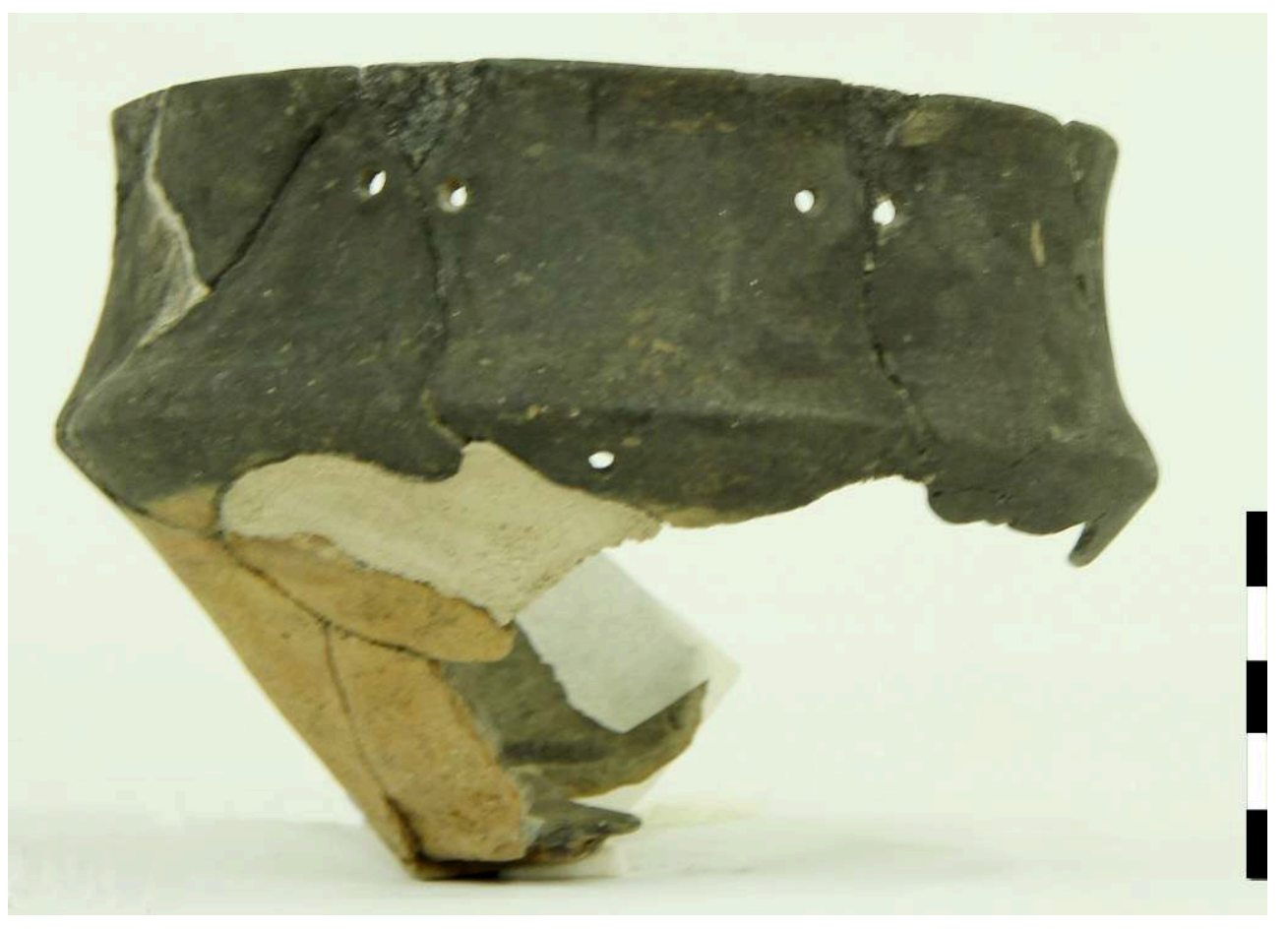

Mission archéologique Korçë. 


\section{Étude typo-chronologique}

L'examen préliminaire du matériel documenté jusqu'à présent nous donne une première idée de l'assemblage céramique du site. Sur l'ensemble des tessons examinés (plus de 20000 ) environ $70 \%$ n'ont pu être caractérisés avec précision : c'est là une preuve évidente $\mathrm{du}$ fort taux d'érosion qui caractérise l'ensemble du matériel. La plupart des fragments appartiennent à des vases ouverts, mais le taux de formes non identifiables est élevé(fig. 8). Le répertoire des formes est varié: sphériques, hémisphériques, cylindriques, carénées et biconiques (fig. 9) caractéristiques du NM et du NR d'Albanie méridionale et de Grèce du Nord. Seuls 3,5\% du matériel enregistré présente un décor, les plus courants étant les décors à la barbotine, en technique black topped et les ornements plastiques ("grains de café »...) (fig. 10). Là encore, ces types de décoration sont tout à fait comparables à ceux que l'on rencontre dans les régions voisines du bassin de Korçë pour cette période. Enfin, un grand nombre de tessons présente une surface extérieure parsemée de taches noires sur fond beige ou beiges sur fond sombre, tandis que les autres sont généralement bruns, noirs, beiges ou gris (fig. 11).

Fig. 8 - Kallamas. Répartition des types de vases par famille (ouverts/fermés).

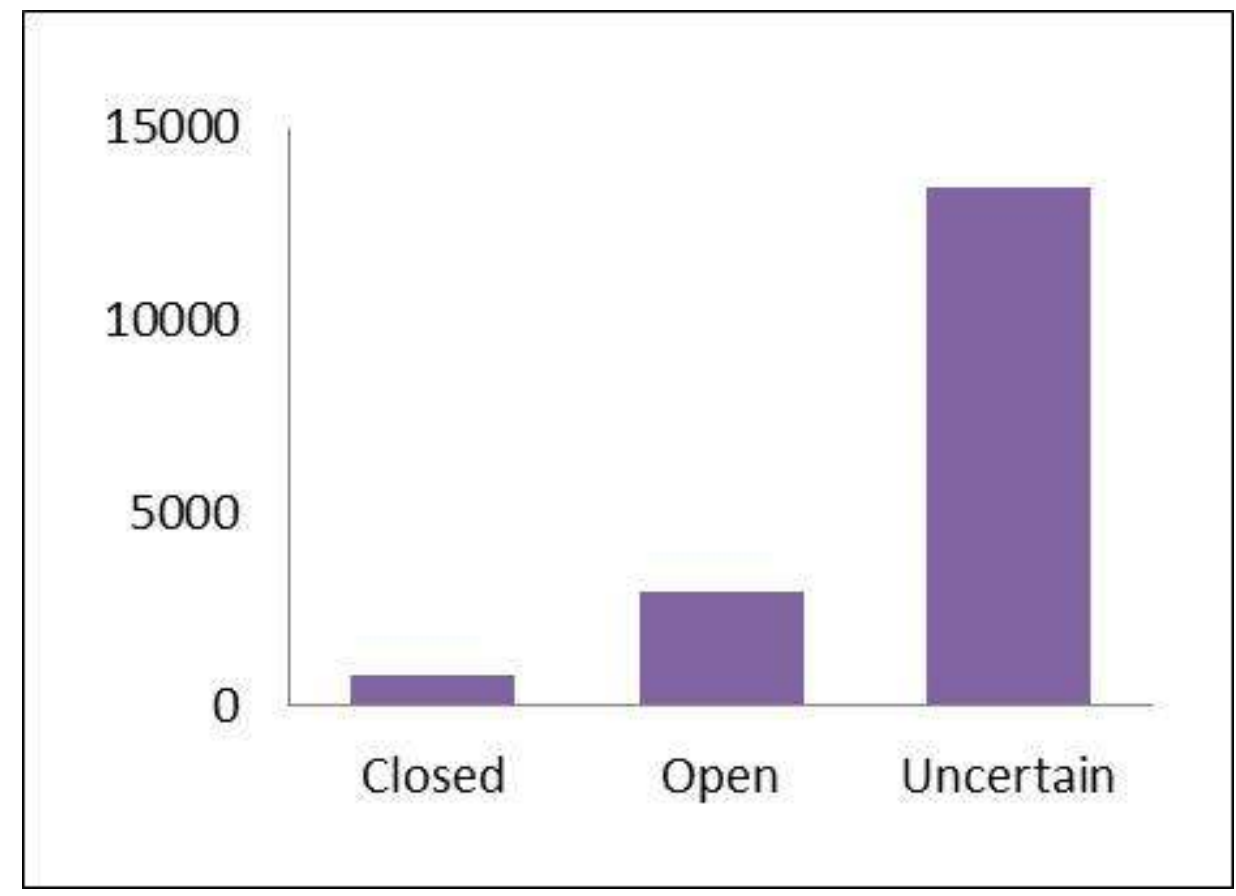

Mission archéologique Korçë. 
Fig. 9 - Kallamas. Typologie des vases.

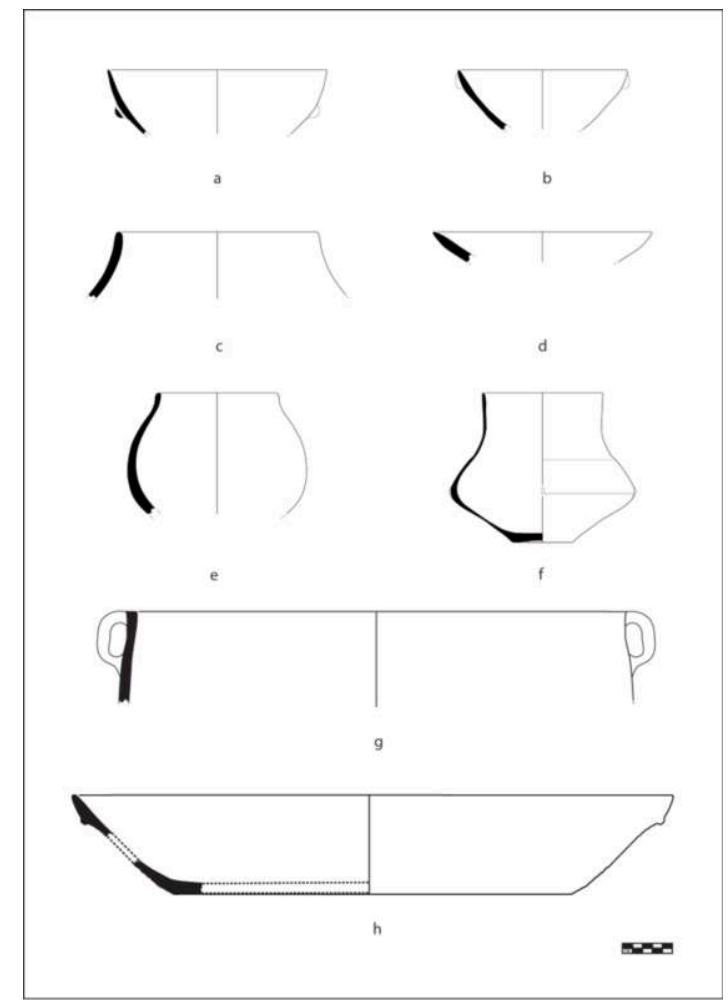

Mission archéologique Korçë.

Fig. 10 - Kallamas. Répartition des catégories de décor céramique.

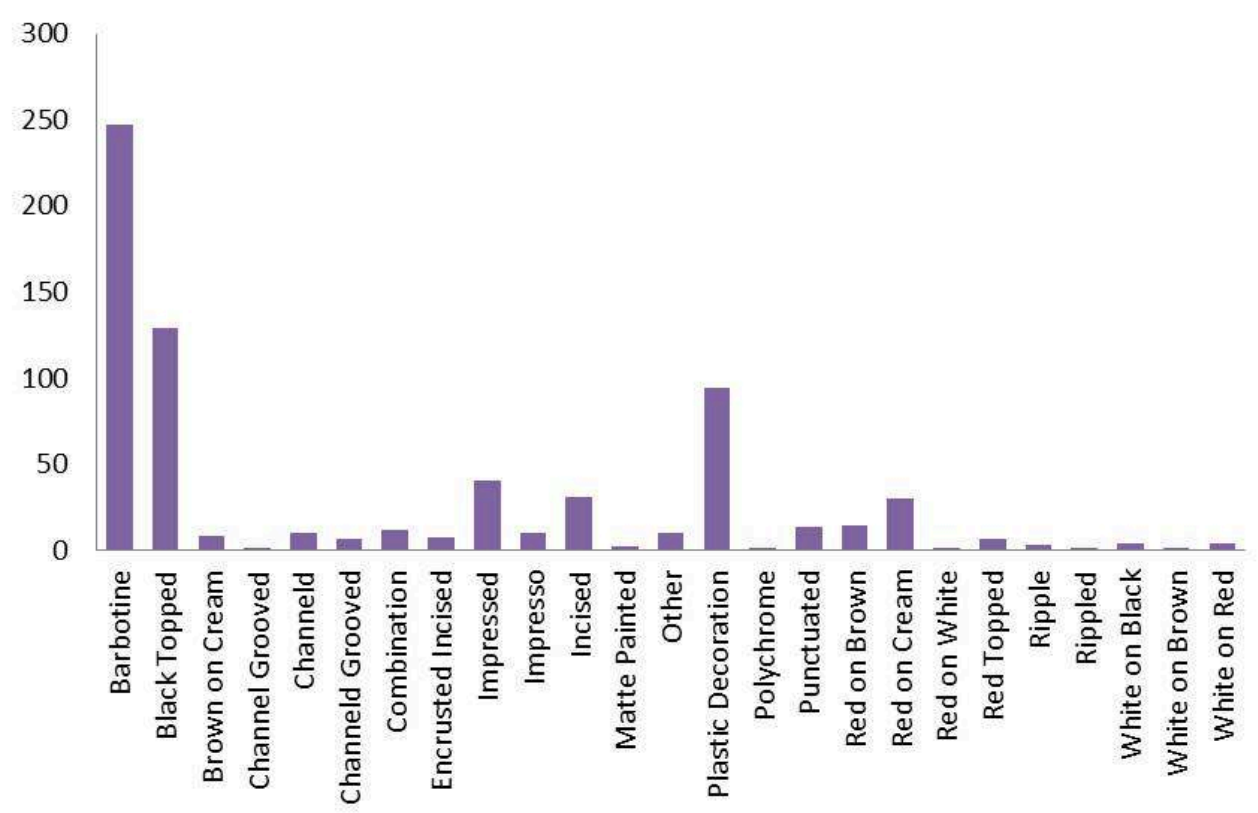

Mission archéologique Korçë. 
Fig. 11 - Kallamas. Couleur de la surface extérieure des vases.

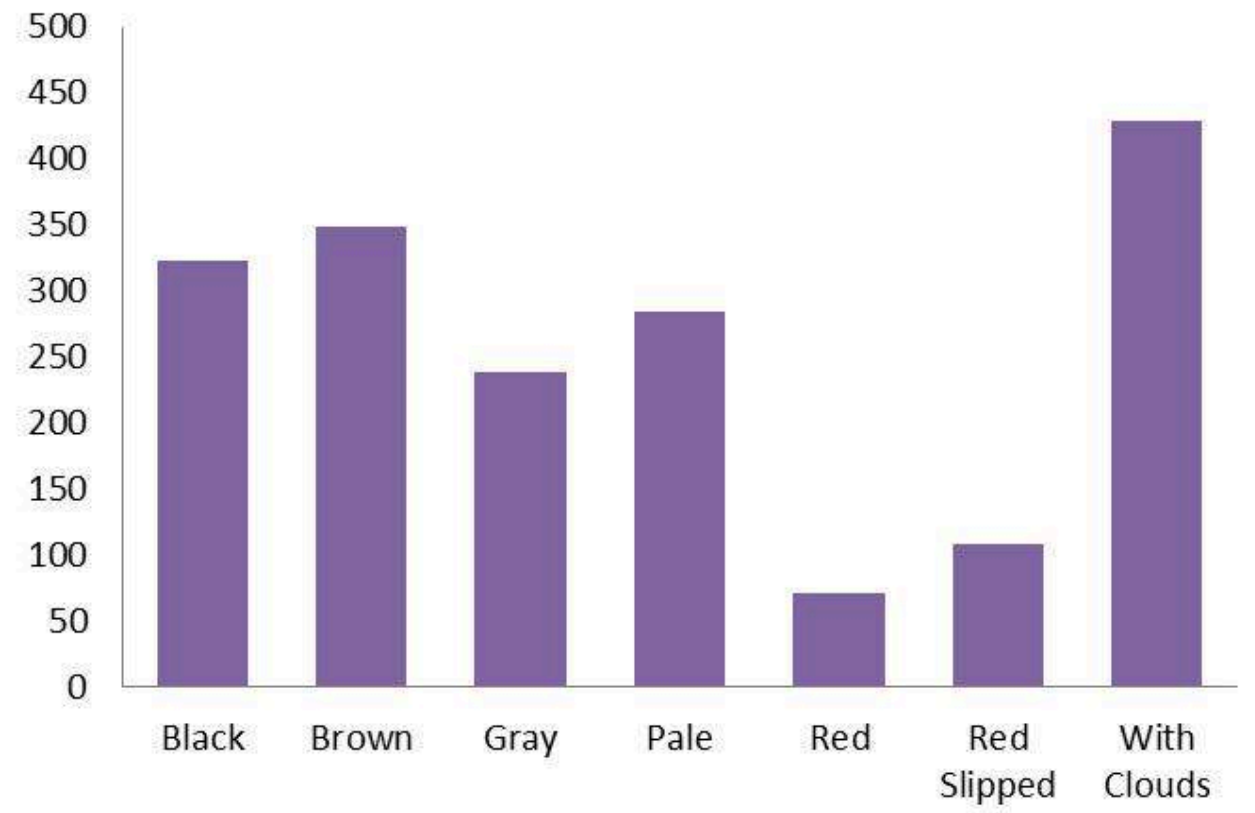

Mission archéologique Korçë.

L'enregistrement de tous les tessons provenant du sondage $\mathrm{C} 1$ a permis de formuler certaines conclusions sur la céramique des quatre phases chronologiques identifiées lors de la fouille (Ib, Ic, II, III), en liaison avec les datations absolues. Tout d'abord, les catégories de décor les plus courantes sont le décor à la barbotine, le décor black topped, les décors plastiques, incisés, imprimés et peints en rouge sur fond crème (fig. 12). 
Fig. 12 - Kallamas. Sondage C1. Les catégories de décor céramique.

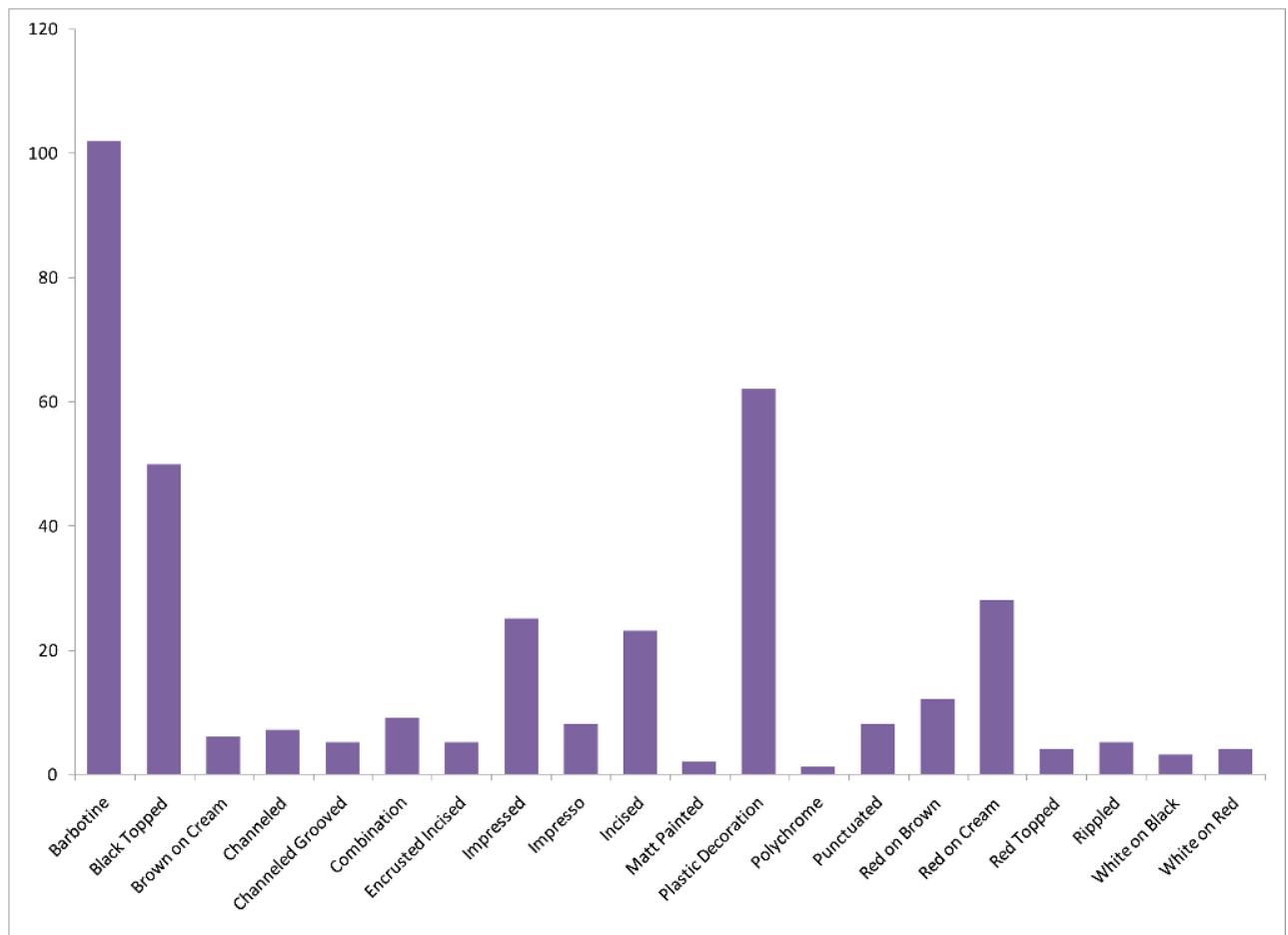

Mission archéologique Korçë.

La céramique décorée à la barbotine est présente dans les quatre phases; elle prédomine dans la phase $\mathrm{III}^{24}$ mais continue d'être présente dans la phase $\mathrm{Ib}^{25}$. La céramique dite black topped apparaît aussi dans toutes les phases mais, contrairement à la précédente, elle est en augmentation constante de la phase la plus ancienne (III) jusqu'à la plus récente $(\mathrm{Ib})$. Quant à la céramique à peinture rouge sur fond crème, elle est absente de la phase III mais représentée par quelques tessons dans les phases II et Ic ; par contre, elle prédomine - avec la céramique black topped - dans la phase Ib. La céramique à décor plastique demeure constante pendant les quatre phases. Concernant la typologie des vases, on observe une diminution des formes carénées entre la phase Ic - où elles prédominent - et la phase $\mathrm{Ib}$, tandis que les formes sphériques et hémisphériques sont en augmentation (fig. 13). 
Fig. 13 - Kallamas. Sondage C1. Les principaux types de vases.

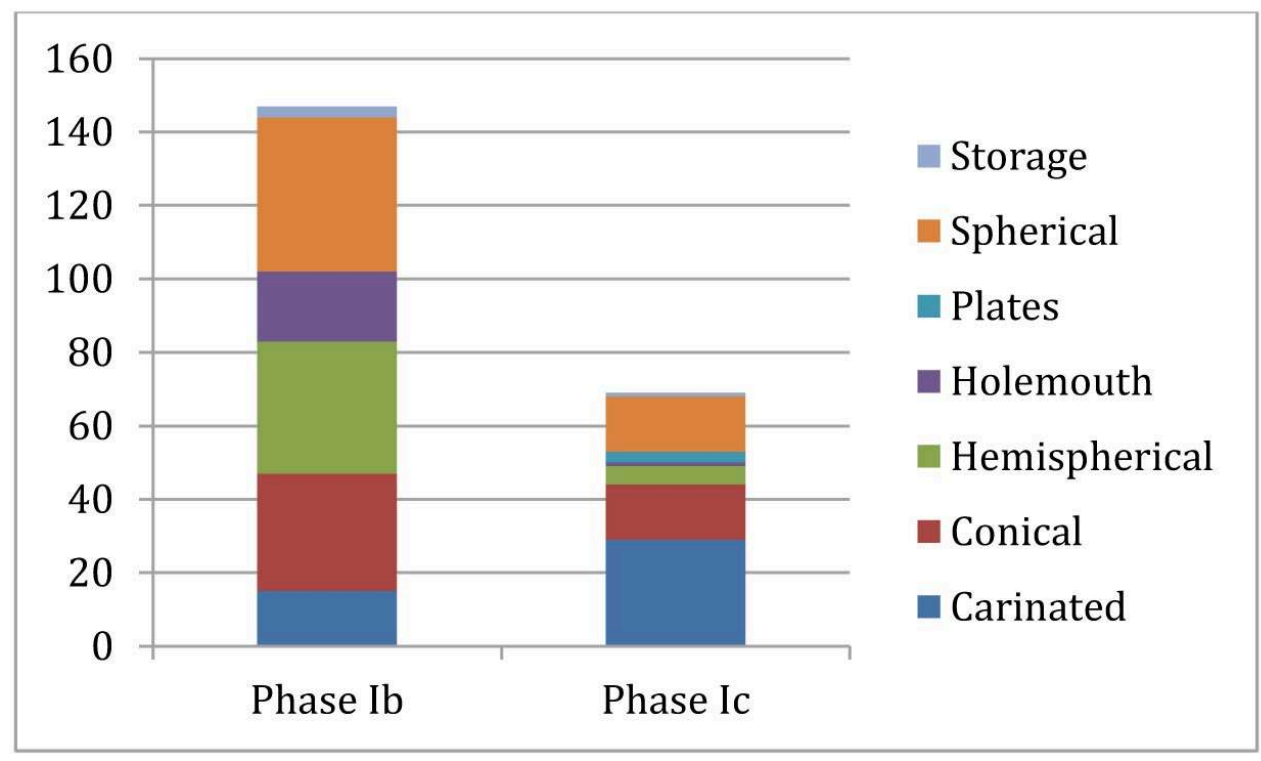

Mission archéologique Korçë.

Par ailleurs, on notera la présence probable d'une nouvelle phase d'occupation plus récente que $\mathrm{Ib}$, passée inaperçue à la fouille mais révélée par la céramique. Celle-ci est caractérisée par un décor blanc « en croûte » (décor à la peinture rose/rouge appliqué après cuisson) et un décor de motifs géométriques peints en blanc sur fond brun ou gris (fig. 14), traits typiques de la céramique chalcolithique (ou énéolithique) de la région. Il est donc probable qu'il existe dans le sondage $\mathrm{C} 1$, immédiatement sous la surface, une phase chalcolithique sans doute très perturbée. On date généralement cette période entre 4800 et $3900 \mathrm{BC}^{26}$ mais, à Kallamas, elle serait sans doute à situer entre 4500 et $4000 \mathrm{BC}$, la phase Ib sous-jacente débutant vers 4400/4500 BC (tableau 5). 
Fig. 14 - Kallamas. Sondage $\mathrm{C} 1$. Céramique décorée des niveaux supérieurs.
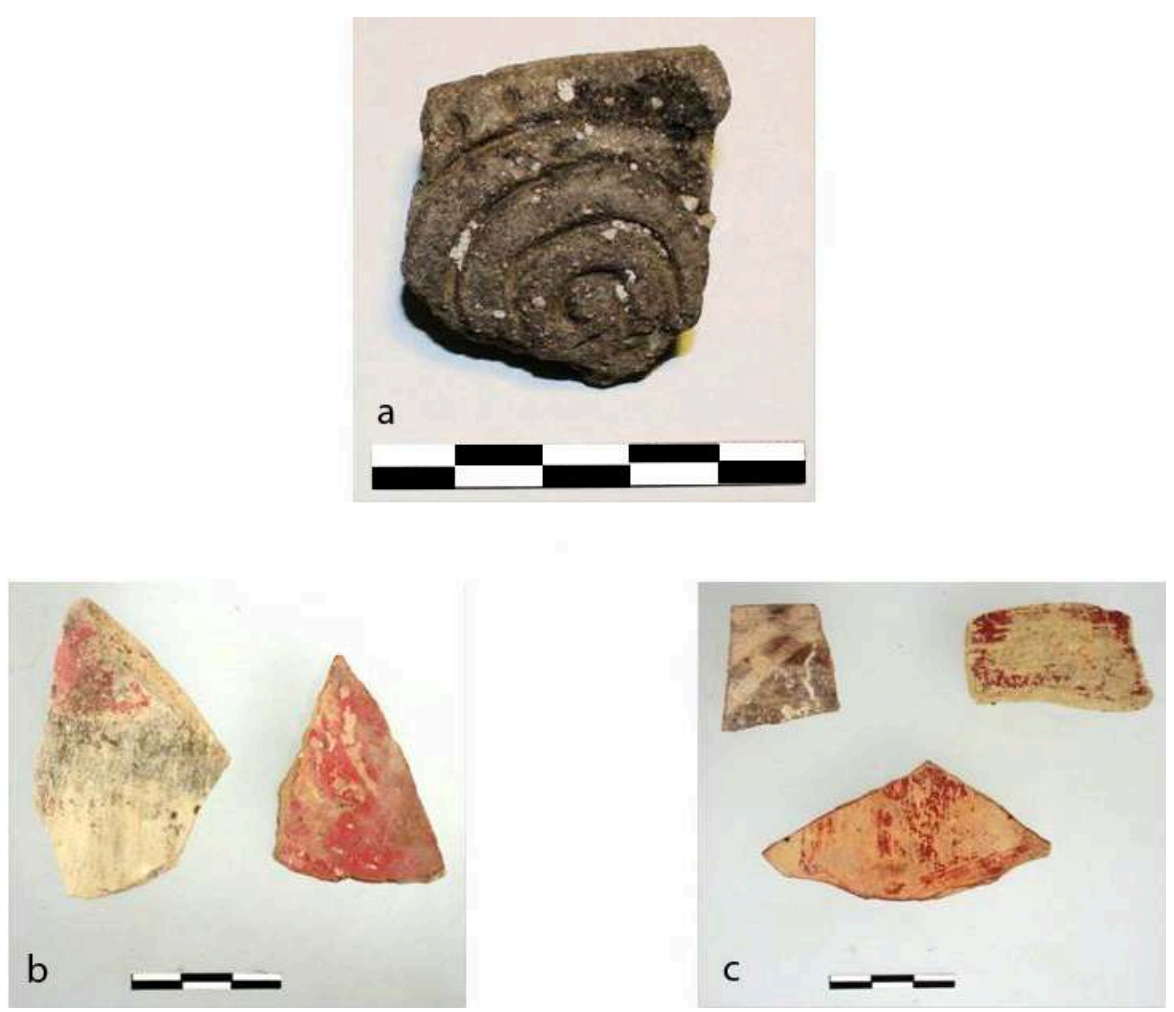

a) décor de type Bratislava, b) décor à peinture rose appliquée après cuisson, c) décor peint en blanc sur brunet décor rouge enduit

Mission archéologique Korçë.

\section{Étude technologique et fonctionnelle}

Le sondage $\mathrm{C} 1$ a par ailleurs fourni une céramique suffisamment abondante pour permettre la reconstitution de la chaîne opératoire de la fabrication des récipients. Les traces de façonnage et du traitement des surfaces sont nombreuses. Elles ont notamment permis de mettre en évidence l'utilisation du montage au colombin, de l'ajout d'une couche d'argile sur la surface intérieure et/ou extérieure du vase, de la fixation des anses par perforation ou simple collage (fig. 15). 
Fig. 15 - Kallamas. Traces de façonnage.

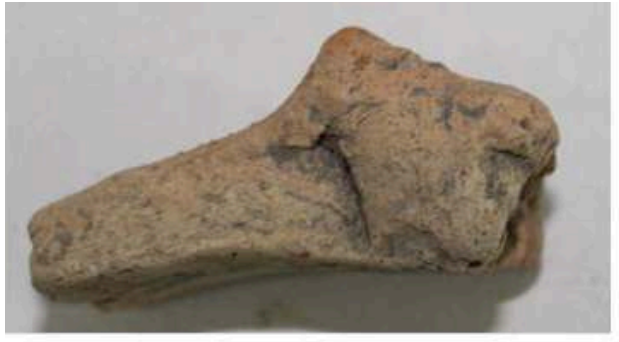

a

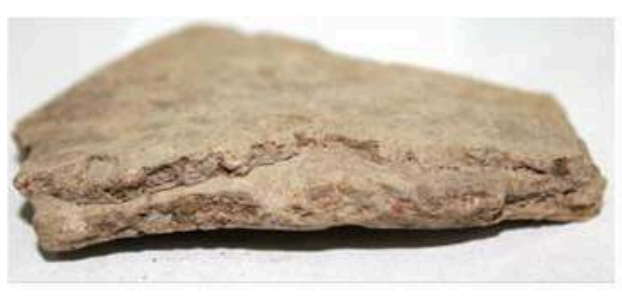

C

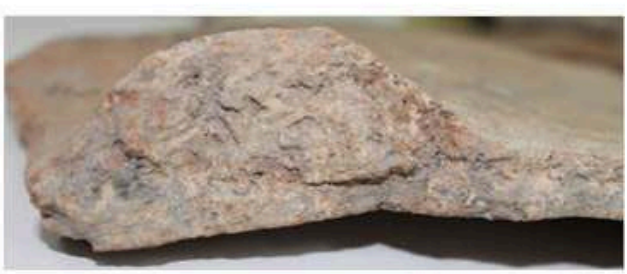

b

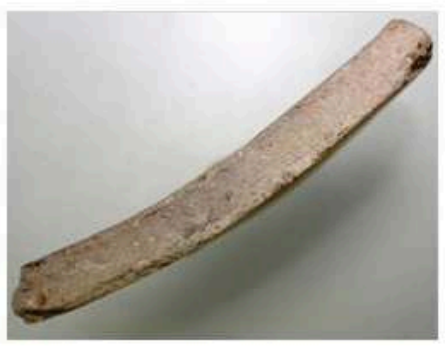

d

a) fixation de l'anse par perforation, b) fixation de l'anse par simple collage, c) ajout d'une couche d'argile supplémentaire, d) joints de colombins.

Mission archéologique Korçë.

Les analyses pétrographiques des premières lames minces sont toujours en cours ${ }^{27}$, mais des résultats préliminaires permettent déjà de noter que les potiers de Kallamas utilisaient différents types d'argile ou de recettes pour la production des vases. On a pu identifier jusqu'à présent des pâtes contenant principalement du dégraissant minéral d'origine plutonique ${ }^{28}$ et métamorphique; une sorte de chamotte et du dégraissant organique ont aussi été identifiés. Dans certains cas aussi, on a pu constater que deux types d'argile étaient mélangés pour le façonnage d'un pot. En complément à ces analyses, plusieurs échantillons d'argile ont été prélevés dans les environs de Kallamas $^{29}$ afin de les comparer aux pièces archéologiques ${ }^{30}$.

Enfin, les premières analyses de résidus organiques des vases de Kallamas ont montré que les acides gras détectés sur certains tessons provenaient surtout de graines, de mammifères terrestres et de poissons (fig. 16) ${ }^{31}$. 
Fig. 16 - Résultats des analyses chromatographiques réalisées sur un vase sphérique de Kallamas.

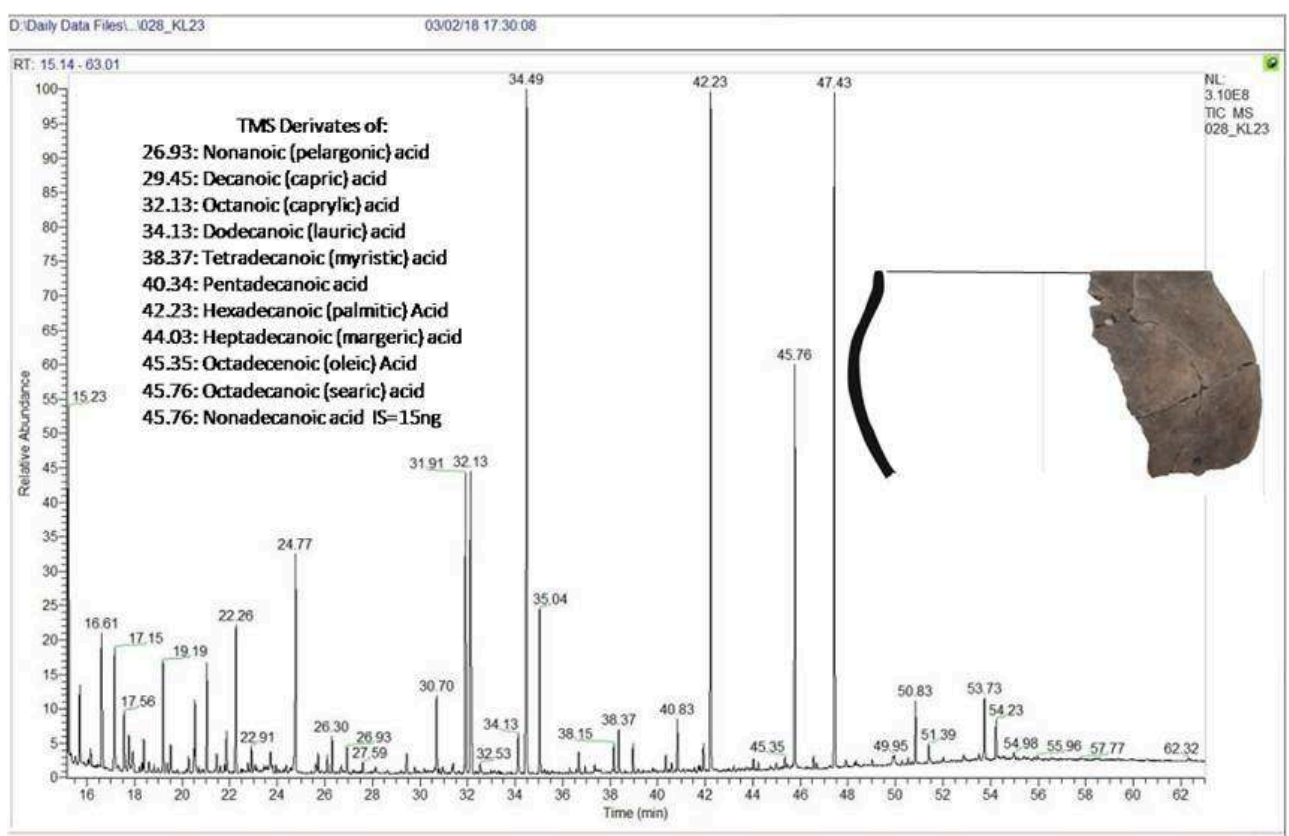

Mission archéologique Korçë.

\section{Les ramassages de surface}

Comme les années précédentes, G. Trajce, habitant de Kallamas qui a participé aux fouilles, a recueilli, à la faveur de travaux agricoles, plusieurs centaines d'artefacts qui sont venus enrichir l'abondante collection de trouvailles de surface enregistrées depuis 2007 :

- Parmi les nombreuses pièces d'outillage lithique poli, signalons plusieurs lames de grand module, une série de petites lames prises sur des éclats (fig. 17), ainsi que deux têtes de massue perforées et un résidu de perforation (fig. 18); 
Fig. 17 - Kallamas. Lames en pierre polie prises sur des éclats
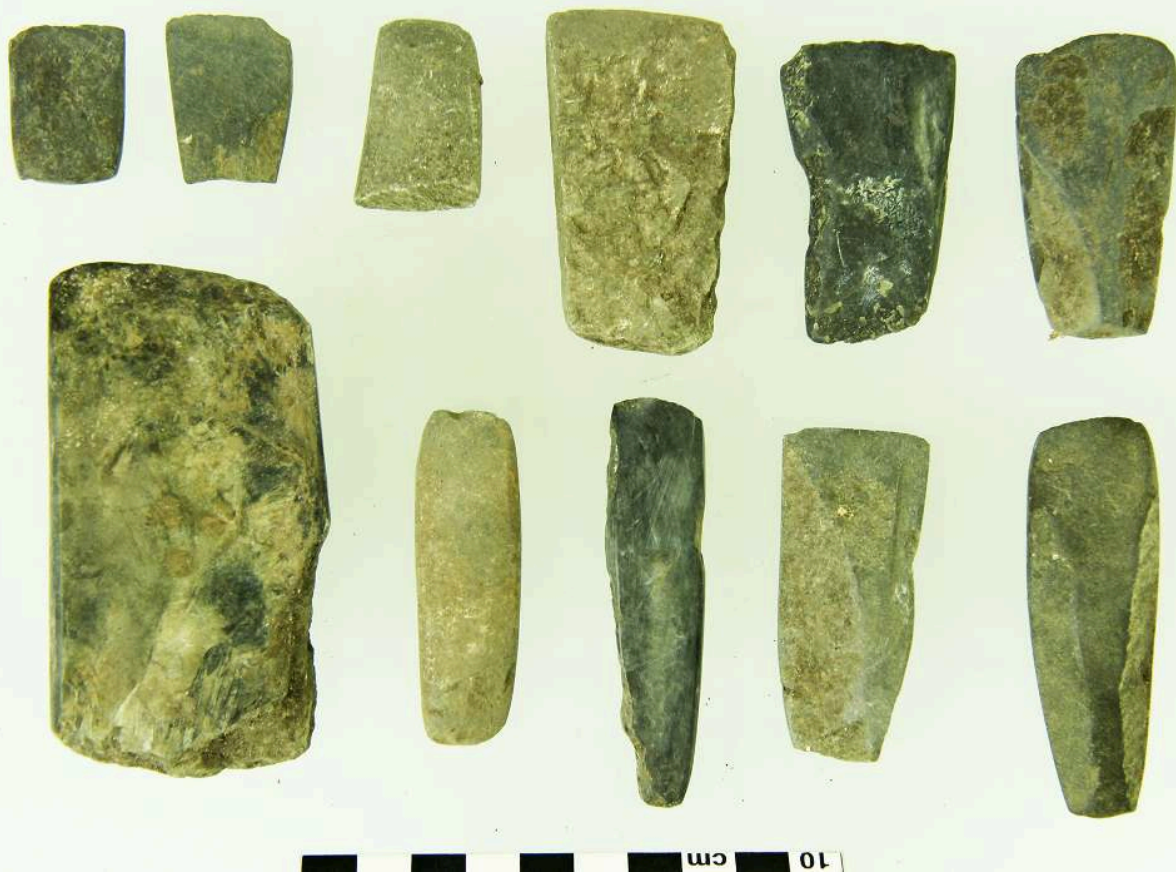

Mission archéologique Korçë

Fig. 18 - Kallamas. Têtes de massue perforées et résidu de perforation.

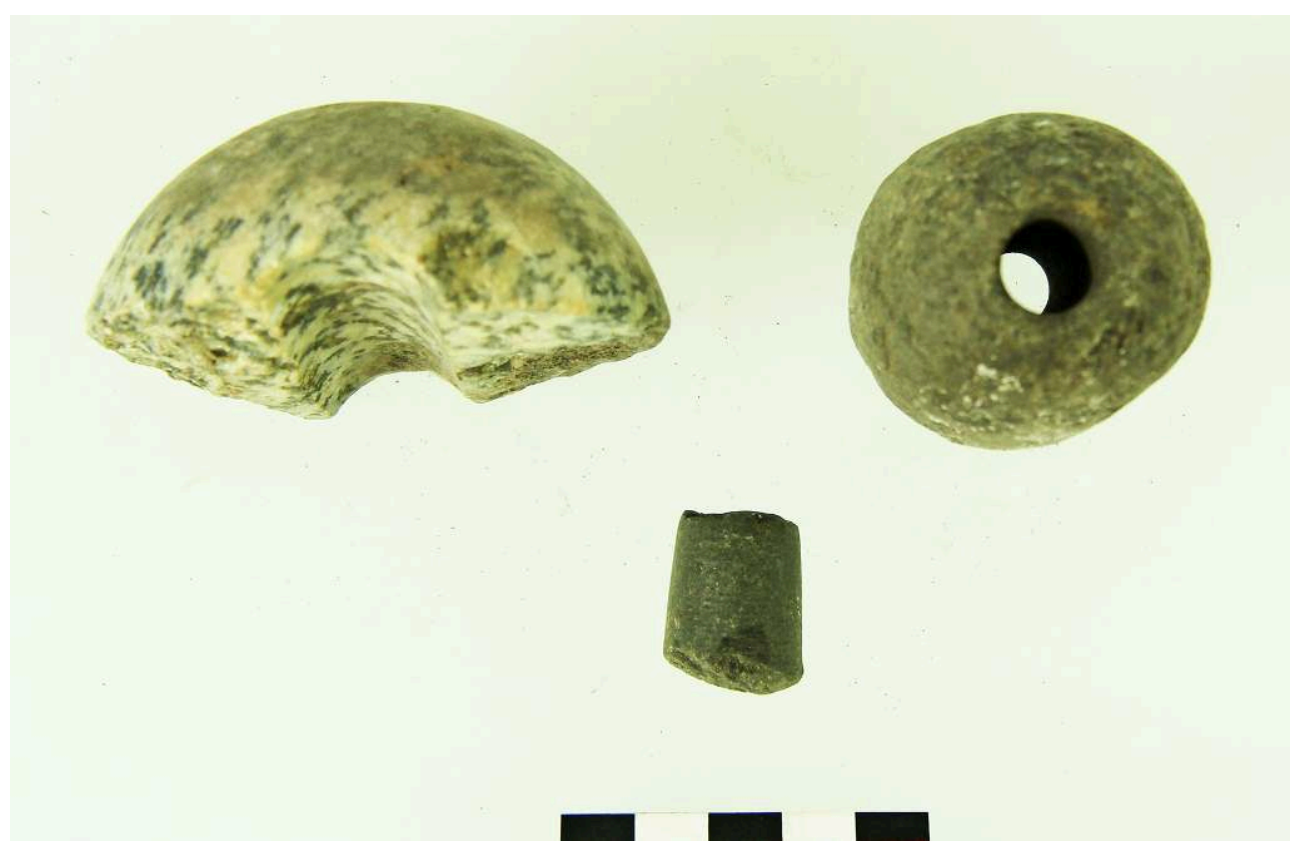

Mission archéologique Korçë.

- La plupart des pièces lithiques taillées sont en silex miel translucide, avec seulement quelques pièces en silex brun chocolat ou noir et une ou deux lamelles qui, sous réserve d'un examen plus approfondi, pourraient être en obsidienne (fig. 19); 
Fig. 19 - Kallamas. Lames et lamelles en silex taillé.

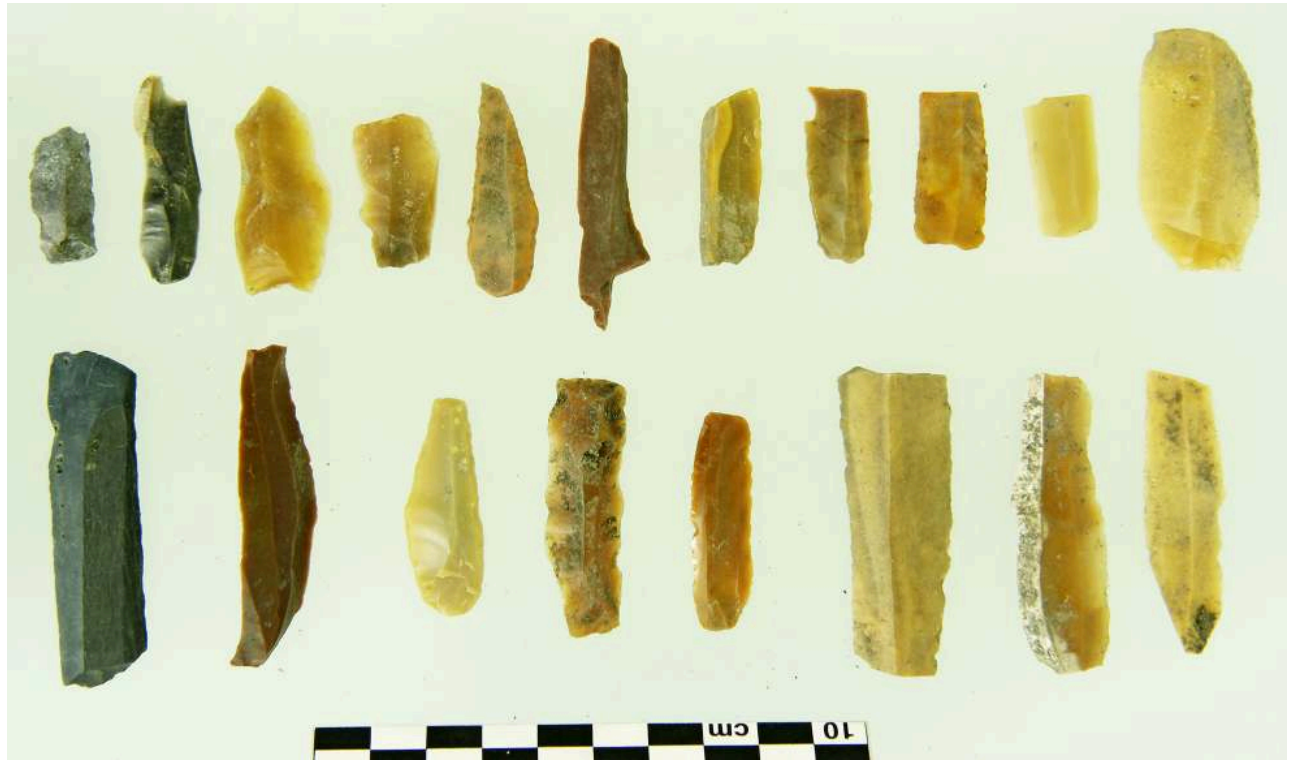

Mission archéologique Korçë.

- Les outils en terre cuite appartiennent pour la plupart aux types habituels (fig. 20-fig. 22), mais aussi à des types moins fréquents, comme un outil dont la forme rappelle celle des " polissoirs de hampes de flèche » en pierre, et un manche de cuiller (fig. 23) ;

Fig. 20 - Kallamas. Tessons à encoches.

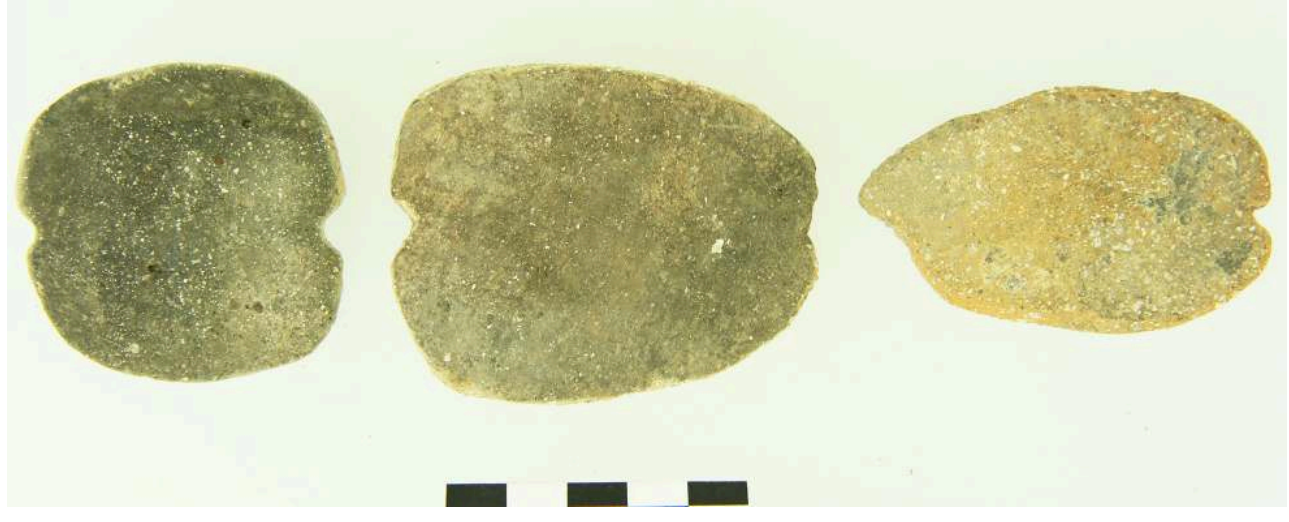

Mission archéologique Korçë. 
Fig. 21 - Kallamas. Fusaïoles discoïdales en terre cuite.

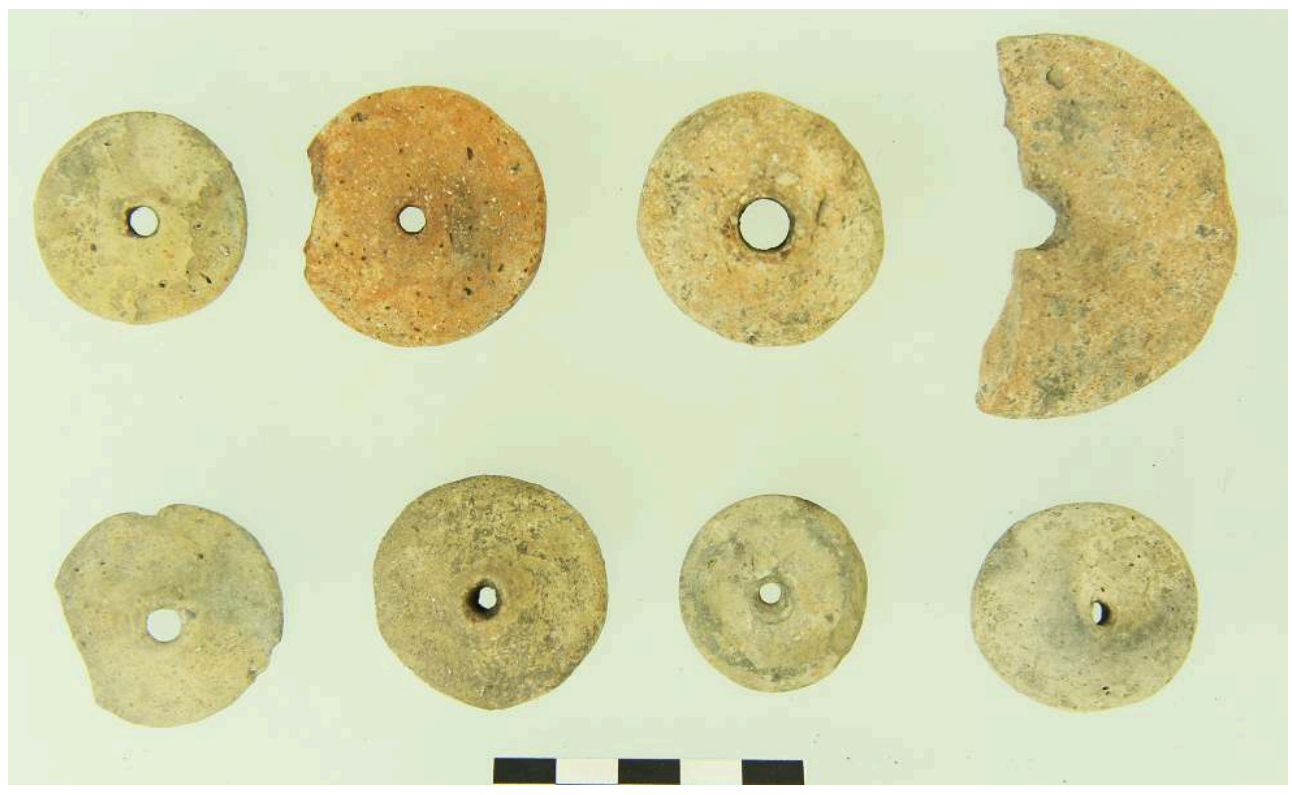

Mission archéologique Korçë.

Fig. 22 - Kallamas. Outils naviformes en terre cuite (poids de filet ?).

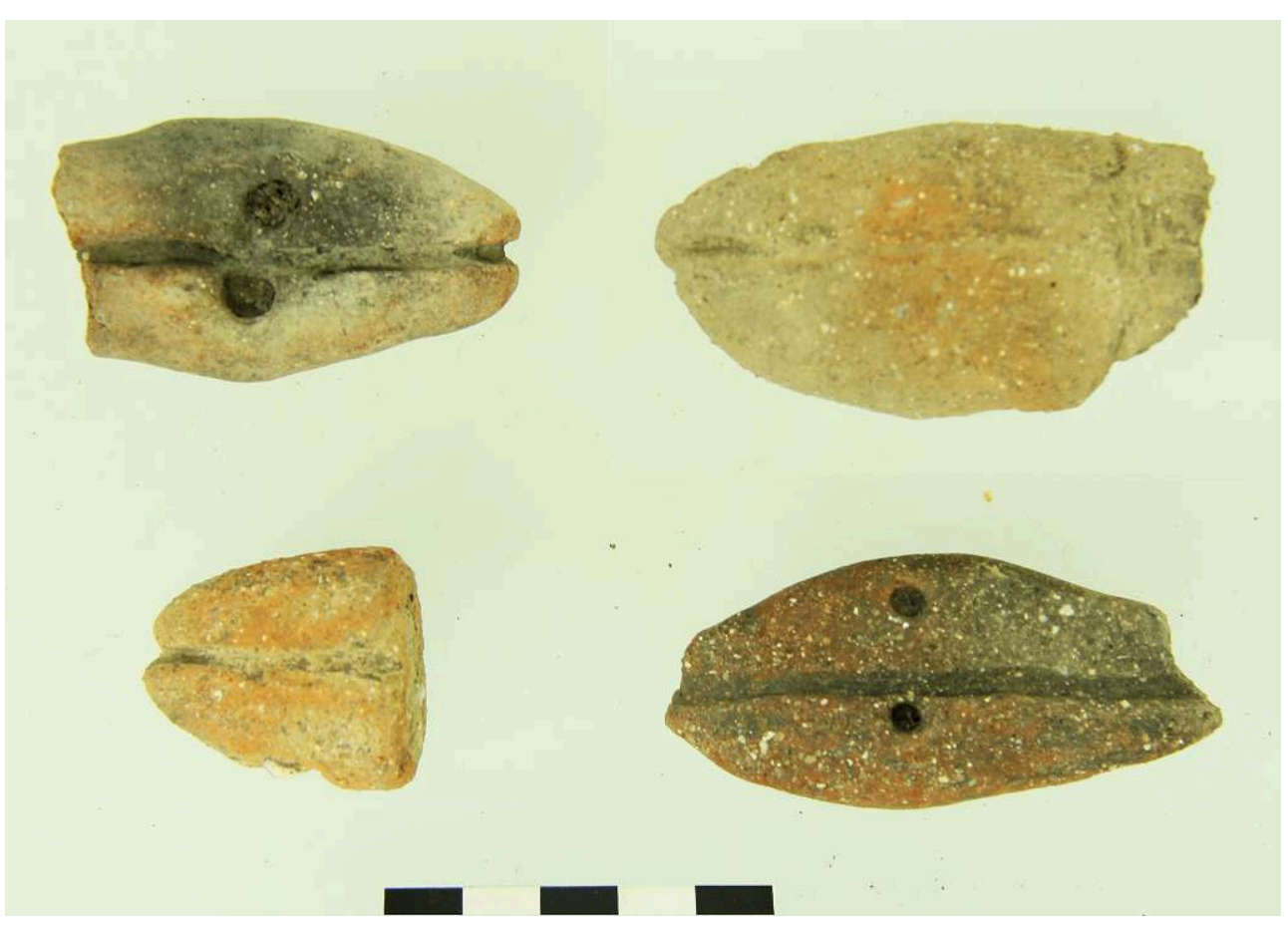

Mission archéologique Korçë. 
Fig. 23 - Kallamas. Polissoir de hampes de flèche (?) et manche de cuiller en terre cuite.

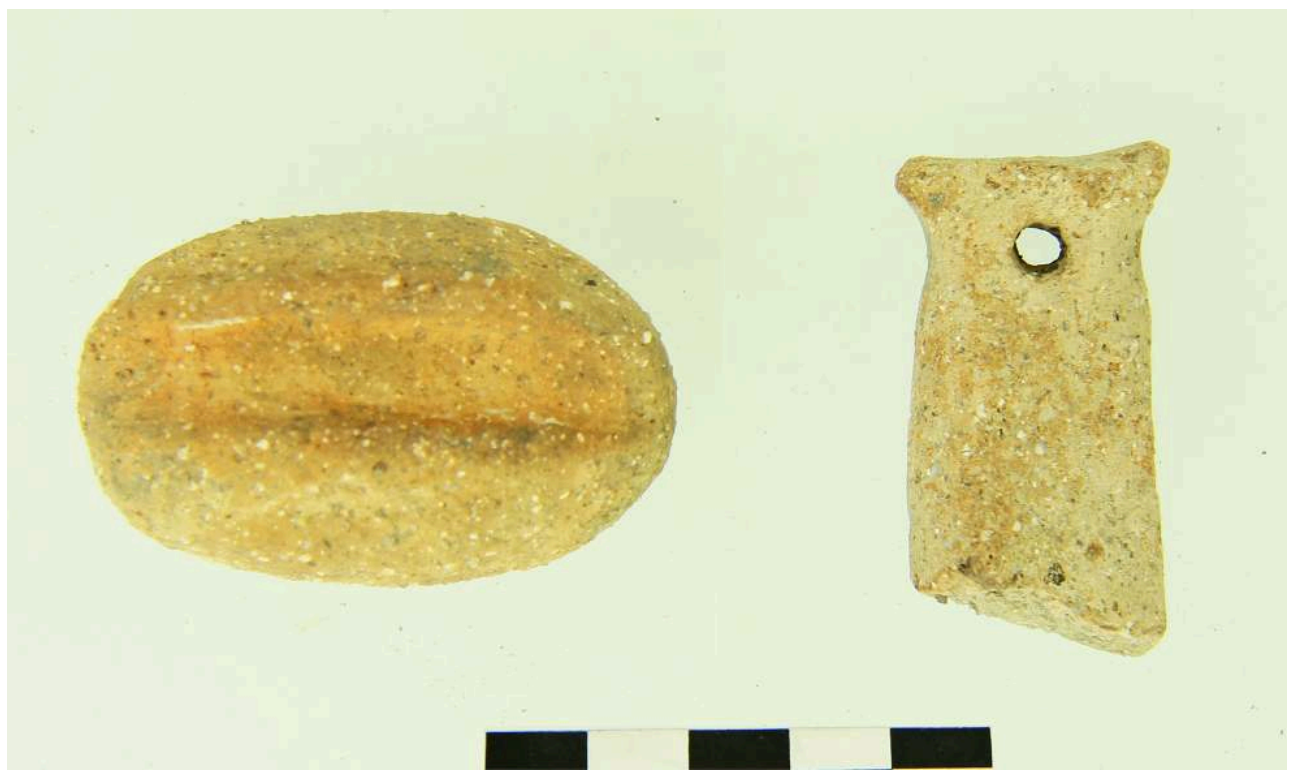

Mission archéologique Korçë.

- Parmi la céramique figurent plusieurs petits vases complets et des dizaines de tessons appartenant à diverses classes céramiques du NR ou du NM et à divers types de récipients, dont plusieurs vases à pied conique (fig. 24) et un vase plastique à décor anthropomorphe (fig. 25) qui a un parallèle exact dans les niveaux les plus anciens du site de Dispilio près de Kastoria $^{32}$;

Fig. 24 - Kallamas. Pieds de vases coniques.

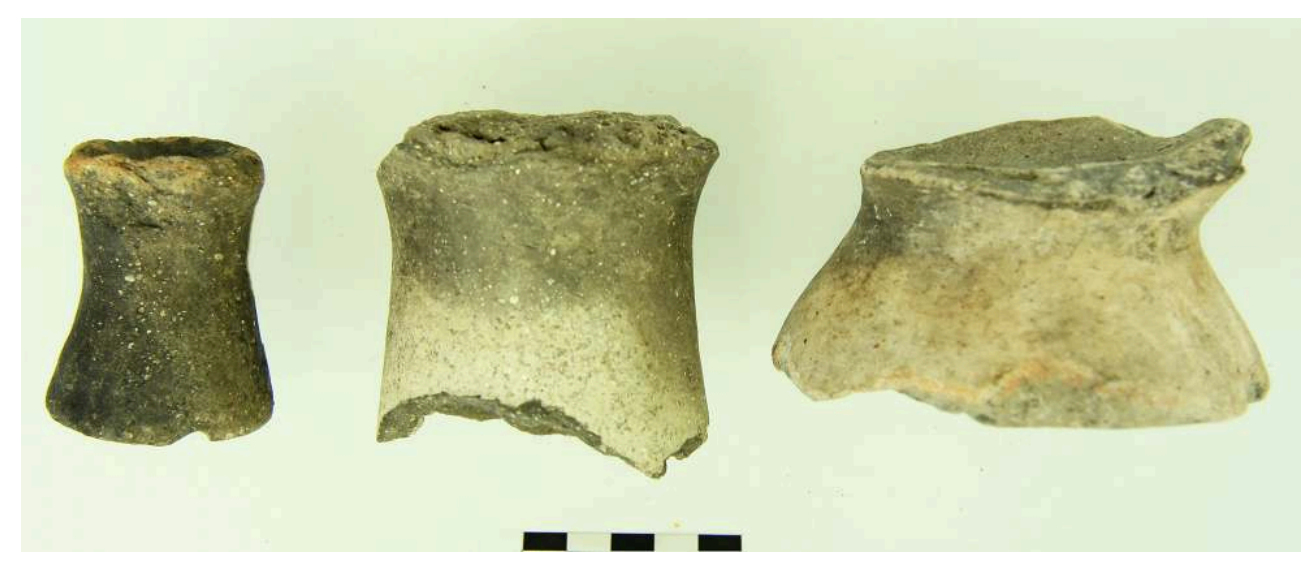

Mission archéologique Korçë. 
Fig. 25 - Kallamas. Tesson à décor plastique anthropomorphe.

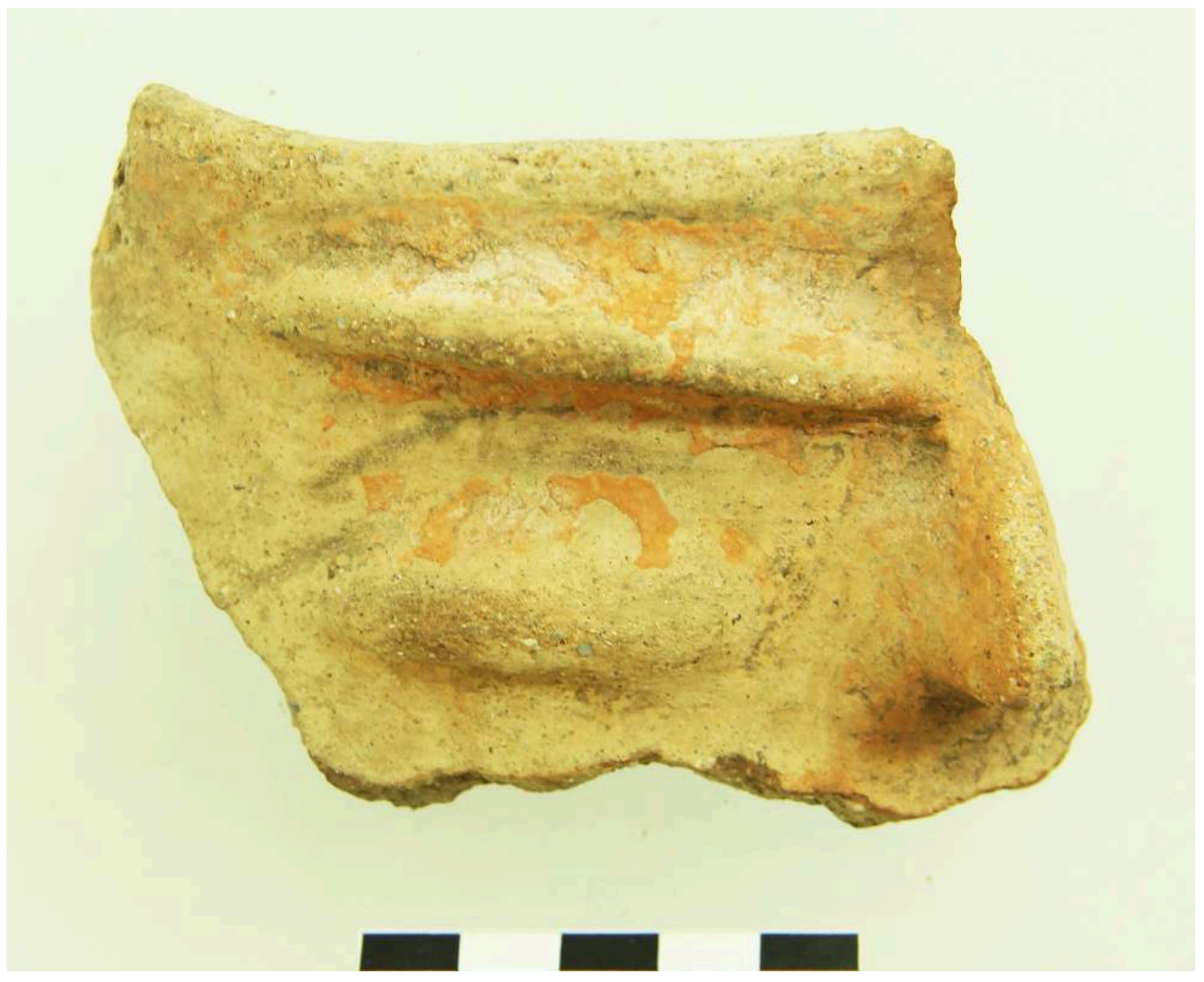

Mission archéologique Korçë.

- Notons enfin une figurine fragmentaire à décor pointillé (fig. 26).

Fig. 26 - Kallamas. Figurine fragmentaire.

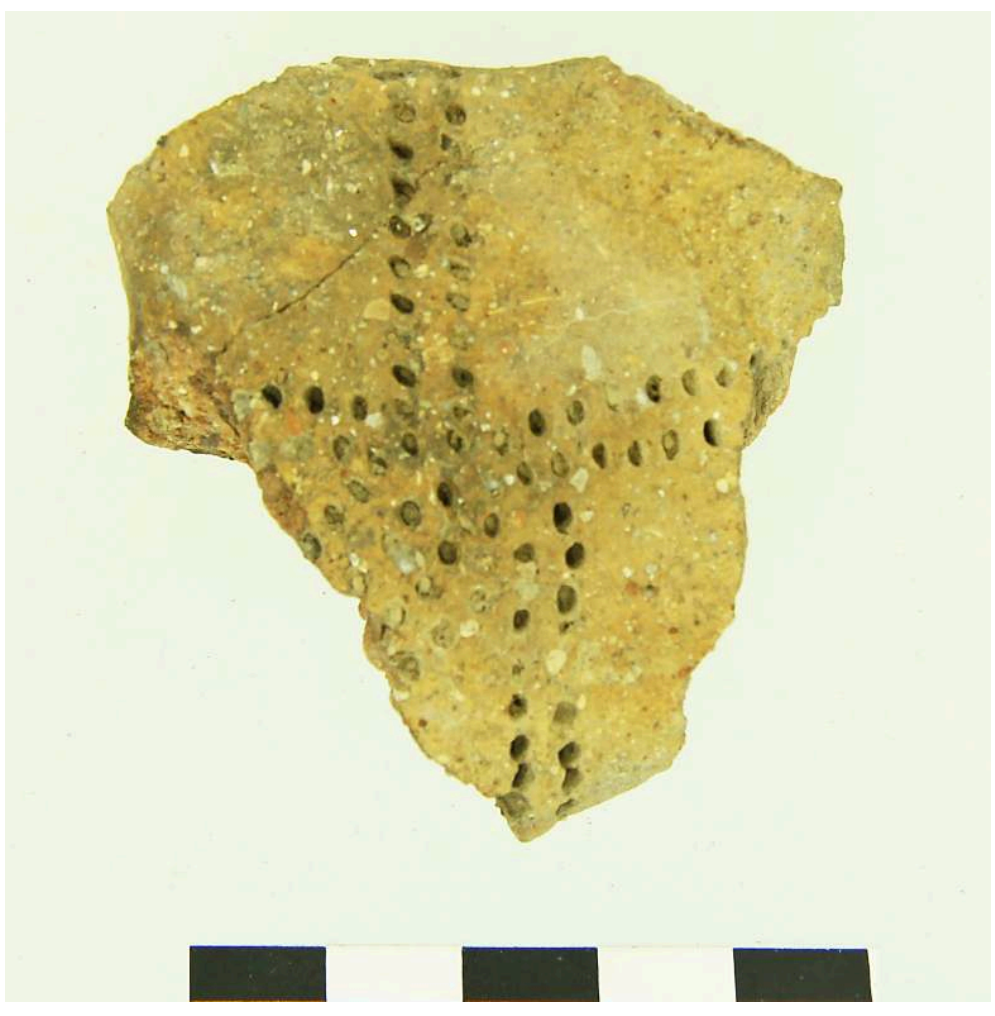

Mission archéologique Korçë. 
Il faut ajouter à ce matériel une dizaine de fragments de céramique plus récents trouvés à environ $200 \mathrm{~m}$ au Nord du site néolithique : trois d'entre eux, décorés à la peinture mate, témoignent d'une occupation à l'Âge du Fer, tandis que les autres, en céramique commune tournée à décor incisé, sont assignables à la période romaine.

\section{L'étude des données du programme PALM}

\section{La céramique de l'Âge du Bronze}

42 L'essentiel de la céramique préhistorique du programme PALM ayant été documenté en 2016, les efforts ont porté l'année suivante sur le dossier graphique : la totalité des dessins a été traitée en DAO (fig. 27). Quelques travaux de restauration ont aussi été effectués, notamment le remontage partiel d'un vase à décor incisé du début du Bronze Ancien provenant du site 17-81.1 (fig. 28).

Fig. 27 - PALM, site 15-78.1. Céramique du BM.

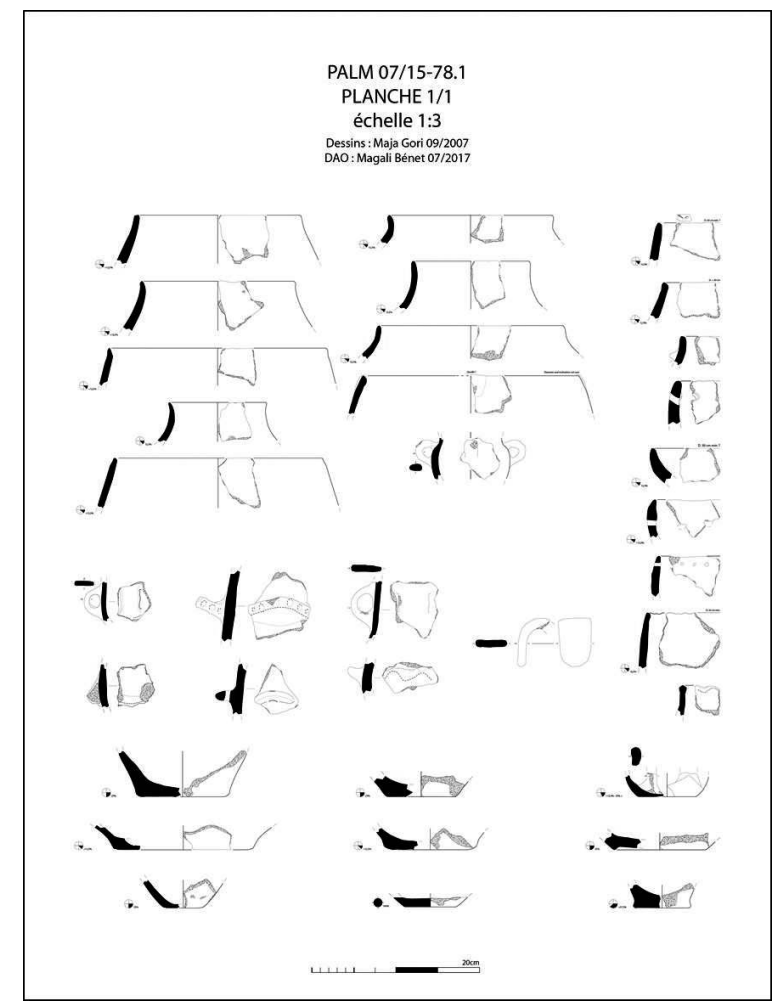

Dessin M. Gori, DAO M. Benet. 
Fig. 28 - PALM, site 17-81.1 (Vreshtasi). Vase du BA partiellement restauré.

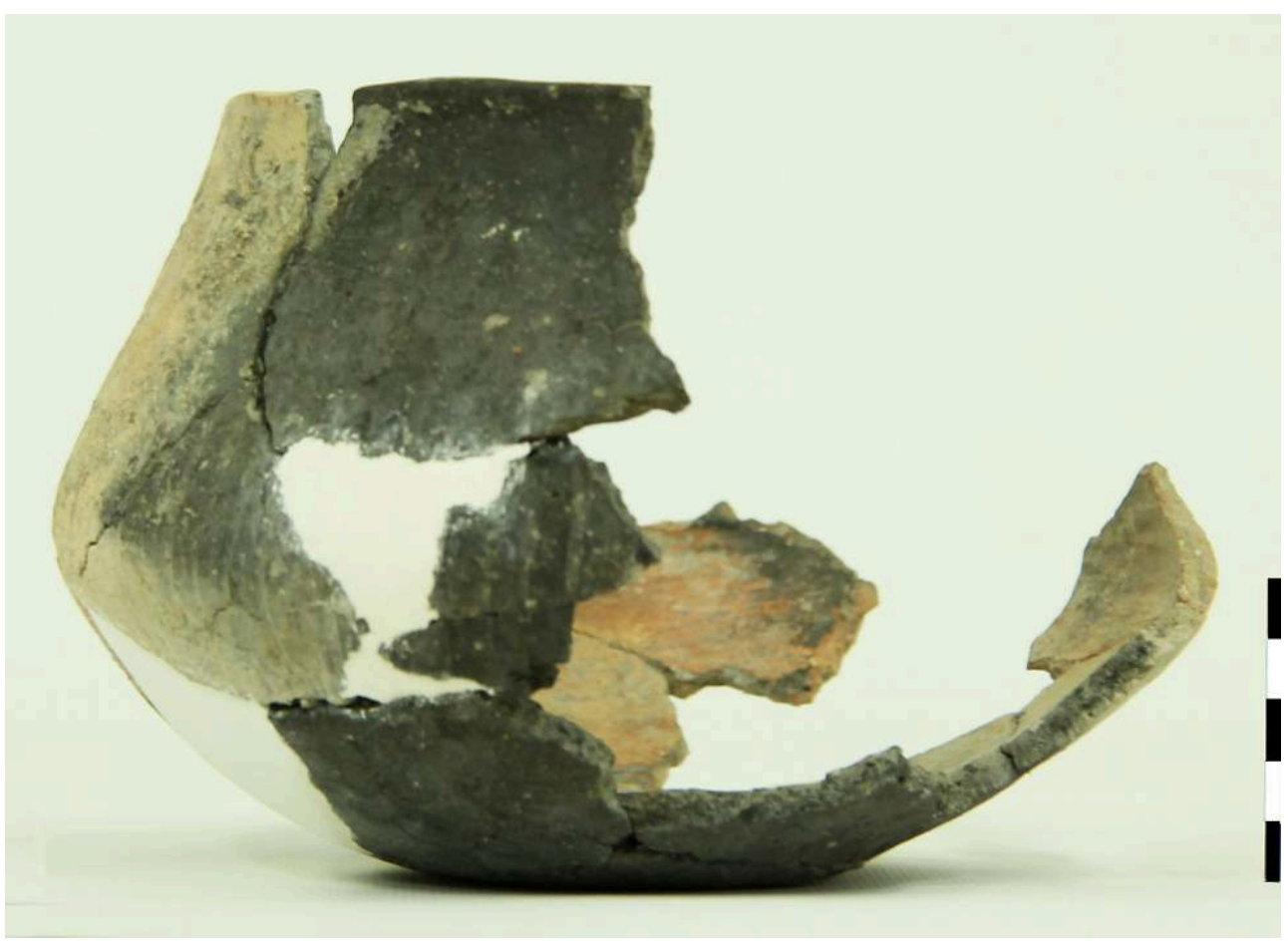

Mission archéologique Korçë.

\section{La céramique antique}

E. Shehi a contrôlé le dossier des dessins de la céramique antique, qui ont presque tous été numérisés sous Illustrator ; il n'y manque que ceux des quelques tessons ramassés sur le site de Hija e Korbit. On a d'autre part identifié, dans la réserve de l'Institut Archéologique de Tirana, deux caisses contenant de la céramique provenant de Symize e Gradisht ${ }^{33}$, dont le matériel devra être dessiné.

\section{La prospection des sites de hauteur du bassin de Korçë}

La prospection des sites de hauteur dans le bassin de Korçë s'inscrit dans le cadre de la nouvelle convention bilatérale signée au printemps 2018 entre l'Institut archéologique de Tirana et l'UMR 7041 « Archéologies et Sciences de l'Antiquité (ArScAn)» du CNRS en lien avec l'École française d'Athènes. La nouvelle convention prévoit, outre la poursuite des travaux en cours, la réalisation d'un nouveau programme de recherche intitulé «Dynamiques de développement des sociétés du Bronze Récent et du Fer Ancien dans le bassin de Korçë: problèmes chronologiques, socio-économiques et historiques ». Celui-ci fait directement suite au programme PALM $^{34}$ puisqu'il vise à explorer certaines des problématiques soulevées par ce dernier. Le premier axe de ce nouveau programme est constitué par la prospection des sites de hauteur, qui a été entreprise pendant l'été 2018, mobilisant une équipe de quatre à six personnes pendant trois semaines ${ }^{35}$. 


\section{Les objectifs}

Korçë pour la transition du Bronze Récent au Fer Ancien et le début de l'Âge du Fer sont les établissements de hauteur, fortifiés pour la plupart ; les autres sites connus pour ces périodes sont les tumuli ou nécropoles tumulaires situés dans la plaine. Les établissements de hauteur sont souvent mentionnés dans la littérature albanaise mais certains d'entre eux ont juste été localisés par P. Lera durant sa longue carrière d'archéologue de terrain dans la région. La majorité d'entre eux est habituellement rattachée à la fin de la période protohistorique, ou plus exactement au Bronze Récent et à l'Âge du Fer, ce qui représente en réalité une fourchette chronologique très large ${ }^{36}$. Ces datations reposent avant tout sur la céramique trouvée en surface, mais celle-ci n'a jamais fait l'objet d'un ramassage ni d'un examen systématique, encore moins d'une publication. Et dans les cas où des sondages ont été pratiqués, comme par exemple à Symizë ${ }^{37}$, le matériel n'est que brièvement évoqué dans un rapport de fouille qui tient lieu de publication.

Le principal objectif du nouveau programme est donc d'éclairer, à la lumière des études céramiques récentes menées notamment à Sovjan (v. supra), les périodes qui y sont réellement attestées, grâce à un examen systématique du matériel collecté. On peut espérer affiner ainsi la chronologie des phases d'occupation de ces habitats qui, dans l'état actuel de la recherche, demeure très incertaine, tout comme leur date de fondation. Or, ces incertitudes limitent considérablement l'utilisation des données archéologiques nécessaires à l'examen des problématiques que nous souhaitons aborder, notamment celle de la période d'abandon des sites de plaine dans la partie Nord du bassin, aux environs du viII ${ }^{e}$ siècle av. J.-C. Les résultats des fouilles de Sovjan et du secteur C de Maliq, ainsi que ceux du programme PALM, ont en effet montré que cette période était marquée par d'importants changements à la fois culturels, sociaux et environnementaux ${ }^{38}$. Elle semble aussi marquée par certains phénomènes plus globaux qui se reflètent dans d'autres aspects de la culture matérielle, comme les rites funéraires ${ }^{39}$. Une datation absolue plus précise de ces sites de hauteur contribuerait à une meilleure compréhension des dynamiques de développement de l'habitat dans la région, et permettrait de s'interroger sur le lien possible entre l'abandon des sites de plaine et l'installation des sites de hauteur souvent fortifiés. On a décidé d'inclure dans la prospection les sites fortifiés des périodes antiques et médiévales car on sait que la réutilisation de points stratégiques de hauteur est un phénomène très courant.

\section{La méthodologie}

Le déroulement de la prospection étant prévu sur deux ans, on a commencé par les sites de la moitié Sud du bassin en 2018. Ceux de la de la moitié Nord seront prospectés en 2019.

\section{Les zones de prospection}

La zone Sud du bassin regroupe sept sites de hauteur (fig. 29), d'Est en Ouest : Kuç i Zi, Barç, Mborja, Boboshtica, Bellovoda, Lumalas et Zhitom. 
Fig. 29 - Carte du bassin de Korçë avec localisation des sites de hauteur.

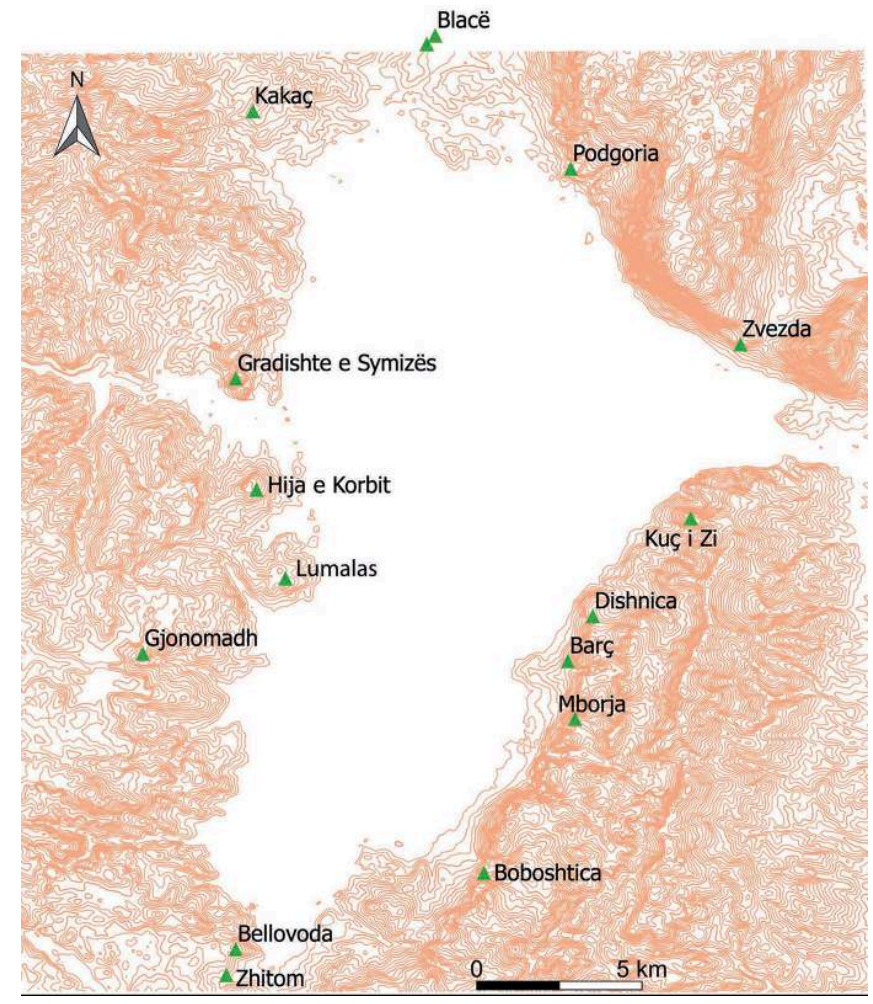

DAO C. Oberweiler.

Le travail de terrain a été précédé, d'une part, par un dépouillement bibliographique exhaustif destiné à rassembler le maximum de données sur chacun des sites (localisation, datation, structures, matériel, topographie, etc.), d'autre part, par une visite préliminaire destinée à faire le point sur la situation actuelle (moyens d'accès, état de conservation des vestiges, couvert végétal, etc.). Toutes ces informations ont été utilisées pour déterminer les zones les plus propices à la prospection. À la différence des prospections dans la plaine (PALM), il est beaucoup plus complexe d'établir une méthode fixe de prospection pour des sites de hauteur, qui présentent chacun des particularités (type de gisement, topographie...). Les flancs des collines sont souvent abrupts et rocheux, ou couverts d'une végétation dense, ce qui les rend très difficiles voire impossibles à prospecter.

Ainsi, à partir des données disponibles, on a établi pour chaque site des zones de prospection prioritaires. La zone principale correspond, de manière générale, aux sommets ou plateformes ceints de murs de fortification - dans le cas où les murs ont disparu (Barç, Boboshticë), on s'est fondé sur les descriptions bibliographiques. Les zones secondaires couvrent les pentes - du moins lorsqu'elles sont accessibles et praticables -, qui ont toujours donné de la céramique, parfois plus que les sommets. Enfin, on a défini une zone tertiaire, qui correspond au pied des collines; elle a été prospectée dans les cas où la présence de céramique avait été constatée lors du repérage ou mentionnée dans les publications.

51 Dans un souci d'homogénéité, on a attribué à chacun des sites un numéro du type 04-87.1, sur le modèle des numéros donnés aux sites du programme PALM ${ }^{40}$. 


\section{Définition du maillage}

Pour chacun des sites à prospecter ${ }^{41}$, on a déterminé un maillage de base pour la zone principale, les zones secondaires et tertiaires.

Pour la zone principale, les sommets ou plateformes ayant une superficie relativement limitée (Boboshtica mesure $120 \times 55 \mathrm{~m}$ par exemple), un maillage serré était approprié pour réaliser un ramassage exhaustif. Grâce aux images satellites de très bonne qualité fournies par le géoportail albanais $\mathrm{ASIG}^{42}$, on a préparé le maillage de chaque site en divisant les zones en unités arbitraires de ramassage, zones qui ont été appelées « unités de prospection » ou UP ${ }^{43}$ et désignées par des lettres de a à z (exemple de Barç, fig. 30). L'UP est donc la plus petite unité de prospection et possède une superficie généralement comprise entre 1300 et $1700 \mathrm{~m}^{2}$, soit environ $30 \times 50 \mathrm{~m}$. L'UP est parcourue en un seul passage. En raison de la diversité de la position et de l'orientation des sites, il n'était pas possible de suivre une direction fixe.

Fig. 30 - Barç. Croquis de prospection du site avec localisation des UP.

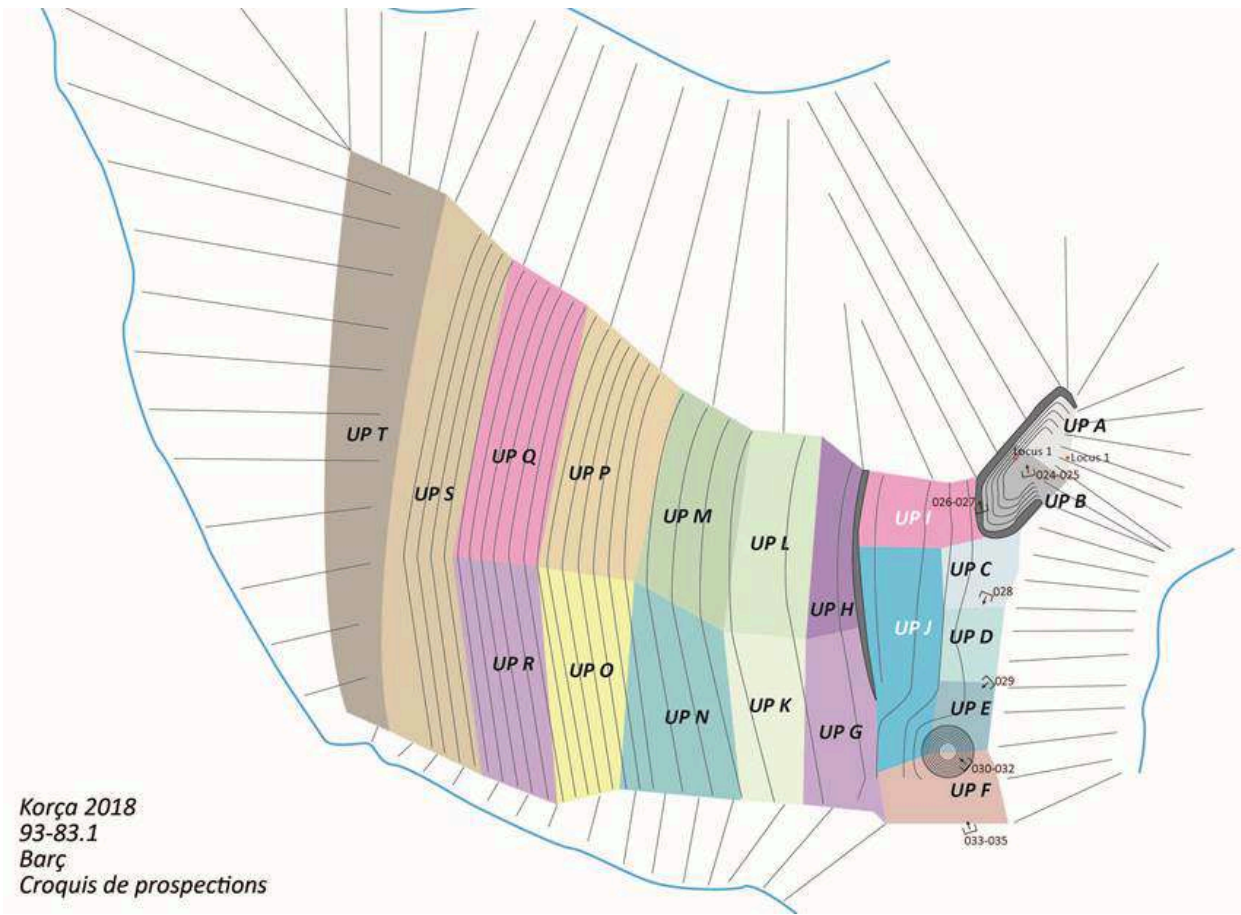

DAO M. Benet.

La prospection d'une UP est déterminée d'un point de vue pratique par le nombre de marcheurs disponibles et leur écartement: 4 marcheurs évoluent dans un couloir théorique d'environ $7 \mathrm{~m}$ de large, distance ajustée sur le terrain mais en respectant la superficie de base de l'UP. Afin de positionner les limites exactes de ces UP sur la carte, les quatre angles de chacune d'entre elles ont été géo-référencés à l'aide du GPS.

Outre la subdivision en UP, il existe aussi des loci, qui correspondent soit à des zones de concentration plus importantes de matériel archéologique, soit à des structures spécifiques. Le locus est localisé dans l'UP au moyen de points GPS, et il est échantillonné avec un sac spécial, différent du sac d'UP. Ces loci sont numérotés en 
continu à partir de 1 et désignés par le millésime, suivi des numéros du site et de l'UP dans laquelle il a été découvert.

Pour les zones secondaires, aucun maillage préliminaire n'a été préparé : on a jugé préférable de choisir une stratégie de prospection adaptée chaque fois à la nature du terrain, à la végétation et à la présence de céramique. Mais pour conserver une certaine homogénéité, on a adopté des dimensions à peu près égales à celles des UP des zones principales.

\section{Échantillonnage et enregistrement}

Compte tenu de la superficie relativement réduite des sites, on a opté pour un ramassage exhaustif, ce qui permet de mettre en relation une densité particulière avec des structures spécifiques, comme c'est le cas à Barç ou à Boboshtica. L'enregistrement des loci (description et coordonnées GPS) assure aussi une documentation détaillée et rigoureuse du matériel de surface. D'autre part, la collecte des informations sur le terrain englobe, outre le mobilier archéologique, l'observation du couvert végétal qui conditionne la visibilité au sol, mais aussi celle du paysage et de la position des fortifications par rapport aux voies de communication, position qui est liée aussi à la question de l'inter-visibilité entre les sites.

Toutes les données recueillies (description des sites, UP et loci, photos, relevés métriques, etc.) ont été enregistrées dans la base de données informatisée créée sous Filemaker Pro. Grâce aux images satellites, toutes les UP géo-référencées avec le GPS ont été précisément localisées sur le site et reportées sur les schémas illustrant chacun d'eux.

\section{Les résultats}

On ne présentera ici qu'un bref aperçu des résultats car le matériel collecté n’a encore fait l'objet que d'un examen préliminaire. Toutefois, plusieurs éléments intéressants méritent d'être mentionnés.

\section{Les vestiges archéologiques et les phases chronologiques représentées}

Un premier tri de la céramique a permis un classement préliminaire des sites prospectés par grandes périodes (tableau 6).

Tableau 6 - Les sites prospectés et leurs périodes d'occupation (en rouge les périodes protohistoriques, en bleu celles de l'Antiquité, en vert la période médiévale).

\begin{tabular}{|c|c|c|c|c|c|c|c|c|c|c|}
\hline \multirow[b]{2}{*}{$\mathrm{N}^{\circ}$ site } & \multirow[b]{2}{*}{ Nom site } & \multirow[b]{2}{*}{$\begin{array}{l}\text { Total } \\
\text { artéfacts }\end{array}$} & \multicolumn{8}{|c|}{ Périodes représentées } \\
\hline & & & Bronze & Fer & $\begin{array}{l}\text { Préh. } \\
\text { ind. }\end{array}$ & $\begin{array}{l}\text { Class.- } \\
\text { Hellen. }\end{array}$ & $\begin{array}{l}\text { Romain- } \\
\text { Ant. } \\
\text { tard. }\end{array}$ & Médiéval & $\begin{array}{l}\text { Hist. } \\
\text { ind. }\end{array}$ & Ind. \\
\hline $04-87.01$ & Kuç i Zi & 432 & & & & & 431 & 1 & & \\
\hline $77-02.01$ & Lumalas & 27 & & & & & 26 & 1 & & \\
\hline
\end{tabular}




\begin{tabular}{|l|l|l|l|l|l|l|l|l|l|l|}
\hline $86-73.01$ & Zhitom & 247 & & & & & 244 & 3 & & \\
\hline $87-73.01$ & Bellovoda & 1414 & & & 61 & & 1329 & & 24 & \\
\hline $90-81.01$ & Boboshtica & 387 & & 20 & 93 & & 254 & & 8 & 12 \\
\hline $93-83.01$ & Barç & 781 & & 17 & 162 & & 578 & & 2 & 22 \\
\hline $96-84.01$ & Mborja & 333 & & & & & & 333 & & \\
\hline
\end{tabular}

En ce qui concerne la représentativité numérique du matériel, il faut prendre en compte non seulement la superficie des zones prospectées sur chaque site mais aussi les interventions récentes, qui sont hélas fréquentes. Ainsi, par exemple, la majeure partie de la céramique du site de Bellovoda a été ramassée dans les sondages clandestins creusés récemment à l'intérieur de l'enceinte ${ }^{44}$. Le site de Lumalas, en grande partie détruit par la mine installée dessus, n'a pas pu être prospecté de manière systématique et le matériel collecté n'est pas représentatif de la réalité archéologique. Ces éléments seront intégrés dans l'étude analytique finale.

\section{Périodes protohistoriques}

Elles ont été identifiées principalement par la céramique, même si certains murs du site de Bellovoda sont censés présenter une technique de construction " protohistorique $~^{45}$. La céramique la plus ancienne appartient à la fin du BR/ début Âge du Fer; elle a été documentée seulement sur trois sites: Bellovoda, Barç et Boboshtica. Cette céramique fine de couleur rouge est caractérisée soit par un décor incisé (motifs géométriques), soit par un décor plastique (cordons digités), soit par un décor exécuté à la peinture mate (motifs géométriques peints en rouge foncé/brun sur fond rouge clair : fig. 31). Dans le bassin de Korçë, cette céramique est présente dans les habitats (Sovjan, Maliq, Drenova), à Symizë (seul site de hauteur fouillé) et dans les nécropoles tumulaires (Kuç i zi, Kamenica, Plasi...). Elle est attestée de la fin du BR au début duFA, mais les études les plus récentes ${ }^{46}$ montrent que le décor diffère légèrement selon les phases. 
Fig. 31 - Céramique à peinture mate collectée sur les sites de Boboshtica et de Barç.
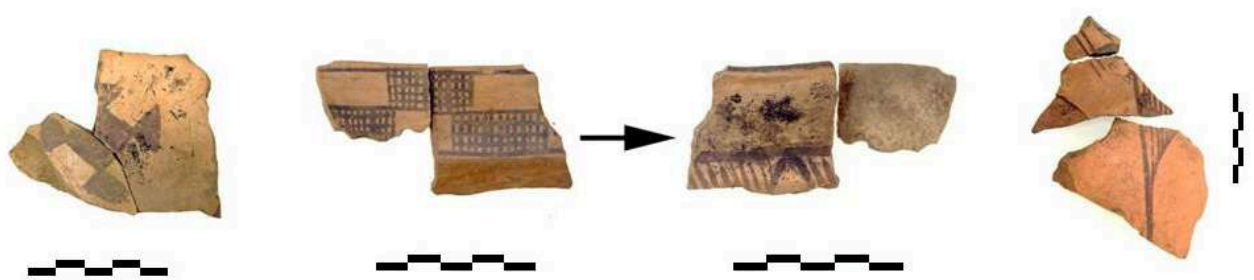

Boboshtica
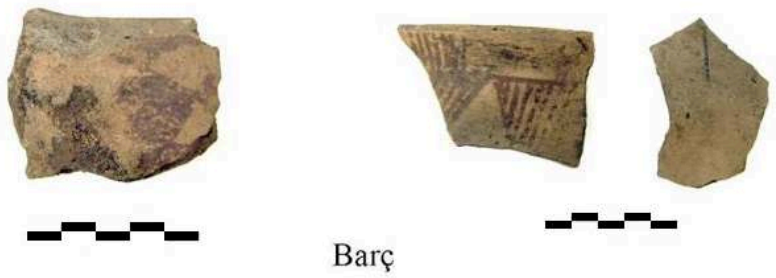

Mission archéologique Korçë.

63 À Bellovoda, cette céramique est très peu visible en surface, l'essentiel provenant de l'un des sondages clandestins (UPc) ou du mur en grosses pierres sèches de l'enceinte. Les autres zones prospectées - à l'intérieur de l'enceinte, sur la pente méridionale et à la base de la colline - ont surtout fourni de la céramique antique. À Barç et à Boboshtica la situation est un peu différente : cette céramique se concentre surtout en contrebas de petits tertres artificiels en pierre et en terre situés hors du périmètre fortifié (fig. 32), tertres qui font penser à des nécropoles tumulaires plus qu'à des éléments d'architecture défensive, du moins pour la période du début de l'Âge du Fer (v. infra). 
Fig. 32 - Boboshtica. Schéma de répartition de la céramique protohistorique ; la structure figurée par des cercles concentriques correspond au tertre artificiel.

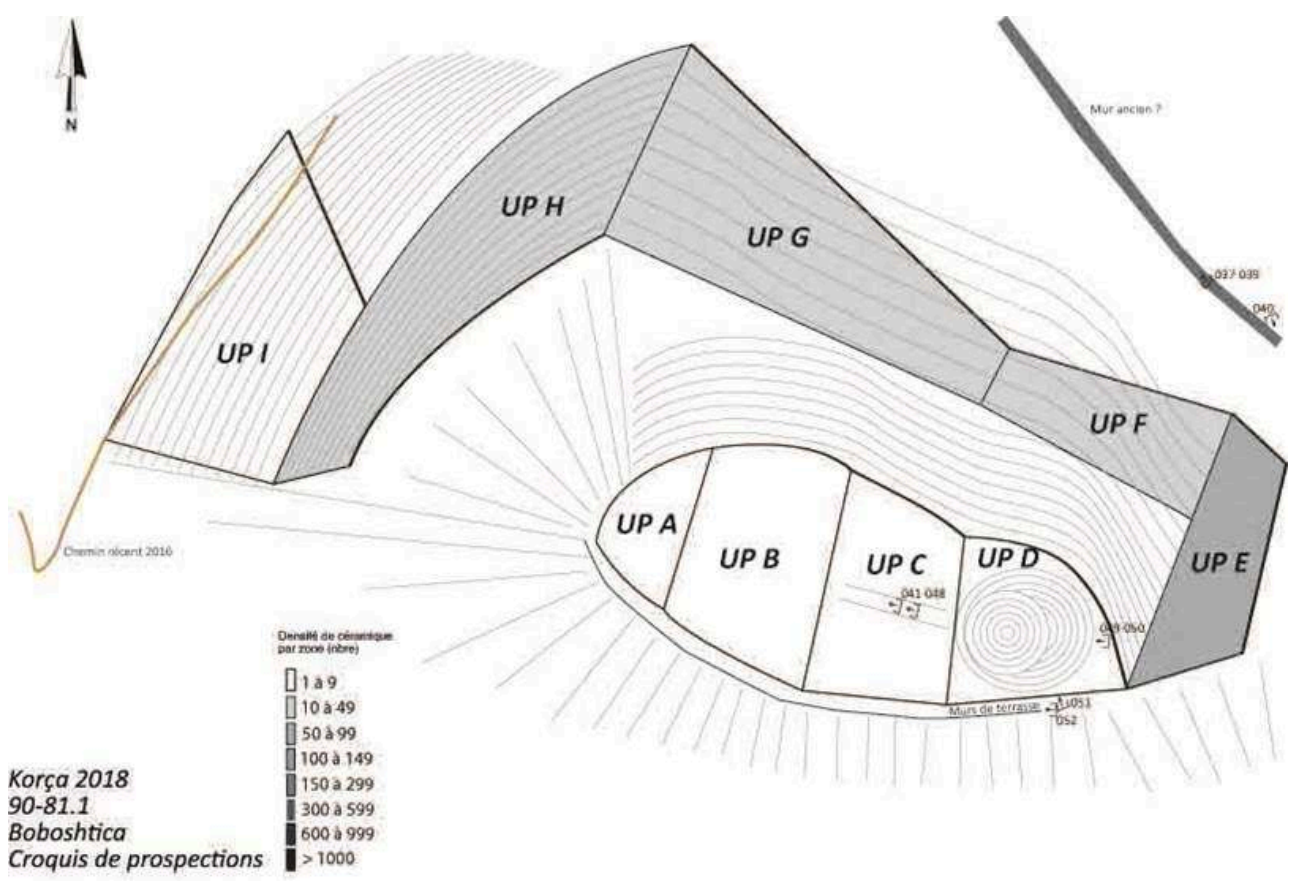

DAO M. Benet.

Période romaine / antiquité tardive protohistorique fut réoccupé. Sur la colline voisine, à Zhitom, c'est la totalité de la céramique collectée qui appartient à cette période, alors que G. Karaskaj et P. Lera avaient mentionné la présence de céramique protohistorique ${ }^{47}$ - mais il est vrai que la colline n'a été prospectée que partiellement par manque de temps. À Barç et à Boboshtica, la céramique romaine et tardive prédomine largement. Le second site a notamment livré quelques fragments de sigillée et un petit vase complet à une anse et décor imprimé en bandes horizontales (fig. 33) qui pourrait être une imitation locale d'un type égéen des II $^{\mathrm{e}}-\mathrm{III}{ }^{\mathrm{e}}$ siècles apr. J.-C. ${ }^{48}$. À Barç, on notera surtout la présence de céramique fine à décor peint en noir, de céramique à décor plastique (fig. 34) et de tessons décorés au peigne, ainsi que la découverte d'une meule en pierre datant probablement de cette même période, ce type de roche n'étant pas utilisé aux périodes protohistoriques. Enfin, sur le site fortifié de Kuç i Zi, la céramique est assez homogène, plutôt grossière, ce qui rend difficile son attribution à l'antiquité tardive - toutefois mieux représentée - qu'à la période médiévale ${ }^{49}$. L'étude détaillée du matériel devrait permettre d'en préciser la chronologie. Pour l'heure, on mentionnera seulement un fragment de bord de pithos timbré datant probablement de l'époque romaine (fig. 35). 
Fig. 33 - Boboshtica. Petit vase romain à décor imprimé.

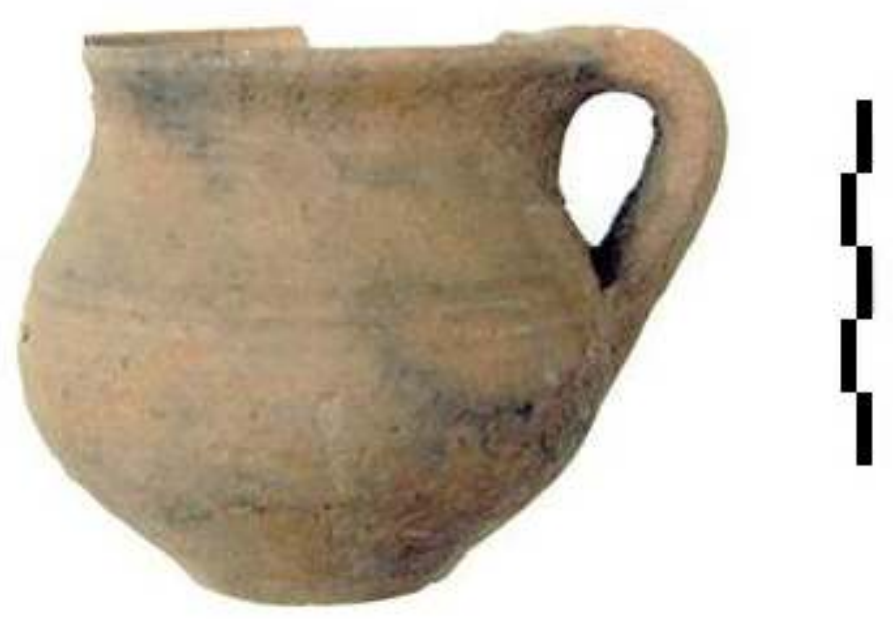

Mission archéologique Korçë.

Fig. 34 - Barç. Céramique romaine à décor plastique.
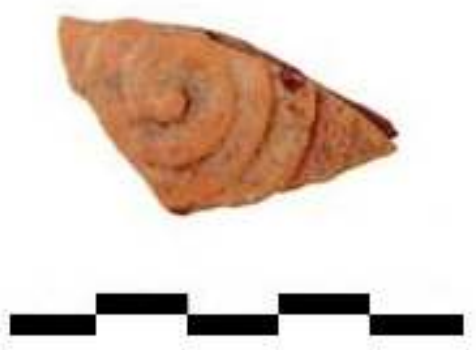

Mission archéologique Korçë. 
Fig. 35 - Kuç i Zi. Fragment de bord de pithos timbré.

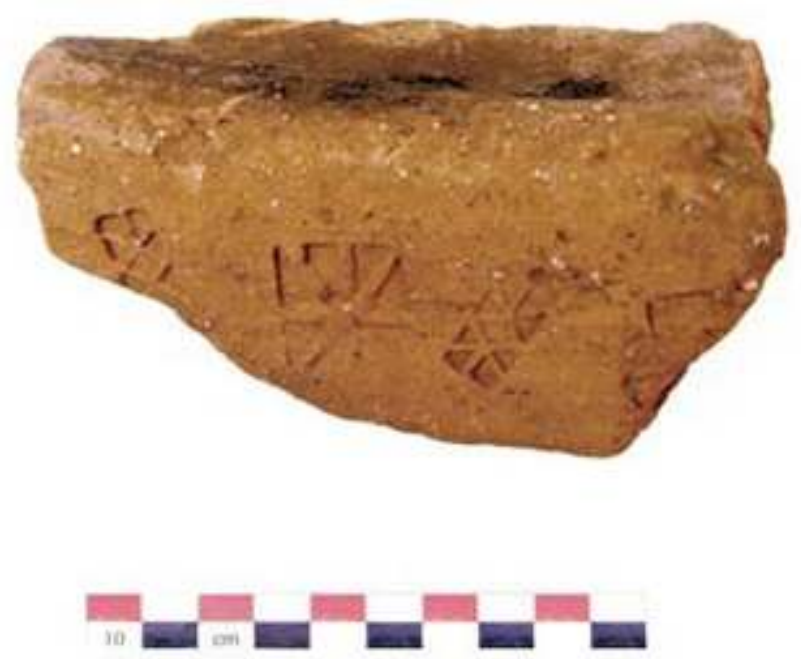

Mission archéologique Korçë.

\section{Période médiévale}

Cette période est surtout représentée sur le site fortifié de Mborja ${ }^{50}$, où l'on n'a jusqu'à présent décelé les traces d'aucune autre phase d'occupation. La céramique collectée comprend des tessons à glaçure de différentes couleurs (fig. 36), à décor peigné (fig. 37) ou à décor plastique (fig. 38).

Fig. 36 - Mborja. Céramique médiévale à glaçure.

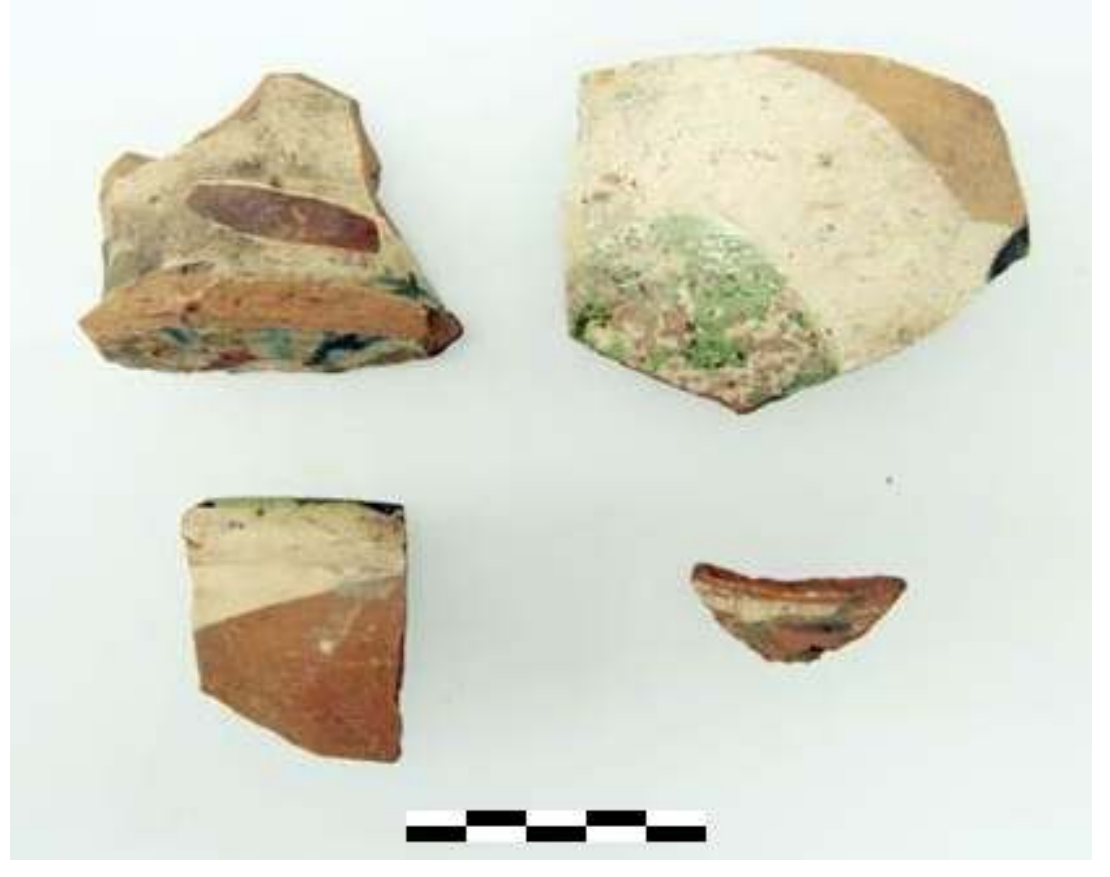

Mission archéologique Korçë. 
Fig. 37 - Mborja. Céramique médiévale à décor peigné.

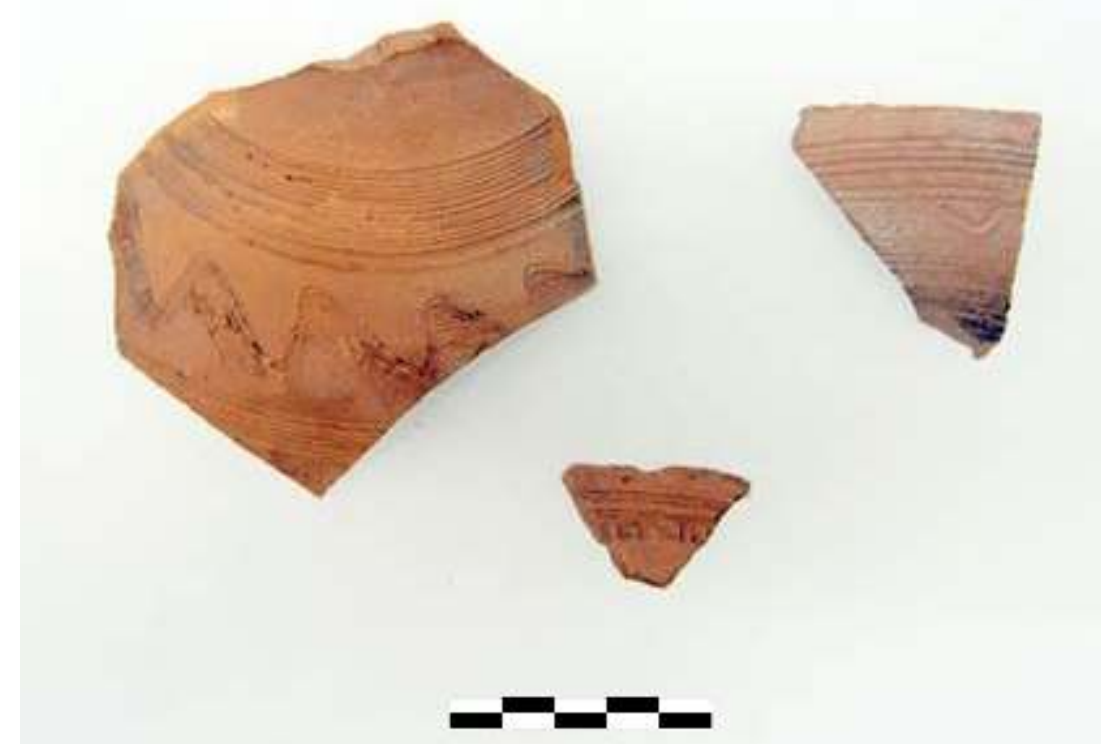

Mission archéologique Korçë.

Fig. 38 - Mborja. Céramique médiévale à décor plastique.

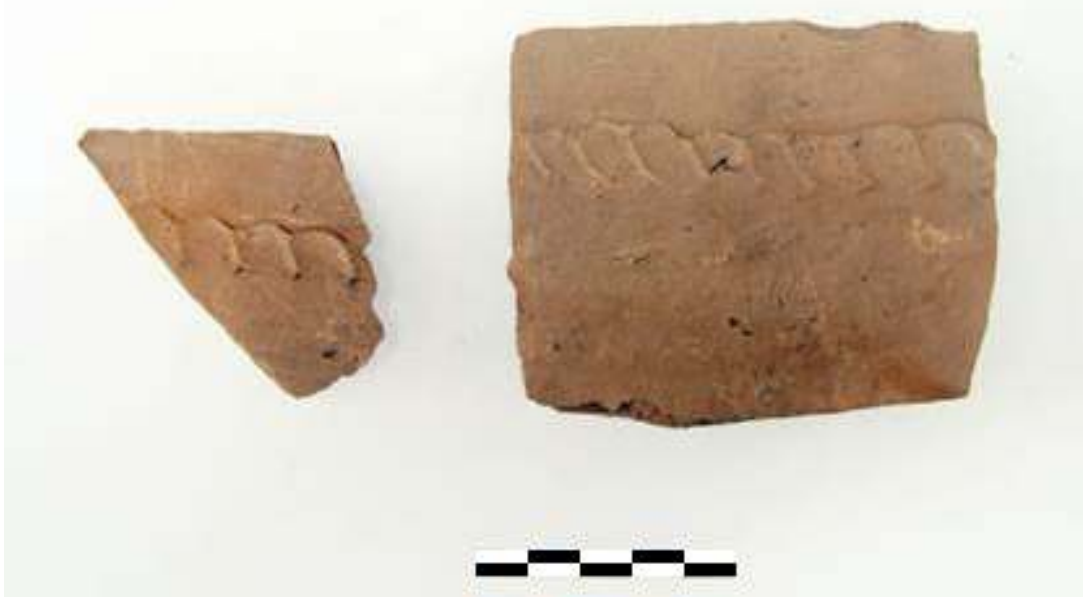

Mission archéologique Korçë.

67 On soulignera enfin que, comme cela avait déjà été observé lors du programme PALM, la période hellénistique est très mal représentée sur tous les sites prospectés, bien qu'elle soit mentionnée dans la bibliographie pour les sites de Bellovoda et de Barç.

\section{Quelques conclusions préliminaires}

De tous les sites de hauteur prospectés en 2018 sur le pourtour méridional du bassin de Korçë, seul celui de Bellovoda est un habitat fortifié dont le plus ancien niveau d'occupation est susceptible de dater de la fin de la période protohistorique, ce qu'un examen approfondi de la céramique associée devrait permettre de vérifier. L'autre période d'occupation du site est très probablement romaine tardive. Le matériel 
collecté ne nous renseigne pas sur l'occupation du site aux périodes intermédiaires, mais il est difficile d'imaginer qu'il ait pu être totalement abandonné.

Le site fortifié voisin de Bellovoda, Zhitom, semble appartenir à la phase de réoccupation de celui de Bellovoda, c'est-à-dire à la période romaine tardive.

Le site fortifié de Lumalas, à la périphérie Sud-Ouest du bassin, a été dégradé pendant la période communiste par l'installation d'un camp militaire, avant d'être détruit par une mine à ciel ouvert. Dans les publications, ce site a été daté de la période protohistorique sur la seule base des vestiges d'un mur en pierres sèches qui entourait un petit espace au sommet de la colline ${ }^{51}$; les auteurs ont d'ailleurs noté l'absence de céramique. La colline visitée cette année a été entamée aux trois quarts par une carrière ; les rares tessons collectés datent de la période antique.

71 Le cas de Barç et de Boboshtica est particulièrement intéressant car les deux sites semblent montrer deux occupations radicalement différentes par leur chronologie et leur nature, l'une des deux étant caractérisée par la présence d'au moins un tertre artificiel.

72 À Barç, le sommet de la colline sur lequel est installé le site est constitué de deux mamelons dont l'un est légèrement plus bas que l'autre et qui sont reliés par une petite ligne de crête. Le tertre artificiel, de plan circulaire et de profil conique arrondi, occupe le plus bas des deux (fig. 39); on y voit les traces d'anciennes fouilles clandestines (trous de forme grossièrement rectangulaire) suggérant l'existence de tombes sans aucun doute pillées (fig. 40) La céramique ramassée en contrebas de ce tertre (UP J, G, $\mathrm{H}$ : voir fig. 30) est une céramique à peinture mate datée de la fin du BR/début de l'Âge du Fer. Ces différents éléments nous conduisent à voir dans ce tertre un possible tumulus car, dans la région, les tumuli de cette période sont le plus souvent couverts de pierre et de terre (Plasa, Kuçi Zi, Kamenica) et que les tombes qu'ils abritent contiennent des vases en céramique de ce type. Il semble donc que ce tertre n'ait pas de rapport direct avec le site fortifié situé sur l'autre sommet, qui n'a livré que de la céramique antique, le seul point commun entre les deux occupations étant leur implantation sur un site présentant une position stratégique, mais à des fins différentes ${ }^{52}$. Il faudrait donc dissocier deux occupations différentes éloignées de quelques dizaines de mètres: un tumulus de la fin du BR/FA et un petit site fortifié antique, sans doute romain. 
Fig. 39 - Barç. Le tertre artificiel (au premier plan) et le site fortifié (à l'arrière-plan).

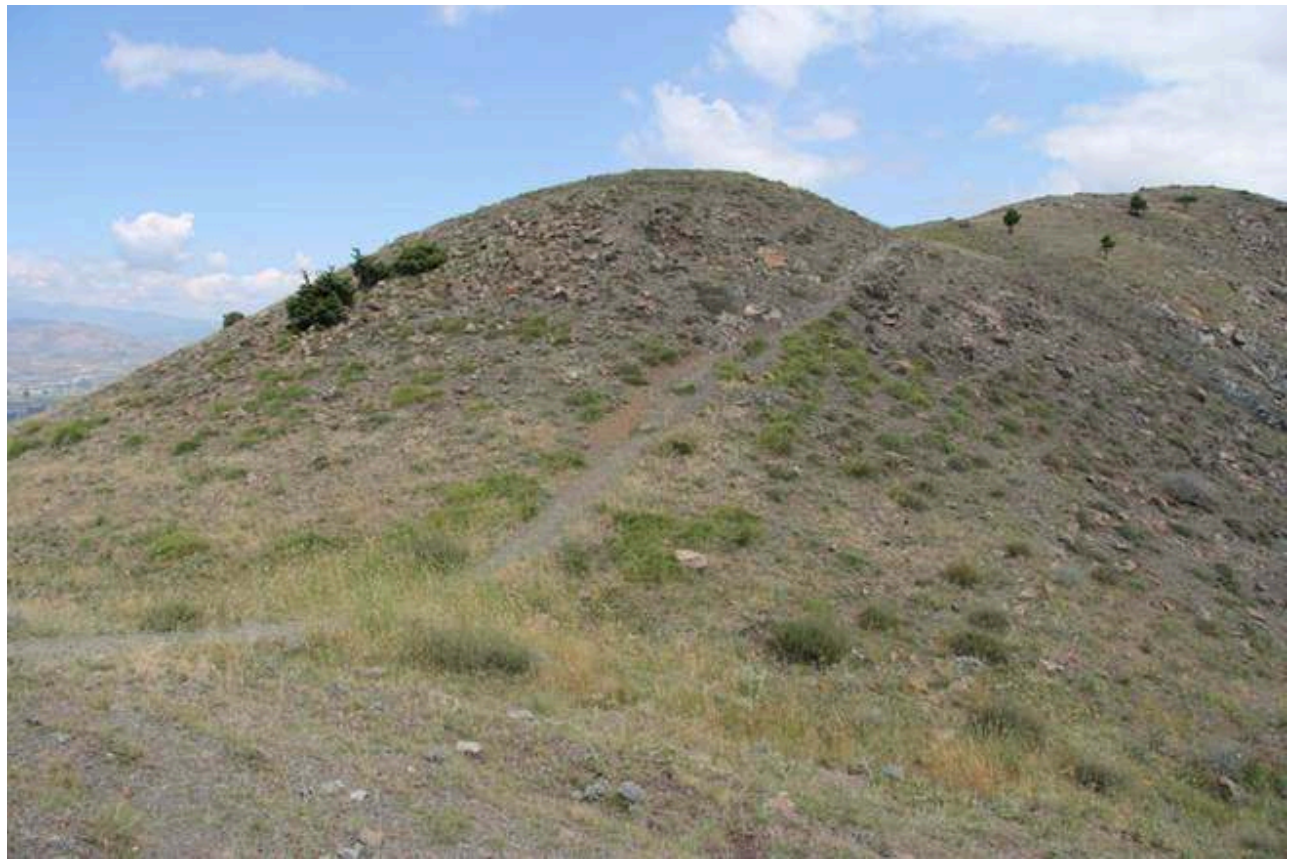

Mission archéologique Korçë.

Fig. 40 - Barç. Traces de fouilles clandestines sur le tertre artificiel.

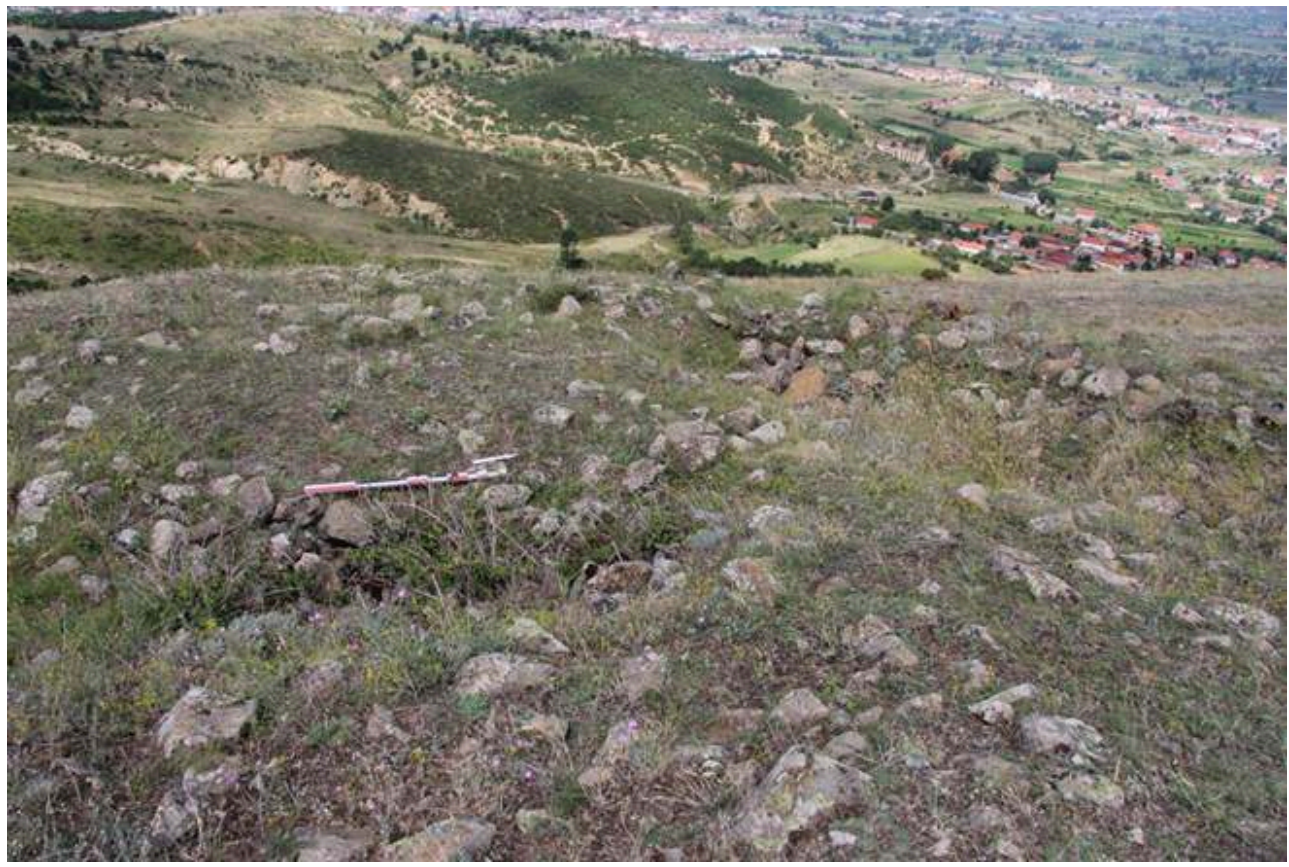

Mission archéologique Korçë.

À Boboshtica, la situation est légèrement différente. Le site occupe tout le sommet d'une colline ; les vestiges architecturaux conservés sont presque inexistants, et c'est à peine si l'on devine le tracé du mur de fortification sur la photo satellite (fig. 41). Le tertre est situé à l'extrémité Est du sommet. Il s'agit d'un grand monticule artificiel également fait de terre et de pierres (fig. 42); deux autres monticules de même nature, 
mais moins hauts et beaucoup moins nets, flanquent le premier à l'Est et à l'Ouest. La céramique ramassée en contrebas (UP E) est une céramique à peinture mate très similaire à celle qui a été trouvée à Barç. On est donc probablement en présence d'au moins un tumulus. Comme à Barç, le site fut réoccupé et fortifié à l'époque romaine, ce dont témoigne la céramique ramassée principalement sur le sommet (UP B et C). Là encore, il faudrait donc dissocier deux occupations différentes sur un même site: un tumulus de la fin duBR/FA et un petit site fortifié d'époque romaine. Sa position stratégique - avec une large visibilité sur le bassin de Korçë d'une part et sur la vallée qui relie le massif d'Opari au bassin d'autre part - et la présence de céramique protohistorique l'ont fait interpréter par P. Lera comme un unique site fortifié de la fin $\mathrm{du} \mathrm{BR} / \mathrm{FA}^{53}$.

Fig. 41 - Boboshtica. Photo satellite avec localisation des «tumuli »; au bout de la flèche on distingue à peine le tracé elliptique de la muraille.

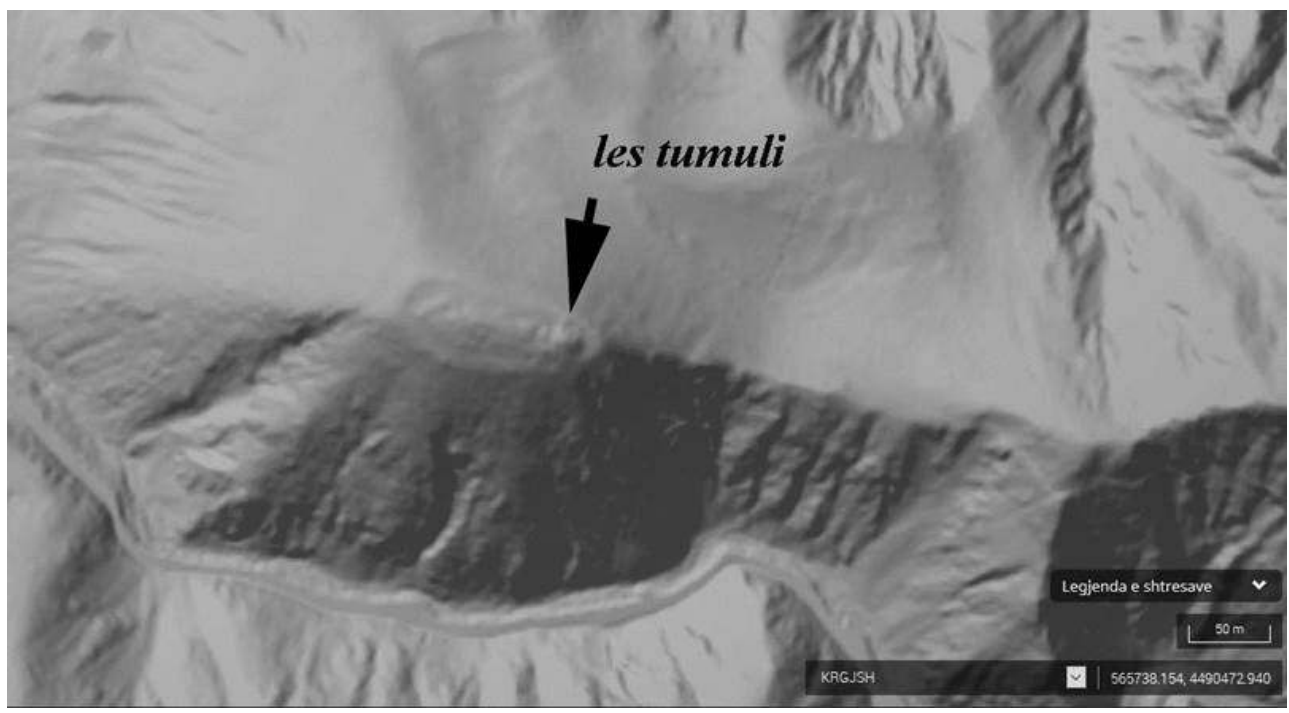

Mission archéologique Korçë. 
Fig. 42 - Boboshtica. Le plus grand des trois tumuli.

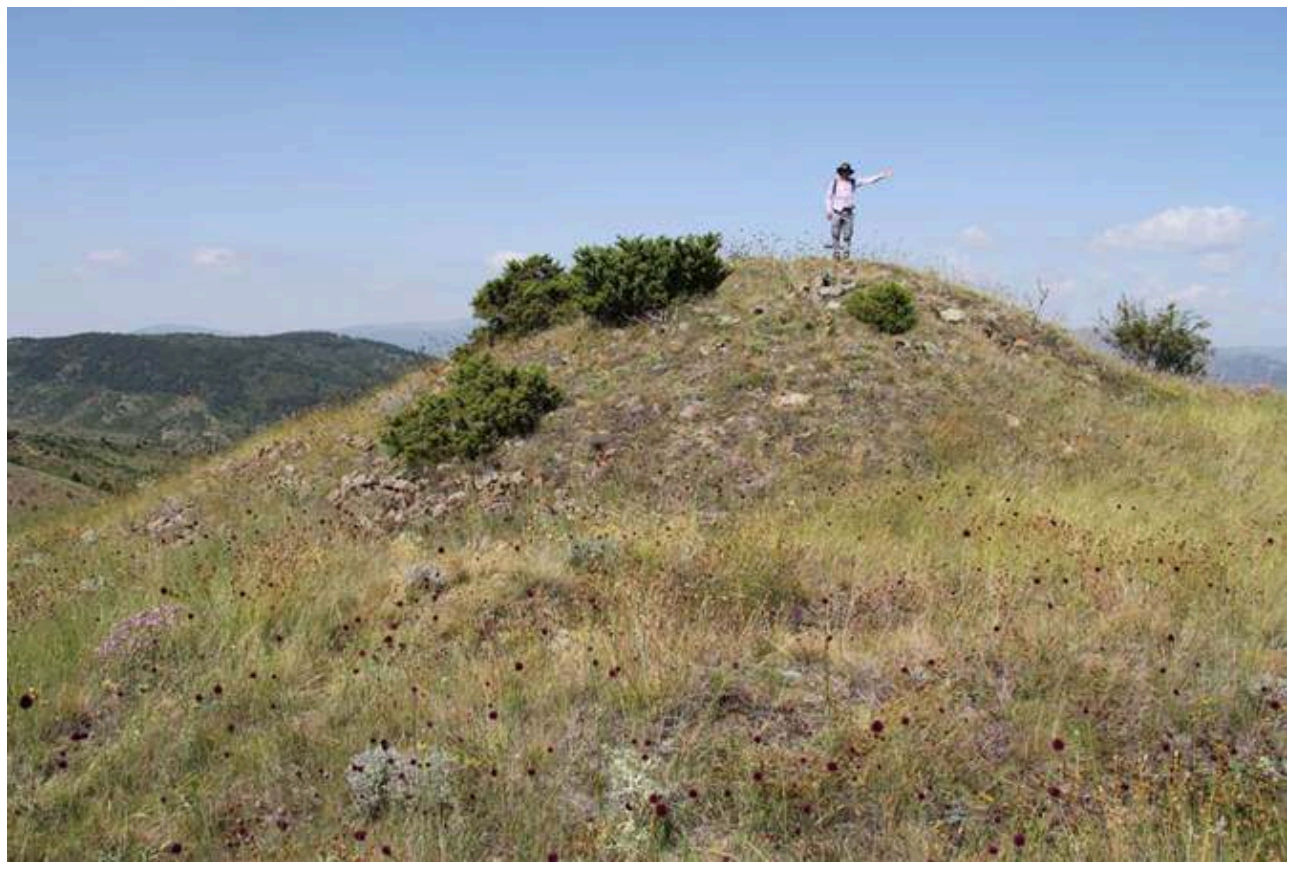

Mission archéologique Korçë.

74 La construction de tumuli sur des positions dominantes est un sujet largement traité dans la littérature. Le tumulus de Lofkënd en Albanie sud-occidentale en est un excellent exemple ${ }^{54}$. Plusieurs nécropoles tumulaires de hauteur ont aussi été découvertes récemment par des prospections dans le Nord-Ouest de l'Albanie ${ }^{55}$. Ainsi, les tumuli de Boboshtica et de Barç, situés sur le sommet de collines, seraient les premiers tumuli de hauteur découverts dans le bassin de Korçë, tous les autres actuellement connus (Kuç i Zi, Barç, Kamenica, Sovjan, Zvirina, Boboshtica) étant situés dans la plaine, sur sa périphérie. Dans ce contexte, les tumuli de hauteur - si leur existence est confirmée - offriraient un nouvel éclairage sur l'organisation du paysage funéraire protohistorique dans le bassin de Korçë. Mais seules des prospections géophysiques ou des sondages permettraient de tester cette hypothèse.

\section{Découverte fortuite}

75 Un nouveau tumulus a été découvert en 2018 près de Boboshtica, à quelques dizaines de mètres à l'Est d'une route secondaire qui mène au village et moins d' $1 \mathrm{~km}$ au Nord de celui-ci ${ }^{56}$. De forme ellipsoïdale, il mesure environ $75 \times 45 \mathrm{~m}$. Rappelons que le tumulus de Kamenica, situé à $4 \mathrm{~km}$ au Sud-Ouest, mesure environ $70 \times 50 \mathrm{~m}$ et que celui de Sovjan a un diamètre supérieur à $60 \mathrm{~m}^{57}$. Au sommet de ce nouveau tumulus on a pu observer les restes de la couche de pierres qui constituait sa couverture, comme à Kamenica.

\section{Conclusion}

76 Avec le renouvellement de la codirection albanaise de la mission et la signature d'une nouvelle convention bilatérale avec l'Institut archéologique de Tirana, les années 2017 
et 2018 marquent le début d'une nouvelle étape dans la vie scientifique de la mission franco-albanaise du bassin de Korçë. Ce cadre renouvelé offre à la mission l'occasion, tout en poursuivant sans relâche, avec le concours de ses plus anciens chercheurs, l'étude et la publication des résultats de ses recherches antérieures, de s'ouvrir à des problématiques nouvelles. Le projet de recherche sur les dynamiques de développement des sociétés du Bronze Récent et du Fer Ancien dans le bassin de Korçë - dont les premiers résultats s'annoncent prometteurs - témoigne de ce renouvellement thématique, qui met en vedette l'étude d'une période charnière encore très mal connue en Albanie, comme dans le reste des Balkans : le passage des sociétés préhistoriques à des modes de vie et d'organisation qui caractérisent, à nos yeux, les périodes historiques, avec tous les phénomènes humains, sociaux, culturels et environnementaux qui l'accompagnent.

\section{Bibliographie complète}

La bibliographie est classée par ordre chronologique de parution, et non par ordre alphabétique.

\section{Rapports préliminaires}

BCH 118, 1994

Petrika Lera, Franco Prendi, Gilles Touchais, René Treuil, «Rapport sur les travaux menés en collaboration avec l'École française d'Athènes en 1993. Sovjan (Albanie)", BCH 118, 1994, p. 531-533.

79 BCH 119, 1995

Petrika Lera, Franco Prendi, Gilles Touchais, «Rapport sur les travaux menés en collaboration avec l'École française d'Athènes en 1994. Sovjan (Albanie) », BCH 119, 1995, p. 783-790.

80 BCH 120,1996

Petrika Lera, Franco Prendi, Gilles Touchais et al., «Travaux menés en collaboration avec l'École française d'Athènes en 1995. Sovjan (Albanie) », BCH 120, 1996, p. 995-1026.

81 Iliria 26, 1996

Petrika Lera, Franco Prendi, Gilles Touchais et al., « Gërmime arkeologjike të vitit 1995. Sovjan » [Fouilles archéologiques en 1995. Sovjan], Iliria 26, 1996, p. 225-272.

82 BCH 121, 1997

Petrika Lera, Franco Prendi, Gilles Touchais, «Travaux menés en collaboration avec l'École française d'Athènes en 1996. Sovjan (Albanie) », BCH 121, 1997, p. 871-879.

83 BCH 122, 1998

Michelle Denèfle, Éric Fouache, Petrika Lera, Franco Prendi, Gilles Touchais, «Travaux menés en collaboration avec l'École française d'Athènes en 1997. Sovjan (Albanie)», BCH 122, 1998, p. 639-642.

BCH 124, 2000

Petrika Lera, Franco Prendi, Gilles Touchais, «Travaux menés en collaboration avec l'École française d'Athènes en 1999. Sovjan (Albanie) », BCH 124, 2000, p. 631-642. 
Zhaneta ANDREA, «Kërkimet arkeologjike në Shqipëri : 1991-1999. Rrheti i Korçës. Sovjan » [Recherches archéologiques en Albanie : 1991-1999. District de Korçë. Sovjan], Iliria 29, 1999-2000, p. 328-332, rés. fr. p. 340-341.

Petrika Lera, Gilles Touchais et al., "Travaux menés en collaboration avec l'École française en 2000. Sovjan (Albanie) », BCH 125, 2001, p. 716-730.

BCH 126, 2002

Petrika Lera, Gilles Touchais et al., "Travaux menés en collaboration avec l'École française en 2001. Sovjan (Albanie) », BCH 126, 2002, p. 627-645.

LERA 2002

Petrika Lera, «Rezultatet e gërmimeve arkeologjike shqiptaro-franceze, në vendbanimin prehistorik të Sovjanit (Gusht-Shtator 2002)» [Résultats des fouilles archéologiques franco-albanaises dans l'habitat préhistorique de Sovjan (aoûtseptembre 2002)], Tempulli 6, 2002, p. 73-81.

127, 2003

Petrika Lera, Gilles Touchais et al., "Travaux menés en collaboration avec l'École française en 2002. Sovjan (Albanie)», BCH 127, 2003, p. 578-609.

91 LAFE 2005

Ols LAFE, « Archaeology in Albania 2000-2004 », ArchRep 51, 2005, p. 131-133.

92 BCH 128-129, 2004-2005

Petrika Lera, Gilles Touchais et al., "Rapport sur les travaux de l'École française d'Athènes en 2003 et 2004. Sovjan », BCH 128-129, 2004-2005, p. 1096-1147.

Petrika Lera, Gilles Touchais et al., «Rapport sur les travaux de l'École française d'Athènes en 2005. Sovjan », BCH 130, 2006, p. 790-809.

BCH 131, 2007

Petrika Lera, Gilles Touchais et al., «Rapport sur les travaux de l'École française d'Athènes en 2006. Sovjan ", BCH 131, 2007, p. 1050-1075. BCH 132, 2008

Petrika Lera, Gilles Touchais et al., «Rapport sur les travaux de l'École française d'Athènes en 2007. Sovjan. Étude et prospection », BCH 132, 2008, p. 875-903.

BCH 133, 2009

Petrika Lera, Gilles Touchais, Cécile Oberweiler et al., "Rapport sur les travaux de l'École française d'Athènes en 2008. Bassin de Korçë, Kallamas ", BCH 133, 2009, p. 689-724.

$97 \quad B C H 134,2010$

Petrika Lera, Gilles Touchais, Cécile Oberweiler et al., «Rapport sur les travaux de l'École française d'Athènes en 2009. Bassin de Korçë, Kallamas ", BCH 134, 2010, p. 617-647.

98 BCH 135, 2011

Petrika Lera, Gilles Touchais, Cécile Oberweiler et al., «Rapport sur les travaux de l'École française d'Athènes en 2010. Bassin de Korçë, Kallamas ", BCH 135, 2011, p. 661-691. 
BCH 136-137, 2012 et 2013 Kallamas », BCH 136-137, 2012-2013, p. 687-722 et 881-907.

BCH 138, 2014 BCH 138, 2014, p. 795-818.

BCH 139-140, 2015-2016 Kallamas », BCH 139-140, 2015-2016, p. 1029-1065.

\section{Études archéologiques}

\section{PRENDI, TOUCHAIS 1995} II $^{\mathrm{e}}$ millénaire av. J.-C., Athènes, 9-11 juin 1995.

PRENDI, TOUCHAIS 1999 Paris, De Boccard, 1999, p. 19-27.

KOURTESSI-PHILIPPAKIS, ASTRUC 2002 BCH Suppl. 42, 2002, p. 73-84.

LERA, TOUCHAIS 2004 et l'Épire dans l'Antiquité IV, Paris, De Boccard, 2004, p. 23-38.

LERA 2003 préhistorique], Tempulli 8, 2003, p. 30-38.

7 TOUCHAIS, LERA 2007

CHRISTIDOU 2008

Petrika Lera, Gilles Touchais, Cécile Oberweiler et al., «II. Rapports 2011. Albanie. Sovjan, Bassin de Korçë, Kallamas ; III. Rapports 2012. Albanie. Sovjan, Bassin de Korçë,

Petrika Lera, Gilles Touchais, Cécile Oberweiler et al., "Rapport sur les travaux de l'École française d'Athènes en 2013. Albanie. Sovjan, Bassin de Korçë, Kallamas ",

Petrika Lera, Gilles Touchais, Cécile Oberweiler et al., «Rapport sur les travaux de l'École française d'Athènes en 2014 et 2015. Albanie. Sovjan, Bassin de Korçë,

Franco Prendi, Gilles Touchais, « Les fouilles de Sovjan et la question des rapports entre l'Albanie et l'Égée à l'Âge du Bronze ", in Congrès international sur l'Égée et l'Europe au

Franco Prendi, Gilles Touchais, « Sovjan. Un habitat de l'Âge du Bronze et du début de l'Âge du Fer dans la plaine de Korça ", in Pierre Cabanes (éd.), L'Illyrie méridionale et l'Épire dans l'Antiquité, Actes du III' Colloque international de Chantilly, 16-19 octobre 1996,

Giorgia Kourtessi-Philippakis, Laurence Astruc, «Les industries lithiques taillées du Bronze Moyen et Récent en Grèce du Nord et en Albanie : l'exemple de Sovjan ", in Gilles Touchais, Josette Renard (éd.), L'Albanie dans l'Europe préhistorique, Athènes, EFA,

Petrika Lera, Gilles Touchais, «Le Bronze Moyen dans le bassin de Korçë à la lumière des fouilles de Sovjan ", in Pierre Cabanes, Jean-Luc Lamboley (éd.), L'Illyrie méridionale

Petrika Lera, «Dëshmi arkeologjike mbi ushtrimin e metalurgjise lokale prehistorike », [Témoignages archéologiques d'une activité métallurgique locale à l'époque

Gilles Touchais, Petrika Lera, "L'Albanie méridionale et le monde égéen à l'âge du Bronze: problèmes chronologiques et rapports culturels ", in Michael I.Galanaki, Helena Tomas, Yannis Galanakis, Robert Laffineur (éd.), Between the Aegean and Baltic Seas: Prehistory Across Borders, Liège, PU, Aegaeum 27, 2007, p. 141-147.

Rosalia Christidou, "The use of metal tools in the production of bone artifacts at two Bronze Age sites in the southwestern Balkans », in Laura Longo, Natalja N. Skakun (éd.), 
"Prehistoric Technology" forty years later: Functional studies and the Russian legacy, Oxford, Archaeopress, BAR is 1783, 2008, p. 253-264.

LERA 2005

Petrika Lera, «Prova arkeologike nga vendbanimet prehistorike të zbuluara në rrethin e Korçës mbi ushtrimin e mjeshtërisë së tekstilit » [Témoignages archéologiques du travail des textiles dans les habitats préhistoriques découverts dans le district de Korçë], Tempulli 11, 2005, p. 95-102.

CHRISTIDOU 2007

Rosalia Christidou, "Aperçu des industries osseuses de l'habitat protohistorique lacustre de Sovjan (bassin de Korçë, Albanie sud-orientale) », BCH 131, 2007, p. 755-803.

111 LERA, TOUCHAIS, OBERWEILER 2010

Petrika Lera, Gilles Touchais, Cécile Oberweiler, «Le passage du Bronze Récent au Fer Ancien sur le site de Sovjan (bassin de Korçë, Albanie): nouvelles données chronologiques ", in Jean-Luc Lamboley, Maria Pia Castiglioni (éd.), l'Illyrie méridionale et l'Épire dans l'Antiquité V, Paris, De Boccard, 2010, p. 41-52.

112 LERA 2010

Petrika Lera, "Aspekte në procesin e neolitizmit të pellgut të Korç̧ës " [Aspects du processus de néolithisation dans le bassin de Korçë], Tempulli 15, 2010, p. 42-48.

113 LERA 2009

Petrika Lera, Vendbanimet e neolitit të vonë në Dërsnik dhe Barç [Les habitats du Néolithique Récent de Dërsnik et de Barç], Korçë, 2009, 189 p.

114 LERA 2010

Petrika Lera, Korça në gjurmimet dhe studimet arkeologjike, Korçë, 2010.

115 LERA, TOUCHAIS, OBERWEILER 2007-2008

Petrika Lera, Gilles Touchais, Cécile Oberweiler, « La contribution des fouilles de Sovjan à la chronologie absolue de la préhistoire albanaise », Iliria 33, 2007-2008, p. 39-50.

CHEVAL 2012

Carole Cheval, «Une utilisation des disques perforés en terre cuite : la série de Sovjan en Albanie méridionale", Bulletin de la Société préhistorique française 109, 2012, p. $157-160$.

117 KRAPF 2014

Tobias Krapf, «Interaction entre production locale et influences externes : le cas de la céramique du Bronze Récent de la Grèce du Nord et de l'Albanie du Sud", in Sarra Ferjani, Amélie Le Bihan, Marylise Onfray, Caroline Tremeaud (éd.), Matières premières et gestion des ressources, Paris, PU Sorbonne, ArchéoDoct 6, 2014, p. 135-254.

118 OBERWEILER, TOUCHAIS, LERA 2014

Cécile Oberweiler, Gilles Touchais, Petrika Lera, «Les recherches franco-albanaises dans la région de Korçë : nouvelles données sur la chronologie absolue de la préhistoire albanaise ", in Proceedings of the International Congress of Albanian Archaeological Studies, 65th Anniversary of Albanian Archaeology (21-22 November, Tirana 2013), Tirana, Centre for Albanian Studies, 2014, p. 83-92.

119 KRAPF 2017

Tobias Krapf, «From Central Greece to the North and then Westwards? Tracing Influences in Matt Painted Pottery from Middle Bronze Age to Early Iron Age ", in 
Michael Fotiadis, Robert Laffineur, Yannis Lolos et Andreas Vlachopoulous (éd.), HESPEROS, The Aegean Seen from the West, Liège, Peeters, Aegaeum 41, 2017, p. 349-360. 
geomorphological evolution: the example of the Korça basin (Albania)", Géomorphologie 2, 1999, p. 111-128.

DENÈFLE, LÉZINE, FOUACHE, DUFAURE 2000

Michelle Denèfle, Anne-Marie Lézine, Éric Fouache, Jean-Jacques Dufaure, «A 12,000Year Pollen Record from Lake Maliq, Albania », Quaternary Research 54, 2000, p. 423-432.

FOUACHE et al. 2001

Éric Fouache, Jean-Jacques Dufaure, Michelle Denèfle, Anne-Marie Lézine, Petrika Lera, Franco Prendi, Gilles Touchais, «Man and Environment around Lake Maliq (Southern Albania) during the Late Holocene », Vegetation History and Archaeobotany 2001, p. 79-86.

\section{FOUACHE 2002}

Éric Fouache, "Dynamiques paléoenvironnementales en Albanie à l'Holocène », in Gilles Touchais, Jacques Renard (éd.), L'Albanie dans l'Europe préhistorique, Athènes, EFA, BCH Suppl. 42, 2002, p. 3-42.

GARDEISEN, GARCIA PETIT, PIQUÈS 2002

Armelle Gardeisen, Lluis Garcia Petit, Gaël Piquès, «La recherche archéozoologique en Albanie : un état de la question à Sovjan (bassin de Korçë) », in Gilles Touchais, Jacques Renard (éd.), L'Albanie dans l'Europe préhistorique, Athènes, EFA, BCH Suppl. 42, 2002, p. 43-60.

\section{ALLEN 2002}

Susan E. Allen, "The Palaeoethnobotany of Sovjan, Albania : Preliminary Results ", in Gilles Touchais, Jacques Renard (éd.), L'Albanie dans l'Europe préhistorique, Athènes, EFA, BCH Suppl. 42, 2002, p. 61-72.

\section{ALLEN 2003}

S. E. ALLEN, «Prehistoric Wetland Agriculture at Sovjan, Albania », 68th Annual Meeting of the Society for American Archaeology, Milwaukee, Wisconsin, April 10-13, 2003.

\section{ALLEN 2004}

S. E. ALLEN, «Food, Fodder and Farming in Southern Albania: Palaeoethnobotanical Research at Sovjan », 105th Annual Meeting of the Archaeological Institute of America, San Francisco, California, January 2-5, 2004.

FOUACHE, DESRUELLES 2007

Éric Fouache, Stéphane Desruelles, «GIS as a tool for palaeogeographical reconstruction in the Holocene: a case study from Lake Maliq in the basin of Korçë (Albania)», $17^{e}$ Colloque de l'INQUA, Cairns (Australie), 29 juillet - 6 août 2007 (communication orale).

\section{BORDON et al. 2009}

Amandine Bordon, Odile Peyron, Anne-Marie Lézine, Simon Brewer, Éric Fouache, Pollen-inferred Late-Glacial and Holocene climate in southern Balkans (Lake Maliq), Quaternary International, 200/1-2, 2009, p. 19-30.

\section{BELMECHERI et al. 2010}

Soumaya Belmecheri, T. Namiotko, Christophe Robert, Ulrich von Grafenstein, D. L. Danielopol, "Climate controlled ostracod preservation in Lake Ohrid (Albania, Macedonia) », Palaeogeography, Palaeoclimatology, Palaeoecology 277/3-4 (15 June 2009), p. 236-245.

\section{FOUACHE et al. 2010}

Éric Fouache, Stéphane Desruelles, Michel Magny, Amandine Bordon, Cécile Oberweiler, 
Cécile Coussot, Gilles Touchais, Petrika Lera, Anne-Marie Lézine, Lionel Fadin, Rébecca Roger, "Palaeogeographical reconstructions of Lake Maliq (Korça Basin, Albania) between 14000 BP and 2000 BP », Journal of Archaeological Science 37, 2010, p. 525-535.

Michel Magny, Boris Vannière, Gianni Zanchetta, Éric Fouache, Gilles Touchais, Petrika Lera, Cécile Coussot, Anne-Véronique Walter-Simonnet, Fabien Arnaud, "Possible complexity of the climatic event around 4200-4000 cal. BP in the central and western Mediterranean ", The Holocene 19, 2009, p. 823-833.

FOUACHE 2010

Éric Fouache, Stéphane Desruelles, Michel Magny, Amandine Bordon, Cécile Oberweiler, Cécile Coussot, Gilles Touchais, Petrika Lera, Anne-Marie Lézine, Lionel Fadin, Rébecca Roger, «Les variations de l'extension du lac Maliq (Bassin de Korçë, Albanie) en relation avec l'occupation humaine entre $14000 \mathrm{BP}$ et $2000 \mathrm{BP}$ », in Jean-Luc Lamboley, Maria Pia Castiglioni (éd.), L'Illyrie méridionale et l'Épire dans l'Antiquité V, Paris, De Boccard, 2010, p. 65-78.

BELMECHERI et al. 2010

Soumaya Belmecheri, Ulrich von Grafenstein, Nils Andersen, Amandine Bordon, Damien Régnier, Christophe Grenier, Anne-Marie Lézine, "Ostracod-based isotope record from Lake Ohrid (Balkan Peninsula) over the last 140 ka. ", Quaternary Science Reviews 29/27-28, 2010, p. 3894-3904.

LÉZINE et al. 2010

Anne-Marie Lézine, Ulrich von Grafenstein, Nils Andersen, Soumaya Belmecheri, Amandine Bordon et alii, «Lake Ohrid (Albania) provides an exceptional multi-proxy record of paleoenvironmental changes during the last glacial-interglacial cycle", Palaeogeography, Palaeoclimatology, Palaeoecology 287/ 1-4, 2010, p. 116-127.

CARON at al. 2010

Benoit Caron, Roberto Sulpizio, Giovanni Zanchetta, Giuseppe Siani, Roberto Santacroce, "The late Holocene to Pleistocene tephrostratigraphic record of Lake Ohrid (Albania) », Comptes Rendus Geoscience 342/6, 2010, p. 453-466.

145 FOUACHE et al. 2014

Éric Fouache, Gilles Touchais, Cécile Oberweiler, Petrika Lera, Stéphane Desruelles, Cécile Coussot, Michel Magny, Anne-Marie Lézine, «Sovjan et le lac Maliq en Albanie. Un site protohistorique dans son environnement ", in Nathalie Carcaud, Gilles ArnaudFassetta (éd.), La géoarchéologie au XXI siècle/French geoarchaeology in the 21st century, Paris, CNRS, 2014, ch. XVI.

\section{Articles de synthèse}

TOUCHAIS, FOUACHE 2007

Gilles Touchais, Éric Fouache, «La dynamique des occupations de bord de lac dans le Sud-Ouest des Balkans: l'exemple de Sovjan, bassin de Korçë (Albanie)», in Hervé Richard, Michel Magny, Claude Mordant (éd.), Environnements et cultures à l'Âge du Bronze en Europe occidentale, Paris, CTHS, 2007, p. 375-386.

147 TOUCHAIS 2008

Gilles Touchais, «Sovjan et l'Âge du Bronze en Albanie », in Jean Guilaine (éd.), Villes, 
villages, campagnes de l'Âge du Bronze. Séminaire du Collège de France, Paris, Errance, 2008, p. 108-123.

TOUCHAIS, OBERWEILER, LERA 2009

Gilles Touchais, Cécile Oberweiler, Petrika Lera, «Natural environment and human settlement around Lake Maliq (Korça basin, south-eastern Albania) during the prehistoric period ", $107^{\text {th }}$ Annual Meeting of the Archaeological Institute of America, Philadelphia, Pennsylvania, January 8-11, 2009.

OBERWEILER, TOUCHAIS, LERA à paraître

Cécile Oberweiler, Gilles Touchais, Petrika Lera, «Prehistoric Lakeside Settlements in the Korçë Area, South-Eastern Albania », Plattform, à paraître.

\section{Travaux universitaires}

GRECK 2004

Sandra Greck, «Étude des structures en bois de l'habitat de Sovjan (Albanie) à l'Âge du Bronze Moyen. Apports de la xylologie et de la dendrochronologie ", Mémoire de DEA, Mention Environnement et Archéologie, Université Paris 1 Panthéon-Sorbonne, 2004.

151 BORDON 2004

Amandine Bordon, «Reconstitution quantitative du climat depuis le Tardiglaciaire (12300 Before Present) à partir de la séquence pollinique du lac Maliq, Albanie : rôle des analogues polliniques actuels dans les reconstitutions climatiques quantitatives", Mémoire de DEA, Université de Franche-Comté, 2004.

EN 2005

Susan E. ALLEN, "A Living Landscape: The Palaeoethnobotany of Sovjan, Albania ", Ph.D., University of Boston, 2005.

2007

Cécile Coussot, "Évolution géomorphologique et paléogéographique du Bassin de Skopje (A.R.Y.M.) à l'Holocène. Incidences sur les choix d'implantation des sites néolithiques ", Thèse de doctorat, Université Paris 12-Val de Marne, 2007, ch. 8.

154 BORDON 2008

Amandine Bordon, "Dynamique de la végétation et variations climatiques dans les Balkans au cours du dernier cycle climatique à partir des séquences polliniques des lacs Maliq et Ochrid (Albanie », Thèse de doctorat, Université de Franche-Comté, 2008.

155 DESIDERIO 2008

A. M. Desiderio, "Étude des empreintes des céréales utilisées comme dégraissant. Application sur la terre à bâtir du site de Sovjan (Albanie) ", Mémoire de master 2, Spécialité Archéologie et Environnement, Université Paris 1 Panthéon-Sorbonne, 2008.

156 BELMECHERI 2008

Soumaya Belmecheri, «La reconstitution du dernier cycle climatique dans le sud des Balkans: géochimie des ostracodes lacustres (Ohrid) », Thèse de doctorat, Université Paris-Sud 11 LSCE, 2008.

157 GORI 2011

Maja Gori, «Between the Adriatic Sea and the Aegean: the South-Western Balkans during the late $3^{\text {rd }}$ and early 2 nd millennium $B C$ in the light of the excavations of Sovjan (Albania) and Sveta Nedela (Republic of Macedonia - FYROM) », Thèse de doctorat en 
cotutelle, Ruprecht-Karls Universität Heidelberg- Université Paris 1 PanthéonSorbonne, 2011. OBERWEILER 2014

Cécile Oberweiler, «Les dynamiques de l'implantation humaine dans le bassin de Korçë en Albanie. Une étude diachronique, de la préhistoire à la période médiévale ", Mémoire présenté à l'Académie des Inscriptions et Belles-Lettres, 2014.

GORI

Maja GORI, Along the rivers and through the mountains. A reviewed chrono-cultural framework from the south-western Balkans in the late 3rd and early 2nd millennium BCE, Bonn, Rudolf Habelt, Universitätsforsch. z. prähist. Archäol 268, 2015.

\section{Grand public}

\section{PRENDI, TOUCHAIS 1997}

Franco Prendi, Gilles Touchais, "Aux marges du monde mycénien: les fouilles de Sovjan (Albanie) », Les Dossiers d'Archéologie 222, avril 1997, p. 86.

\section{PAPATSAROUCHA 2000}

E. Papatsaroucha, «Sovjan. Un habitat lacustre palafittique en Albanie du Sud-Est » [en grec], Corpus 14, mars 2000, p. 12-14.

CRANÇON, DUPRÉE 2000

Sophie Crançon, Axel Duprée, « Albanie, l'espoir et le doute », Archéologia 373, déc. 2000, p. 34-37.

\section{TOUCHAIS 2005}

Gilles Touchais, "La Mission archéologique du bassin de Korçe, Albanie », in Archéologies. Vingt ans de recherches françaises dans le monde, Paris, Maisonneuve et Larose, 2005, p. 108-109.

TOUCHAIS, OBERWEILER, LERA 2014

Gilles Touchais, Cécile Oberweiler, Petrika Lera, «Découvrir la préhistoire du bassin de Korçë : la vie quotidienne au bord des lacs », fascicule trilingue : Fr, Angl, Alb, 2014.

\section{Posters}

Éric Fouache, Anne-Marie Lézine, Gilles Touchais, Petrika Lera et alii, « Dynamique des écosystèmes forestiers des Balkans: histoire climatique et implications pour les populations humaines », Colloque ECLIPSE du CNRS, Paris, octobre 2002.

6 Béatrice Szepertyski, Gilles Touchais, Petrika Lera, "Sovjan : un habitat lacustre de l'Âge du Bronze Moyen en Albanie. Apports de la dendrochronologie", Colloque Archéométrie 2003, GMPCA, Université Michel de Montaigne Bordeaux 3-CNRS, UMR 5060 IRAMAT, Bordeaux, 16-19 avril 2003.

67 Gilles Touchais, Cécile Oberweiler, Petrika Lera et alii, « L'habitat préhistorique lacustre de Sovjan (Albanie): dix ans de recherches franco-albanaises (1993-2003)», in Philippe Della Casa, Martin Trachsel (éd.), WES '04. Wetlands Economies and Societies. Proceedings of the International Conference, Zurich, 10-13march 2004, Zurich, Schweizerisches Landesmuseum, 2005, p. 255-258.

Rosalia Christidou, «Bone tools from Sovjan, Albania. Elements for a discussion on crafts and households of the Bronze Age », in Anna Philippa-Touchais, Gilles Touchais, 
Sofia Voutsaki, James Wright (éd.), Mesohelladika. La Grèce continentale au Bronze Moyen, Athènes, EFA, BCH Suppl. 52, 2010, p. 1005-1012.

Amandine Bordon, Odile Peyron, Anne-Marie Lézine, Michelle Denèfle, « Pollen contributors (2006). Quantitative reconstruction of the Lateglacial to Holocene climate at lake Maliq, Albania, from pollen data ", $\mathrm{XV}^{\mathrm{e}}$ Congrès de l'Union internationale des Sciences préhistoriques et protohistoriques, Lisbonne, Portugal, 4-9 septembre 2006.

Cécile Coussot, Gilles Touchais, Petrika Lera, Éric Fouache, «Apports de la micromorphologie à l'étude du site de Sovjan (Albanie): aspects archéologiques et géomorphologiques", "Old Man River». Aspects géo-archéololgiques des rivières et des plaines alluviales, Colloque international, Gand, 22-24 septembre 2006.

Éric Fouache, Stéphane Desruelles, Michel Magny, Cécile Oberweiler, Cécile Coussot, Gilles Touchais, Petrika Lera, Anne-Marie Lézine, Amandine Bordon, «Palaeogeographic Reconstructions around Maliq Lake (Korçë Basin) on the Holocene ", Colloque ECLIPSE II \& ARTEMIS Project «Climate Change and Ecosystem Dynamics in Southern Balkans during the Last Climatic Cycle », Paris, 15-16 octobre 2007.

Gilles Touchais, Petrika Lera, Cécile Oberweiler, Béatrice Szepertyski, Éric Fouache, Cécile Coussot, «La dynamique d'implantation des habitats protohistoriques sur les rives du lac Maliq (bassin de Korçë, Albanie) : l'exemple de Sovjan », ibid.

Cécile Oberweiler, Gilles Touchais, Petrika Lera, Éric Fouache, Stéphane Desruelles et Michel Magny, «L'impact des facteurs environnementaux sur la dynamique d'implantation des habitats protohistoriques dans le bassin de Korçë (Albanie)», $14^{\mathrm{e}}$ Rencontre Égéenne Internationale: PHYSIS. L'environnement naturel et la relation homme-milieu dans le monde égéen protohistorique, Paris, INHA, 11-14 décembre 2012.

174 Athina Boleti, «Les lames en pierre polie du site néolithique de Kallamas (Prespa): approche technologique) », $\mathrm{VI}^{\mathrm{e}}$ Colloque international sur l'Illyrie Méridionale et l'Épire dans l'Antiquité, Tirana, 20-24 mai 2015.

175 Tobias Krapf et al., "Southern Balkan regional variety and connectivity: Results of a new international collaboration ", 117th Annual Meeting of the American Institute of Archaeology (AIA), San Francisco, 6-9 janvier 2016.

176 Tobias Krapf et al., «Balkan Bronze Age borderlands. Along ancient routes from the Aegean to Albania, FYROM, Kosovo and SW Bulgaria ", in Michael Fotiadis, Robert Laffineur, Yannis Lolos et Andreas Vlachopoulous (éd.), HESPEROS, The Aegean Seen from the West, Liège, Peeters, Aegaeum 41, 2017, p. 279-285.

177 Ole C. Aslaksen, Maja Gori, Tobias Krapf, «Characterising Bronze and Early Iron Age ceramics of Sovjan (SE Albania) with the use of pXRF-scanning ", 41st International Symposium on Archaeometry (ISI), Kalamata, 15-21 mai 2016. 


\section{BIBLIOGRAPHIE}

ANDREA 1968

Zhaneta Andrea, «Rezultatet e kërkimeve informative në rrethin e Korçës », Materiale të Sesionit Arkeologjik, 2-3/X/1967 [1968], p. 125-135.

CEKA 1983

Neritan Ceka, «Lindja e jetës qytetare tek ilirët e jugut », Iliria 13/2, 1983, p. 135-192.

CHRYSOSTOMOU 2015

Panicos Chrysostomou, « The Culture of Four Lakes: Conclusions from the archaeological research in Amindeon basin (2000-2014), in Panicos Chrysostomou (éd,), The "Culture of Four Lakes". Wooden artifacts from the prehistoric lakeside settlements of Amindeon basin, Thessalonique, Epikentron, 2015.

CHRYSOSTOMOU, JAGOULIS, MÄDER 2015

Panicos Chrysostomou, Tryfon Jagoulis, Andreas Mäder, « The "Culture of Four Lakes".

Prehistoric lakeside settlements (6th-2nd mill. BC) in the Aminteon basin, Western Macedonia, Greece ", Archéologie Suisse 38/3, 2015.

FOUACHE, LÉZINE à paraître

Éric Fouache, Anne-Marie Lézine dans Sovjan, village préhistorique lacustre d'Albanie sudorientale. Le site dans son environnement, ch. I, 1 (à paraître).

GORI, KRAPF 2016

Maja Gori, Tobias Krapf, « The Bronze and Iron Age Pottery from Sovjan », Iliria 39, 2016, p. 91-135.

HOURMOUZIADIS 2002

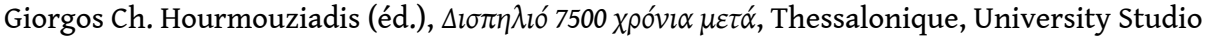
Press, 2002.

KARAISKAJ 1981

Gjerak Karaiskaj, 5000 vjet fortifikime në Shqipëri, Tirana, 8 Nëntori, 1981.

KARAISKAJ, LERA 1974

Gjerak Karaiskaj, Petrika Lera, « Fortifikimet e periudhës së parë të hekurit në pellgun e Korçës », Kuvendi I $i$ Studimeve Ilire, Tirana, Akademia, 1974.

KORKUTI 1973

Muzafer Korkuti, « Rreth vendbanimeve të fortifikuara ilire të periudhës së parë të hekurit në territorin e Shqipërisë », Studime Historike 3, 1973, p. 107-121.

Korkuti 2010

Muzafer Korkuti, Qytetërimi neolitik dhe eneolitik në Shqipëri, Tirana, Akademia e Shkencave e Shqipërisë, 2010.

KRAPF 2017

Tobias Krapf, « From Central Greece to the North and then Westwards? Tracing Influences in Matt Painted Pottery from Middle Bronze Age to Early Iron Age », in Michael Fotiadis, Robert Laffineur, Yannis Lolos et Andreas Vlachopoulous (éd.), HESPEROS, The Aegean Seen from the West, Liège, Peeters, Aegaeum 41, 2017, p. 349-360. 
KURTI, RUKA, GJIPALI 2014

Rovena Kurti, Rudenc Ruka, Ilir Gjipali, « Rezultate paraprake të ekspeditës përnjohëse ne Malin e Rencit dhe malin e Kakarriqit në Shqipërinë veriperëndimore », Iliria 38, 2014, p. 181-190.

KURTI, RUKA 2018

Rovena Kurti, Rudenc Ruka, « Raport mbi vëzhgimin arkeologjik në zonën kodrinore të Shqipërisë veriperëndimore (Lezhë-Shkodër, 2017) / Report on the archaeological survey of the hilly region of northwest Albania (Lezhë-Shkodër, 2017) », Candavia 7, 2018, p. 139-172.

LERA 1992

Petrika Lera, « Vendbanimi Ilir në Gradishtën e Symizës [L'habitat illyrien à Gradishte de Symiza] », Iliria 22, 1992, p. 177-208.

LERA, TOUCHAIS, OBERWEILER 2010

Petrika Lera, Gilles Touchais, Cécile Oberweiler, «Le passage du Bronze Récent au Fer Ancien sur le site de Sovjan (bassin de Korçë, Albanie) : nouvelles données chronologiques », in Jean-Luc Lamboley, Maria Pia Castiglioni (éd.), l'Illyrie méridionale et l'Épire dans l'Antiquité V, Paris, De Boccard, 2010, p. 41-52.

LÉZINE et al. 2010

Anne-Marie Lézine, Ulrich von Grafenstein, Nils Andersen et alii, « Lake Ohrid, Albania, provides an exceptional multi-proxy record of environmental changes during the last glacial-interglacial cycle », Palaeogegraphy, Palaeoclimatology, Palaeoecology 287, 2010, p. 116-127.

OBERWEILER, TOUCHAIS, LERA 2018

Cécile Oberweiler, Gilles Touchais, Petrika Lera, « Les dynamiques d'implantation des habitats dans le bassin de Korçë (Albanie) de la préhistoire à la période médiévale : facteurs humains et paléoenvironnementaux ", in Jean-Luc Lamboley, Luan Përzhita, Altin Skenderaj (éd.), L'Illyrie méridionale et l'Épire dans l'antiquité VI, Paris, De Boccard, 2018, vol. III, p. 935-946.

PAPADOPOULOS et al. 2014

John K. Papadopoulos, Sarah P. Morris, Lorenc Bejko, Lynne A. Shepartz, The Excavation of the Prehistoric Tumulus Burial at Löfkend, Albania, Los Angeles, Cotsen Institute of Archaeology, 2014.

PRENDI, BUNGURI 2014

Franco Prendi, Adem Bunguri, Studime per Prehistorine e Shqiperise, Tirana, Monografi me bashkautorë, 2014.

\section{NOTES}

1. Voir BCH 120, 1996, p. 1006 ; 128-129, 2004-2005, p. 1123.

2. Série de datations réalisées en 2007 par AMS sur des graines, voir LERA, TOUCHAIS, OBERWEILER 2010, p. 49-51.

3. Les datations par le radiocarbone et les datations relatives fondées sur l'étude céramique concordent parfaitement, voir GORI, KRAPF 2016.

4. US 94/279.1 : Ly-7345 = 1621-1306 BC cal. $(2 \sigma)$, et US 94/247.1 : Ly-7340=1628-1423 BC cal. $(2 \sigma)$, calibration Intcal13.14c (voir n. 2).

5. Voir BCH 128-129, 2004-2005, p. 1123. 
6. Ces datations ont aussi été réalisées au laboratoire d'archéométrie Demokritos dans le cadre d'un programme de recherche sur l'apparition du Néolithique en Grèce dirigé par Y. Maniatis.

7. Voir BCH 127, 2003, p. 606.

8. Voir CHRYSOSTOMOU 2015 et CHRYSOSTOMOU, JAGOULIS, MÄDER 2015, p. 24-32.

9. Voir BCH 128-129, 2004-2005, p. 1128 ; 132 (2008), p. 887.

10. Voir FOUACHE, LÉZINE à paraître ; LÉZINE et al. 2010.

11. $B C H$ 128-129, 2004-2005, p. 1121 et fig. 42-43.

12. BCH 128-129, 2004-2005, p. 1131-1133.

13. BCH 128-129, 2004-2005, p. 1121 et fig. 42-43.

14. Rappelons que l'aubier est la partie du tronc qui se trouve juste sous l'écorce; il fait partie des tissus vivants de l'arbre, ce qui explique son intérêt dans le cas de prélèvements ADN.

15. Les analyses dendro- et radiochronologiques seront réalisées au laboratoire de dendrochronologie de l'université de Bern (Suisse) par le Pr. Albert Hafner et son équipe.

16. Ce matériel, déposé initialement dans la réserve de Korçë, avait été transféré à Tirana avant d'avoir pu être étudié intégralement.

17. Les analyses seront réalisées au département de minéralogie de l'université de Tübingen par le Dr. Silvia Rita Amicone.

18. $B C H$ 136-137, 2012-2013, p. 883 et fig. 1-2.

19. Rappelons que cette étude fait partie de la thèse de doctorat de G. Elezi à l'UCLA, voir BCH 139-140, 2015-2016, p. 1041-1042.

20. Intitulé «Kallamas, habitat néolithique au bord du lac de la Grande Prespa (Albanie). Sondages exploratoires 2008-2011 ", ce volume sera publié dans la série des Recherches Archéologiques Franco-Albanaises (RAFAL) de l'École française d'Athènes.

21. BCH 139-140, 2015-2016, p. 1036.

22. BCH 136-137, 2012-2013, p. 698.

23. Voir le rapport sur la campagne de 2016.

24. La phase III est datée du NM en termes de chronologie albanaise traditionnelle, et du NR I selon la chronologie égéenne.

25. La phase Ib correspond au NR en chronologie albanaise et au NR II selon la chronologie égéenne.

26. En Grèce, on a longtemps parlé de Néolithique Final mais les chercheurs s'accordent désormais pour parler de la fin du NR II; dans les Balkans, on parle encore d'Énéolithique ou de Chalcolithique, voir KORKUTI 2010 et PRENDI, BUNGURI 2014, p. 295-296.

27. Elles sont réalisées en collaboration avec le Dr. Christian Fischer au Cotsen Institute of Archaeology, UCLA.

28. Type de roche magmatique, par ex. le granite.

29. Les échantillons d'argile ont été collectés avec l'aide de Gjergji Tracje, ouvrier sur la fouille du site. Selon lui, certaines de ces argiles étaient encore utilisées récemment par les villageois de Kallamas pour la réalisation de tuiles, briques... 
30. Comme les échantillons archéologiques, les échantillons d'argile moderne seront analysés par pétrographie et fluorescence des rayons $\mathrm{X}$.

31. Les échantillons ont été préparés et analysés par chromatographie en phase gazeuse couplée à la spectrométrie de masse (GC/MS) au Passarow Lab, UCLA, en collaboration avec les professeurs Hans Barnard et Kym Faull.

32. HOURMOUZIADIS 2002, p. 229 et fig. 13.

33. Voir supra.

34. Voir les rapports sur les campagnes de 2007 à 2017.

35. Ont participé à la prospection: R. Kurti, Ch. Blein, M. Benet, P. Lera, E. Hasa et L. Rakipllari.

36. KARAISKAJ 1981, p. 9-36 ; KARAISKAJ, LERA 1974, p. 263-290 ; KORKUTI 1973; CEKA 1983, p. 143-157.

37. LERA 1992.

38. OBERWEILER, TOUCHAIS, LERA 2018.

39. Rovena Kurti, «Parure, costume et modes vestimentaires en Albanie à l'Âge du Bronze final et à l'Âge du Fer à travers la documentation funéraire ", thèse de doctorat, EPHE, Paris, 2016.

40. Voir $B C H 132,2008$, p. 890-891. Ainsi, le premier chiffre correspond à la numérotation de 01 à 18 en ordonnées sur le quadrillage virtuel de la carte topographique du bassin au 1:25000 et le second correspond à la numérotation de 70 à 84 en abscisses, ce qui permet de localiser le carré dans lequel se trouve le site sur la carte, tandis que le troisième chiffre indique simplement le $\mathrm{n}^{\circ} \mathrm{du}$ site de ce carré ; Kuç i Zi, 04-87.1, est donc le premier site localisé dans la zone 04-87 sur la carte topographique.

41. Pour les sites de Bellovoda et Lumalas, le maillage est un peu plus hétérogène : Bellovoda a été le premier site prospecté et il a donc servi de test; quant au site de Lumalas, sa situation passée (ancienne base militaire) et actuelle (sur un front de carrière) font que la méthode était inapplicable.

42. ASIG (Autorité Nationale de l'Information Géospatiale) est un portail d'État albanais créé en 2012 (https://geoportal.asig.gov.al).

43. Le nom d'UP (utilisé pour PALM) a été donné en référence à celui d'US (Unité Stratigraphique) en fouille, du fait de son rôle similaire : à chaque UP correspond un sac de ramassage par une équipe. Voir BCH 132, 2008, p. 891.

44. La consultation des archives photographiques des années 1970 à 1990 a montré la dégradation rapide des sites de Bellovoda et Mborja, qui s'est encore accélérée ces dernières années par des fouilles clandestines d'une ampleur inégalée. Ces destructions ont été signalées aux services compétents du ministère de la culture (locaux et nationaux), qui avaient déjà été alertés en 2016 à la suite de fouilles clandestines repérées sur le site de Hija e Korbit (voir le rapport sur la campagne de 2016).

45. G. Karaskaj et P. Lera mentionnent en effet l'existence de deux phases de construction dont l'une daterait de la période protohistorique et l'autre de la période romaine ou de l'antiquité tardive. Malheureusement, en l'absence de fouille, rien ne permet d'affirmer cela avec certitude : KARAISKAJ, LERA 1974, p. 268-269 et KARAISKAJ 1981, p. 15-16. 
46. KRAPF 2017, p. 349-360.

47. KARAISKAJ, LERA 1974, p. 269

48. Observation préliminaire d'Eduart Shehi, céramologue.

49. D'après Zh. Andrea, la céramique est médiévale (ANDREA 1968, p. 125-135) tandis que pour P. Lera le site n'aurait connu qu'une seule phase d'occupation datée des $\mathrm{x}^{\mathrm{e}}$ $\mathrm{XI}^{\mathrm{e}}$ siècles apr. J.-C. (communication orale).

50. Un tesson médiéval a été ramassé sur le site de Kuç i Zi.

51. ANDREA 1968, p. 131-132 ; KARAISKAJ, LERA 1974, p. 268 ; KARAISKAJ 1981, p. 18.

52. C'est du reste cette position stratégique et la céramique protohistorique collectée qui avaient poussé Zh. Andrea à suggérer l'existence d'un site fortifié de la fin du BR/FA (ANDREA 1968, p. 125-126 n. 39).

53. Communication orale.

54. PAPADOPOULOS et al. 2014.

55. KURTI, RUKA 2018 ; KURTI, RUKA, GJIPALI 2014.

56. Sur les tumuli découverts antérieurement voir BCH 120, 1996, p. 1025 et BCH 126, 2002, p. 644.

57. $B C H 130,2006$, p. 808-809 ; BCH 132, 2008, p. 901-902.

\section{INDEX}

lieux https://ark.frantiq.fr/ark:/26678/pcrt19bSKWqKS7

sujets https://ark.frantiq.fr/ark:/26678/pcrt1DMOWvDF4j, https://ark.frantiq.fr/ark:/26678/ pcrtQuZiT5nYY2, https://ark.frantiq.fr/ark:/26678/pcrtMr3tb79bV8, https://ark.frantiq.fr/ark:/ 26678/pcrtpSis9hZLUb, https://ark.frantiq.fr/ark:/26678/pcrtkyIAFWLoSn, https:// ark.frantiq.fr/ark:/26678/crtLh0HBfem1I, https://ark.frantiq.fr/ark:/26678/pcrtM6WKp5XFlj, https://ark.frantiq.fr/ark:/26678/pcrteFHjryOQqT chronologie https://ark.frantiq.fr/ark:/26678/pcrtH8P95EucZz, https://ark.frantiq.fr/ark:/ 26678/pcrtGTWPtWn8qu, https://ark.frantiq.fr/ark:/26678/pcrtW9SpIgIk7Q

Thèmes : EFA

Année de l'opération : 2017, 2018

\section{AUTEURS}

CÉCILE OBERWEILER

UMR 7041 « Archéologies et Sciences de l'Antiquité (ArScAn)»

\section{PETRIKA LERA}

Institut archéologique de Tirana 


\section{ROVENA KURTI}

Institut archéologique de Tirana

GILLES TOUCHAIS

Université Paris 1, UMR 7041 « Archéologies et Sciences de l'Antiquité (ArScAn) »

OLE CHRISTIAN ASLAKSEN

Université de Göteborg

\section{CHARLOTTE BLEIN}

EHESS, UMR 5189 « Histoire et Sources des Mondes Antiques (HiSoMA)»

\section{GAZMEND ELEZI}

University of California Los Angeles

MAJA GORI

Université de Bochum

\section{TOBIAS KRAPF}

Université de Bâle, Université de Paris 1, École suisse d'archéologie en Grèce

YANNIS MANIATIS

Centre Demokritos

\section{STÉPHANIE WAGNER}

Université Bordeaux I, UMR 1202 « Biodiversité, gènes et communautés (INRA) » 